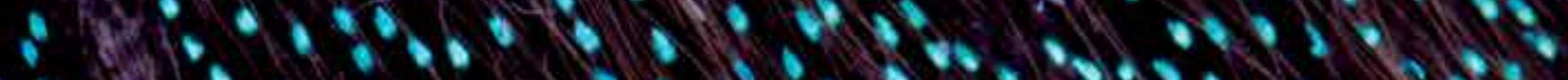

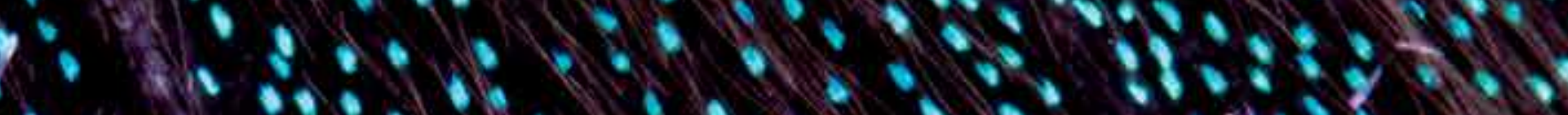

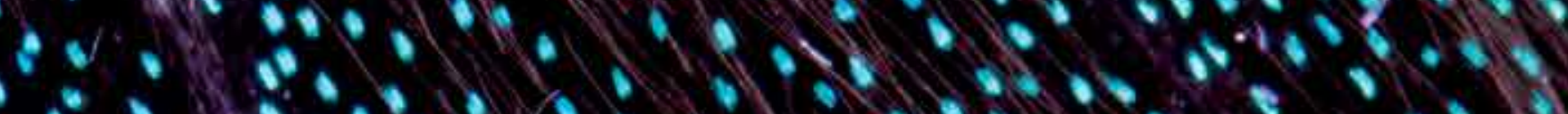
- Mo.".

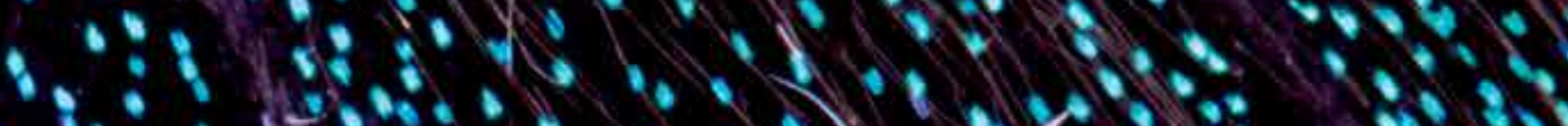

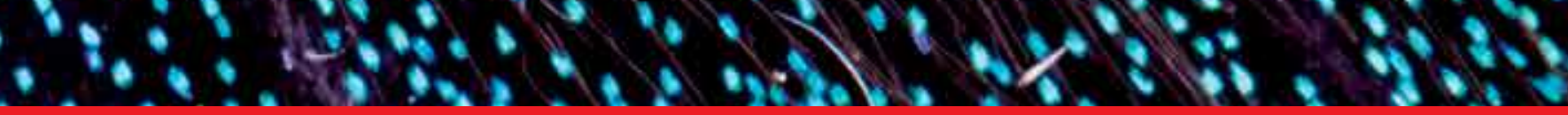

\author{
IntechOpen
}

\title{
Receptors P1 and P2 as Targets for Drug Therapy in Humans
}

Edited by Robson Faria
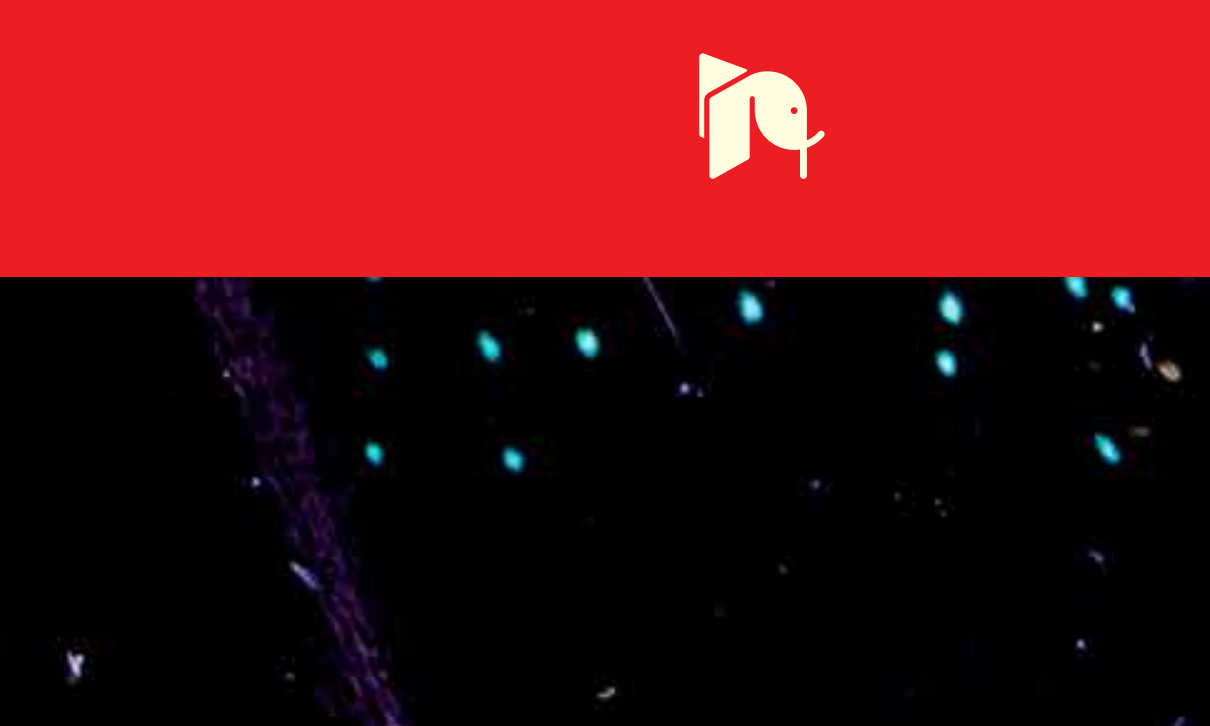



\section{Receptors P1 and P2 as Targets for Drug Therapy in Humans \\ Edited by Robson Faria}



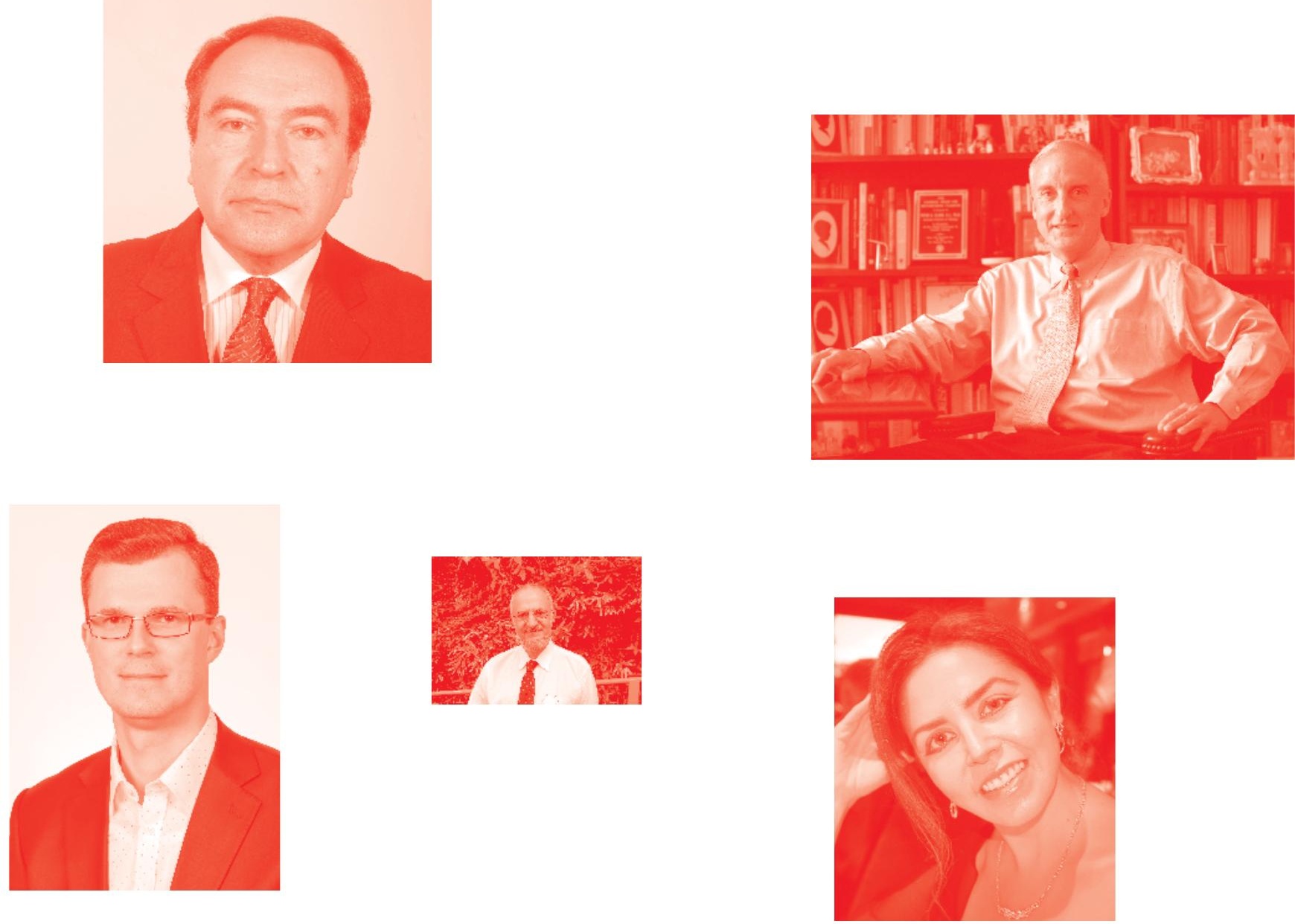

Supporting open minds since 2005
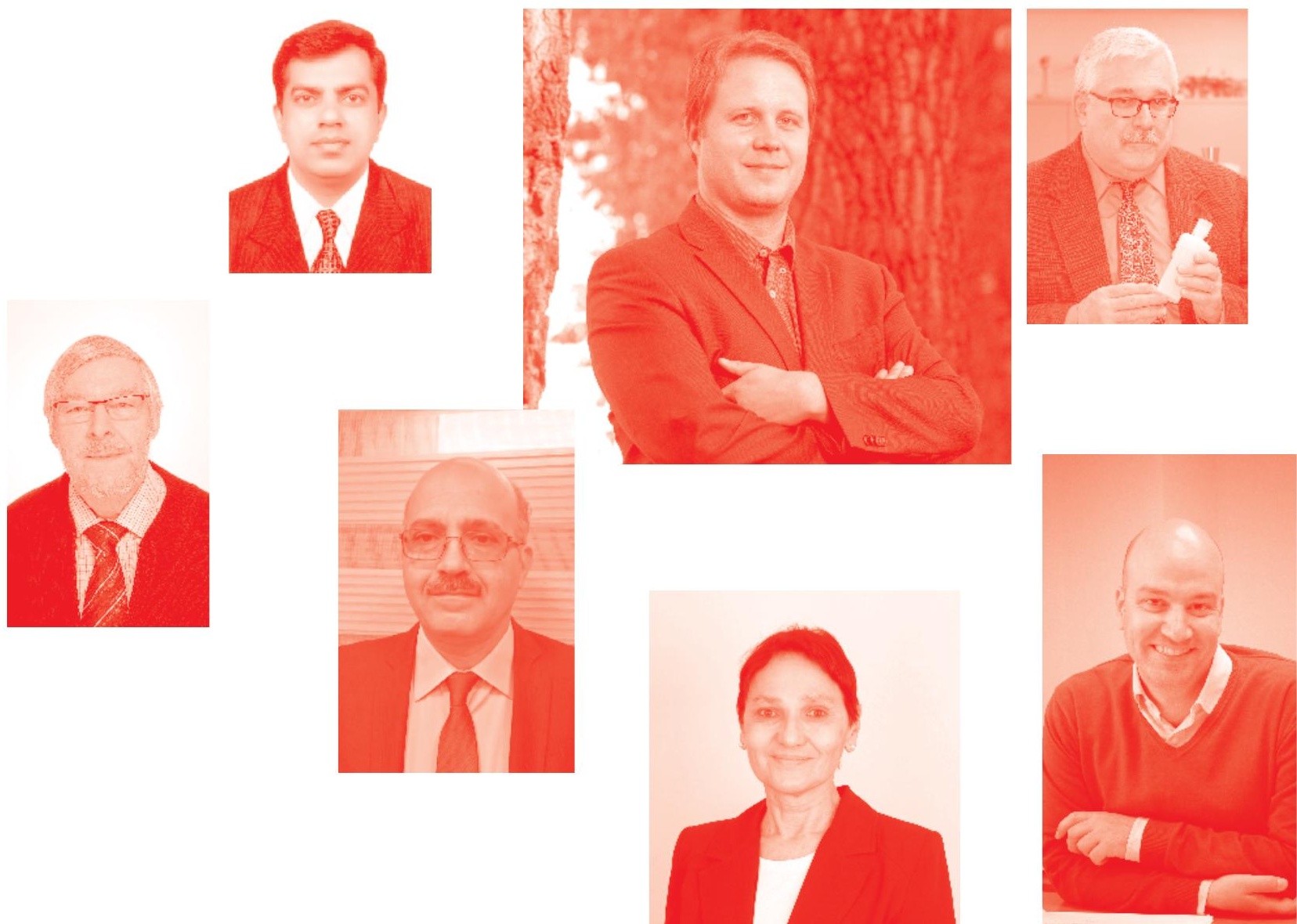
Receptors P1 and P2 as Targets for Drug Therapy in Humans

http: //dx. doi. org/10.5772/intechopen. 78115

Edited by Robson Faria

Contributors

Luiz A. Alves, Anael V.P. Alberto, Rafael Ferreira, Lucianna H.S. Santos, Dinarte N. M. Ferreira, Xiuxin Liu, Eren Sarikaya, Renato Rozental, Tagore M. Morais-Lima, Joana C. Vicentini, Natiele C. da Silva Ferreira, Pallab Bhattacharya, Deepaneeta Sarmah, Gopika Das, Bharati Sinha, Pedro H. M. de Freitas, Xin Wang, Caio M. Perret, Robson Faria

() The Editor(s) and the Author(s) 2020

The rights of the editor(s) and the author(s) have been asserted in accordance with the Copyright, Designs and Patents Act 1988. All rights to the book as a whole are reserved by INTECHOPEN LIMITED . The book as a whole (compilation) cannot be reproduced, distributed or used for commercial or non-commercial purposes without INTECHOPEN LIMITED's written permission. Enquiries concerning the use of the book should be directed to INTECHOPEN LIMITED rights and permissions department (permissions@intechopen.com).

Violations are liable to prosecution under the governing Copyright Law .

\section{(cc) BY}

Individual chapters of this publication are distributed under the terms of the Creative Commons Attribution 3.0 Unported License which permits commercial use, distribution and reproduction of the individual chapters, provided the original author(s) and source publication are appropriately acknowledged. If so indicated, certain images may not be included under the Creative Commons license. In such cases users will need to obtain permission from the license holder to reproduce the material. More details and guidelines concerning content reuse and adaptation can be found at http : //www . intechopen . com/copyright-policy . html.

\section{Notice}

Statements and opinions expressed in the chapters are these of the individual contributors and not necessarily those of the editors or publisher. No responsibility is accepted for the accuracy of information contained in the published chapters. The publisher assumes no responsibility for any damage or injury to persons or property arising out of the use of any materials, instructions, methods or ideas contained in the book.

First published in London, United Kingdom, 2020 by IntechOpen

IntechOpen is the global imprint of INTECHOPEN LIMITED, registered in England and Wales,

registration number: 11086078, 7th floor, 10 Lower Thames Street, London,

EC3R 6AF, United Kingdom

Printed in Croatia

British Library Cataloguing-in-Publication Data

A catalogue record for this book is available from the British Library

Additional hard and PDF copies can be obtained from orders@intechopen.com

Receptors P1 and P2 as Targets for Drug Therapy in Humans

Edited by Robson Faria

p. cm.

Print ISBN 978-1-78984-534-1

Online ISBN 978-1-78984-535-8

eBook (PDF) ISBN 978-1-83880-078-9 


\section{We are IntechOpen, \\ the world's leading publisher of Open Access books}

Built by scientists, for scientists

\section{$4,700+$}

Open access books available

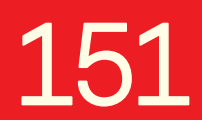

Countries delivered to
$120,000+$

International authors and editors

Our authors are among the

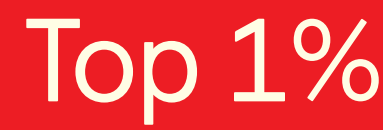

most cited scientists

Contributors from top 500 universities
$135 \mathrm{M}+$

Downloads

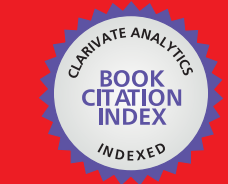

WEB OF SCIENCE ${ }^{\mathrm{MM}}$

Selection of our books indexed in the Book Citation Index in Web of Science ${ }^{\mathrm{TM}}$ Core Collection (BKCI)

\section{Interested in publishing with us? \\ Contact book.department@intechopen.com}

Numbers displayed above are based on latest data collected.

For more information visit www.intechopen.com 



\section{Meet the editor}

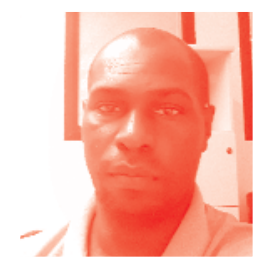

Robson Faria received his degree in Biological Sciences (2001) from the Federal University of Rio de Janeiro and M.Sc. (2003) and D.Sc. (2006) from the Oswaldo Cruz Foundation's Cellular and Molecular Biology program. He has been a Public Health Researcher at the Oswaldo Cruz Foundation since 2007. During the past 15 years, Dr. Robson has been working with the purinergic receptors, especially $\mathrm{P} 2 \mathrm{X} 7 \mathrm{R}$, and the action of synthetic molecules and derivatives of natural products to discover new prototypes capable of treating neglected diseases. 



\section{Contents}

Preface

Section 1

Purinergic Receptors

Chapter 1

Introductory Chapter: Receptors P1 and P2 as Targets for Drug Therapy in Humans

by Robson Faria

Section 2

Functions

Chapter 2

Functions of Purinergic Receptors

by Eren Sarikaya

Chapter 3

Purinergic Signaling and Dental Orofacial Pain

by Xiuxin Liu

Chapter 4

The Role of Purinergic Signaling in the Pathophysiology of Perinatal Hypoxic-Ischemic Encephalopathy

by Tagore M. Morais-Lima, Joana C. Vicentini, Anael V.P. Alberto, Pedro H.M. de Freitas, Caio M. Perret, Natiele C. da Silva Ferreira, Deepaneeta Sarmah, Bharati Sinha, Gopika Das, Pallab Bhattacharya, Xin Wang, Luiz A. Alves and Renato Rozental

Section 3

Structure and New Prototypes

Chapter 5

A Brief View of Molecular Modeling Approaches to P2 Receptors by Anael V.P. Alberto, Lucianna H.S. Santos, Rafael Ferreira, Dinarte N.M. Ferreira and Luiz A. Alves 



\section{Preface}

Purinergic receptors are physiologically activated by extracellular adenosine 5 '-triphosphate (ATP) and its derivatives, such as adenosine. P2Y metabotropic receptors have eight subtypes in humans, and $\mathrm{P} 2 \mathrm{X}$ ionotropic receptors have seven; both of which are activated by ATP. Adenosine activates P1 receptors that have four subtypes in mammals. These receptors are widely distributed in mammals and are responsible for regulating a large number of cellular events, including inflammation, pain, growth, and cell death. The understanding and therapeutic control of inflammation and cell growth blocking these receptors have been widely studied for the clinical treatment of inflammatory and autoimmune diseases, in addition to some types of cancer. However, there is a shortage of selective antagonists with potent in vitro and in vivo activity and primarily therapeutic efficacy in humans.

This book provides a brief view of these receptors as a drug target. In the first chapter, we briefly describe the function and pharmacology of these receptors. Then, the functions of these receptors in the body are discussed as well as the intracellular signaling of these receptors in specific systems such as dental orofacial pain and perinatal hypoxic-ischemic encephalopathy. Finally, we briefly highlight the bioinformatics tools used in the study of these receptors and the planning and discovery of new drugs.

I add that this book would not have been possible without the work of the authors and collaborators involved in this project.

Robson Faria, PhD.

Laboratory of Toxoplasmosis and other Protozoans, Pavilion Carlos Chagas, Oswaldo Cruz Institute, Oswaldo Cruz Foundation, 

Section 1

\section{Purinergic Receptors}





\title{
Introductory Chapter: Receptors P1 and P2 as Targets for Drug Therapy in Humans
}

\author{
Robson Faria
}

\section{Purinergic receptor classification and functions in physiological conditions}

One of the most abundant molecules in living cells serving as an intracellular energy source is adenosine-5'-triphosphate (ATP) [1]. Additionally, this molecule acts as the substrate for adenosine $3^{\prime}, 5^{\prime}$-cyclic monophosphate (cAMP) production, which is extensively used in intracellular signaling.

Although there was resistance to recognize the action of ATP in the extracellular medium, nowadays, diverse mechanisms of cellular communication in living organisms have been considered as dependent on purinergic signaling. Numerous cell types released ATP autocrinally as a ubiquitous biologic and physiologic process [2]. A large number of purinergic receptors are activated for extracellular ATP and its metabolic breakdown acting on autocrine and paracrine manner [3, 4]. Thus, adenosine and other nucleotides activate the $\mathrm{P} 1$ and $\mathrm{P} 2$ receptors, respectively. $\mathrm{P} 1$ receptors are selective for adenosine, and $\mathrm{P} 2$ receptors are activated by purine and by pyrimidine nucleotides. Adenosine activates $A_{1}, A_{2 A}, A_{2 B}$, and $A_{3}$ receptors coupled to $\mathrm{G}$-protein subtypes. Purines and pyrimidines may activate the P2Y receptors (eight subtypes in mammalian $\mathrm{P}_{2} \mathrm{Y}_{1}, \mathrm{P} 2 \mathrm{Y}_{2}, \mathrm{P}_{2} \mathrm{Y}_{4}, \mathrm{P} 2 \mathrm{Y}_{6}, \mathrm{P}_{11} \mathrm{Y}_{11}, \mathrm{P}_{2} \mathrm{Y}_{12}, \mathrm{P}_{2} \mathrm{Y}_{13}$, and $\mathrm{P} 2 \mathrm{Y}_{14}$ ) coupled to G-protein. $\mathrm{P} 2 \mathrm{X}$ receptors are preferentially activated for purines (seven subtypes in mammalian $\mathrm{P} 2 \mathrm{X}_{1}, \mathrm{P} 2 \mathrm{X}_{2}, \mathrm{P} 2 \mathrm{X}_{3}, \mathrm{P} 2 \mathrm{X}_{4}, \mathrm{P} 2 \mathrm{X}_{5}, \mathrm{P} 2 \mathrm{X}_{6}, \mathrm{P} 2 \mathrm{X}_{7}$ ) forming homotrimers and heterotrimers.

$\mathrm{P} 1$ and $\mathrm{P} 2$ receptors are abundant and widely distributed in all tissues of the body, mainly in mammals. In physiological conditions, they participate on neurotransmission, neuromodulation, sensory transduction, regulation of heart rate, smooth muscle contraction, bile secretion, endocrine regulation, immune responses, proliferation in development and regeneration, ischemia, and inflammation [5].

\section{Purinergic receptor participation in pathological conditions}

The immune system uses pattern recognition receptors (PRRs) that recognize pathogen-associated molecular patterns (PAMPs) [6]. Besides pathogens, the immune system also reacts to particles that can cause damage-associated molecular patterns (DAMPs) [7], which are called hazard signaling molecules. Antigen presenters recognize them, once released or produced under stress conditions or cell death, which become activated and generate costimulatory signals and thus initiate immune responses and inflammation [8]. Different chemical agents are 
capable of inducing the inflammatory response, even in the absence of infection. Sterile inflammation is marked by neutrophil and macrophage recruitment and for cytokine production such as TNF- $\alpha$ and IL-1 $\beta$ [9]. Nucleotides (ATP, UTP, or ADP) can act as DAMPS in the extracellular medium under stressful conditions and are released with other molecules out of the cell. In the environment, these nucleotides are recognized by a cell expressing purinergic receptors, including the antigen-presenting cells (APCs). Thus, they serve as signaling molecules of danger to APCs. In this context, in an ATP cell release event injured, many classes of receptors (sometimes of different actions) are activated in effector cells and can generate a network of intracellular signaling cascades responsible for late effects [10]. Several studies in recent years have shown that purinergic signaling plays an essential regulatory role in many inflammatory diseases [11]. Additionally, these receptors may modulate diverse diseases such as chronic pain, brain trauma ischemia, epilepsy, Alzheimer disease, amyotrophic lateral sclerosis, depression, anxiety, schizophrenia thrombosis and stroke, dry eye, atherosclerosis, kidney failure, osteoporosis, bladder incontinence, colitis, neurodegenerative diseases, and cancer [12-14].

\section{Purinergic receptor as therapeutic targets}

Classically, in the function of ubiquitous purinergic receptor expression, the agonists and antagonists for these receptors exhibit a lack of drug selectivity and the possibility of side effect in vivo. However, the advance of medicinal chemistry area in the last decades has developed potent and selective synthetic agonists and antagonists for purinergic receptors. The boost of bioinformatic analysis with power tools allows studying purinergic receptors' structure in details and discovering, in some cases, allosteric modulators with therapeutic window better than orthosteric compounds [15-17].

Undoubtedly, purinergic receptors, $\mathrm{P} 2 \mathrm{X}$ receptor, $\mathrm{P} 2 \mathrm{Y}$ receptor, and ectonucleotidase pharmacology is an attractive area for pharmacotherapeutic development and, therefore, provides a contemporary understanding of the purinergic signaling in physiological and pathological conditions. Additionally, this content will include of the relationship between purinergic receptors subtypes and ectonucleotidases at molecular, pharmacological, and therapeutic conditions.

We are grateful to all the authors for their valuable contribution and hope that this book could represent, for the scientific community, a solid basis for further studies on purinergic receptors. 
Introductory Chapter: Receptors $P_{1}$ and $P_{2}$ as Targets for Drug Therapy in Humans

DOI: http://dx.doi.org/10.5772/intechopen.90040

\section{Author details}

Robson Faria ${ }^{1,2,3}$

1 Laboratory of Toxoplasmosis and other protozoans, Instituto Oswaldo Cruz, Fiocruz, Rio de Janeiro, RJ, Brazil

2 Biology Institute, Federal Fluminense University, Niterói, RJ, Brazil

3 Oswaldo Cruz Institute, Oswaldo Cruz Foundation, RJ, Brazil

*Address all correspondence to: robson.xavier@gmail.com

\section{IntechOpen}

(C) 2020 The Author(s). Licensee IntechOpen. This chapter is distributed under the terms of the Creative Commons Attribution License (http://creativecommons.org/licenses/ by/3.0), which permits unrestricted use, distribution, and reproduction in any medium, provided the original work is properly cited. (cc) BY 


\section{References}

[1] Alberts B, Bray D, Lewis J, et al. Molecular Biology of the Cell. 3rd ed. New York: Garland Publishing; 1994. pp. 65-67

[2] Lazarowski ER, Boucher RC, Harden TK. Mechanisms of release of nucleotides and integration of their action as P2X and P2Y receptor activating molecules. Molecular Pharmacology. 2003;64(4):785-795

[3] Sattin A, Rall TW. The effects of adenosine and adenine nucleotides on the cyclic adenosine $3^{\prime}, 5^{\prime}$-phosphate content of Guinea pig cerebral cortex slices. Molecular Pharmacology. 1970;6:13-23

[4] Corriden R, Insel PA. Basal release of ATP: An autocrine-paracrine mechanism for cell regulation. Science Signaling. 2010;3(104):re1

[5] Burnstock G. Short- and longterm (trophic) purinergic signalling. Philosophical Transactions of the Royal Society of London. Series B, Biological Sciences. 2016;371(1700):20150422-20150432

[6] Mogensen TH. Pathogen recognition and inflammatory signaling in innate immune defenses. Clinical Microbiology Reviews. 2009;22(2):240-273

[7] Matzinger P. The danger model: A renewed sense of self. Science. 2002;296(5566):301-305

[8] Gallo PM, Gallucci S. The dendritic cell response to classic, emerging, and homeostatic danger signals. Implications for autoimmunity. Frontiers in Immunology. 2013;4:138

[9] Chen GY, Nuñez G. Sterile inflammation: Sensing and reacting to damage. Nature Reviews. Immunology. 2010;10(12):826

[10] Vénéreau E, Ceriotti C, Bianchi ME. DAMPs from cell death to new life. Frontiers in Immunology. 2015;6:422

[11] Burnstock G, Knight GE. The potential of $\mathrm{P} 2 \mathrm{X} 7$ receptors as a therapeutic target, including inflammation and tumour progression. Purinergic Signalling. 2018;14(1):1-18

[12] Borea PA, Gessi S, Merighi S, et al. Adenosine as a multi-signalling Guardian angel in human diseases: When, where and how does it exert its protective effects? Trends in Pharmacological Sciences. 2016;37(6):419-434

[13] Burnstock G. Purinergic signalling: Pathophysiology and therapeutic potential. Journal of Drug Research and Development. 2016;2(4):1. DOI: 10.16966/2470-1009.122

[14] Hansson E, Werner T, Björklund U, et al. Therapeutic innovation: Inflammatory-reactive astrocytes as targets of inflammation. IBRO Reports. 2016;1:1-9

[15] Zhan C, Yang J, Dong XC, et al. Molecular modeling of purinergic receptor $\mathrm{P} 2 \mathrm{Y} 12$ and interaction with its antagonists. Journal of Molecular Graphics and Modelling. 2007;26(1):20-31

[16] Huo H, Fryatt AG, Farmer LK, et al. Mapping the binding site of the P2X receptor antagonist PPADS reveals the importance of orthosteric site charge and the cysteine-rich head region. The Journal of Biological Chemistry. 2018;293:12820-12831

[17] Rodríguez A, Guerrero A, Gutierrez-de-Terán $\mathrm{H}$, et al. New selective $A_{2 A}$ agonists and $A_{3}$ antagonists for human adenosine receptors: Synthesis, biological activity and molecular docking studies. Medicinal Chemistry Communications. 2015;6:1178-1185 
Section 2

Functions 



\title{
Functions of Purinergic Receptors
}

\author{
Eren Sarikaya
}

\begin{abstract}
Purinergic receptors, also known as purinoceptors, are a family of plasma membrane molecules found in many mammalian tissues. Purinergic receptors are transmembrane receptors consisting of two main categories. $\mathrm{P} 1$ receptors are stimulated by adenosine. Those that respond to extracellular nucleotides (ATP, ADP, UTP and UDP) are $\mathrm{P} 2$ receptors. The $\mathrm{P} 2 \mathrm{X}$ receptors are ligand-gated ion channels. The $\mathrm{P} 1$ and $\mathrm{P} 2 \mathrm{Y}$ receptors are bound to the $\mathrm{G}$ protein. Both of these metabotropic receptors are distinguished by taking into account their reactivity to specific activators. P1 and $\mathrm{P} 2 \mathrm{Y}$ receptors are widely distributed in the brain, heart, kidneys and adipose tissue.
\end{abstract}

Keywords: purinergic receptors, P1, P2, ATP, UTP

\section{Introduction}

\subsection{The possible physiological sources of nucleotides and nucleosides}

ATP and other described nucleotides treat both metabotropic (P2Y) and ionotrophic $(\mathrm{P} 2 \mathrm{X})$ receptors. $\mathrm{P} 2 \mathrm{X}$ receptors subunits $(\mathrm{P} 2 \mathrm{X} 1-\mathrm{P} 2 \mathrm{X} 7)$ form ligand-gated cation channels, like homomultimers or heteromultimers. $\mathrm{P} 2 \mathrm{X} 3$ subunits contribute to the ion permeability pathway by joining the fields of each subunit. P2X3R has the lowest recorded relative $\mathrm{Ca}^{2+}$ permeability of the family. $\mathrm{P} 2 \mathrm{X} 7$, in addition to cation channels, is associated to contain large cytolytic pores; that are found in macrophages and brain microglial cells. P2Y receptors can activate or inhibit adenylate cyclase according to the subtype and consequently the type of coupled $G$ protein. Adenylate cyclase and especially for the $\mathrm{Ca}^{2+}$ channel inhibition appears. P2Y receptors form as subset of G-protein-linked receptors; most mate to phospholipase $\mathrm{C}$ via the $\mathrm{G}$ protein, but inhibition of adenylate cyclase and $\mathrm{N}$-type $\mathrm{Ca}^{2+}$ channels and activation of $\mathrm{K}^{+}$channels also occurs. The expressed $\mathrm{P} 2 \mathrm{Y}$ receptors are generally pharmacologically distinguished by the rank order of the agonists; some prefer pyrimidine to purine. Several P2Y receptors have a very common tissue distribution [1]. Molecular structures of ATP and BzATP are shown in Figure 1.

Adenine nucleotides inhibit isoproterenol and forskolin-induced cyclic AMP accumulation in C6-2B rat glioma cells. This inhibition occurs in the presence of a phosphodiesterase inhibitor. Adenine nucleotides did not cause effects in measurements of the direct phosphodiesterase activity in intact cells. Pretreatment of C6-2B glioma cells with pertussis toxin blocked the inhibitory effects of P2Y-purinergic receptor agonists. A number of ATP and ADP analogs produced a rank potency order (2-methylthioadenosine 5 -triphosphate $>$ or $=2$-methylthioadenosine $5^{\prime}$-diphosphate $>$ adenosine $5^{\prime}$-O-(2-thiodiphosphate) $>2$-chloro-adenosine ADP $=$ adenosine 5' $-\mathrm{O}$-(3-thio- triphosphate) > ATP > UTP) expected from a P2Ypurinergic receptor activation; and the $\mathrm{P} 2 \mathrm{X}$-purinergic receptor agonists, alpha, 

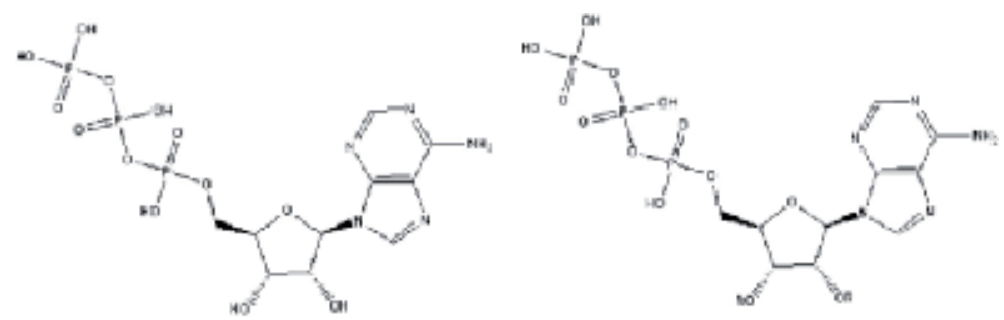

ATP

BzATP=mixture of $2^{\prime}, 3^{\prime}$ Isomers

Figure 1.

Molecular structures of ATP and BzATP [2].

beta-methyleneadenosine $5^{\prime}$-triphosphate and beta, gamma-methylene-adenosine 5 '-triphosphate had no effect. Phospholipase $\mathrm{C}$ activity occurs in response to $\mathrm{P} 2$-purinergic receptor activation in many target tissues, therefore the effects of $\mathrm{P} 2 \mathrm{Y}$ receptor agonists on inositol phosphate accumulation were measured in C6-2B cells. No evidence was found for the regulation of $\mathrm{P} 2 \mathrm{Y}$-purinergic receptor mediated by inositol lipid metabolism under conditions where the activation of muscarinic cholinergic receptor or AIF4 increased the inositol phosphate accumulation. These results indicate that a $\mathrm{P} 2$-purinergic receptor subtype with different signaling characteristics is present on the C6-2B rat glioma cells. Although this receptor expresses the general pharmacological properties of a phospholipase C-linked P2Y-purinergic receptor, it may represent a unique receptor subtype because it inhibits adenylyl cyclase [3].

Purines were thought to be limited to the intracellular compartment in which they were used for energy processing, nucleic acid synthesis and a large number of biochemical reactions. Karl Lohmann isolated ATP, which is the key intracellular energy currency, in 1929 [4]. However, adenosine and adenosine triphosphate (i) are abundant biochemical components of the tumor microenvironment, (ii) are strong modulators of immune cell responses and cytokine release, and (iii) are key players in host-tumor interaction. In addition, both nucleotides directly affect tumor cell growth. Adenosine is a potent immunosuppressant (mainly effective at $\mathrm{A} 2 \mathrm{~A}$ receptors) and a cell growth modulator (mainly effective at $\mathrm{A} 3$ receptors). ATP is a proinflammatory agent (effective in P2Y1, P2Y2, P2Y4, P2Y6 and P2Y12 and at $\mathrm{P} 2 \mathrm{X} 4$ and $\mathrm{P} 2 \mathrm{X} 7$ receptors), an immunosuppressant (effective in P2Y11) and a growth promoter (effective in P2Y1, P2Y2 and P2X7). This complex signaling network produces a number of inhibitory and stimulating responses that affect immune cell function, tumor growth and metastatic spread.

Purinergic receptors, represented by many families, are the most abundant receptors in living organisms, possibly occurring in the early stages of evolution. Purinergic signaling in peripheral and central nervous systems is a rapidly expanding field. Examination of these receptors makes it possible to develop therapeutic strategies for these disorders with novel mechanisms of action, including purulent, pathogenic conditions, including pain, trauma, ischemia, epilepsy, migraine, psychiatric disorders and drug dependence [5].

In micromolar/nanomolar concentrations, extracellular adenosine triphosphate (ATP) has been shown to produce significant functional changes in a wide variety of normal and transformed cell types. Although ATP can be specifically released 
from the cytosol of damaged cells, it is also packaged in some exocytotic vesicles/ granules containing conventional neurotransmitters and hormones. Various biological responses to ATP are mediated by various P2-purinergic cell surface receptors activated upon binding of ATP and other nucleotides. Recent physiological, biochemical and pharmacological studies have shown that there are multiple types of ATP receptor subtypes. These include: (1) G-protein-bound ATP receptors that induce inositol phospholipid hydrolysis, $\mathrm{Ca}^{2+}$ mobilization and activation of protein kinase C; (2) ATP receptors that directly activate non-selective cation channels in plasma membranes of various cell types and (3) ATP receptors capable of producing cytotoxic or activation responses in T lymphocytes and other immune effector cells by rapid induction of surface membrane pores permeable to ions and endogenous metabolites (with molecular weights until $900 \mathrm{Da}$ ). In addition to these functional criteria, these default ATP receptor subtypes can be pharmacologically distinguished by characteristic potency for various structurally modified ATP analogs [6].

Intracellular nucleotides play a fundamental and ubiquitous role in energy metabolism, nucleic acid synthesis and enzyme regulation. It is widely understood that extracellular nucleotides and nucleosides carry out important biological actions in many tissues and cells [7]. GLUTs (facilitate transport of glucose into the cells), SGLTs (facilitate the re-absorption of glucose back into circulation) and KATP (ATP-sensitive potassium channels) metabolic sensors play an important role in glucose homeostasis and metabolism in the body and in many specific organs (e.g., intestine, pancreas, heart, skeletal muscle and brain) [8].

KATP bind metabolic signals to cell excitability and play an important role in many tissues, including regulation of insulin secretion, control of vascular tone and protection of neurons and muscles from ischemia. KATP channels are octameric complexes consisting of four sulfonylurea receptors (SUR.x) and four inwardly rectifying potassium channels (Kir6.x). They are regulated by intracellular ATP and ADP. While ATP inhibits channel activity, ADP antagonizes the inhibitory effect of ATP in the presence of $\mathrm{Mg}^{2+}$ and stimulates the channel activity. These gate properties are essential for this channel to detect metabolic changes in cells. Thus, in pancreatic $\beta$ cells, the [ATP]/[ADP] ratio increases in response to blood glucose levels augment, leading to closure of the KATP channel, membrane depolarization, activation of voltage-gated $\mathrm{Ca}^{2+}$ channels and insulin release. However, when the blood glucose levels are low, the $[\mathrm{ATP}] /[\mathrm{ADP}]$ ratio decreases, KATP channels are opened and insulin secretion decreases [9].

The catastrophic channels in the pancreas are activated as follows; in the event of $\beta$-cell glucose level is increased, the intracellular ratio of ATP to ADP also increases, leading to closure of the KATP channel, depolarization of cells and insulin release [10].

The P-sensitive $\mathrm{K}^{\prime}(\mathrm{K}+[\mathrm{ATP}])$ stream is thought to be regulated by GTP-binding proteins ( $G$ proteins), but the pathways combining the receptor, $G$ protein and channel are not identified. The regulation of tolbutamide-sensitive $\mathrm{K}^{\prime}$ [ATP] current in neonatal rat ventricular myocytes is determined. Activated ATP-sensitive $\mathrm{K}+(\mathrm{K}+[\mathrm{ATP}])$ channels are present in cells when intracellular ATP levels decrease. Intracellular ATP levels are found when intracellular ATP levels are reduced in the cell, intracellular skeletal muscle, brain and pancreas. Little is known about the function of $\mathrm{K}+[\mathrm{ATP}]$ channels in heart cells, although their important role in controlling insulin secretion from pancreatic P-cells has been well established. When pharmacologically activated, these channels greatly reduce the duration of action potential and have been proposed to be responsible for the shortening of action potential in metabolically dangerous ischemic muscles. However, the ATP concentration in the metabolically blocked caste remains above the level, which prevents the channels in 
the excised membrane patches. A possible explanation for this discrepancy is that the ATP sensitivity of the channels can be modulated by intracellular mechanisms [11].

ATP-responsive $\mathrm{K}^{+}$channels, called KATP channels, provide a link between cellular metabolism and membrane electrical activity in various tissues. Channel isoforms are targets for compounds that stimulate and inhibit their activity resulting in membrane hyperpolarization and depolarization, respectively. Vascular smooth muscle and stimulating insulin secretion loosening are examples for these situations above [12]. Adenosine agonists and the openers of the ATP-sensitive potassium (KATP) channel were reported to limit infarct size (IS) [13]. ATP-sensitive potassium (KATP) channels are well defined in the heart, skeleton and smooth muscle, pancreatic cells, pituitary, central and peripheral nervous system both electrophysiologically and pharmacologically. The activities and hence the various cellular functions are controlled by the cellular metabolism. In general, the changes in ATP (causing channel closure) and in MgADP (channel activating) are believed to have dual metabolism to channel activity 6 . It is described that the cellular localization of two mRNA transcripts that is expected to generate ATP-sensitive $\mathrm{K}^{+}$channels in the murine brain. There is evidence that the KATP channel in pancreatic cells is composed of a Kir6.2 and a complex of SUR1 subunits. KATP channels with similar characteristics (type I) have been described in various neurons, including those with brain cortex, basic nigra, caudate, and hippocampus [14].

Almost all tumor cells and all immune cells express plasma membrane receptors for extracellular nucleosides (adenosine) and nucleotides (ATP, ADP, UTP, UDP and sugar UDP). The tumor microenvironment is characterized by an unusually high concentration of ATP and adenosine. Adenosine is an important determinant of the immunosuppressive tumor environment. Serial hydrolysis of extracellular ATP catalyzed by CD39 and CD73 is the main pathway for adenosine formation in the tumor interstitium. Extracellular ATP and adenosine mold are both host and tumor responses. Depending on the activated specific receptor, extracellular purines mediate host-side immunosuppression or immunostimulation and tumor-side growth stimulation or cytotoxicity. Recent developments in this area provide the key to deciphering this complex scenario, using the potential benefits of therapy. Preclinical data indicate that targeting the adenosine producing pathway or adenosinergic receptors attenuates immunosuppression and strongly inhibits tumor growth. On the other hand, the growth of experimental tumors is strongly inhibited by targeting the receptor of P2X7 ATP selective cancer and immune cells. The role of extracellular purines (purinergic signaling) acts in host-tumor interaction and highlights new treatment options from recent advances. There is now a consensus that ATP and adenine are the main components of tumor microenvironment (TME), in which TME affects tumor growth, immune cell functions and tumorhost interaction in different ways. In view of the widespread observation that many malignant tumors overexpress several P1R or P2R subtypes, a simple approach would require targeting these receptors with selective receptors to suppress tumor receptor growth. On the same line of interference, the enzymes involved in the metabolism of extracellular nucleotides and nucleosides (CD39, CD73 and adenosine deaminase) are viewed. Although the effectiveness of several simple preclinical models has been proven, this simple approach is clearly very pure. P1Rs, P2Rs and ATP/adenosine-disrupting enzymes are expressed together with host immunostimulatory and stromal cells, which have very important functions for host integrated complex formation around the tumor. Careful selection of the candidate purinergic receptor in combination with modulators of extracellular adenosinergic pathways may allow inhibition of tumor cell growth and concomitantly increase the antitumor host response. This anti-cancer agent will provide an additional powerful weapon for combinative treatments [15]. 
Nucleotides and their receptors are emerging as potential actors in host-tumor interaction, such as new and important inflammatory and immune modulators. A large number of $\mathrm{P} 2$ and $\mathrm{P} 1$ receptors expressed by tumor and inflammatory cells exhibiting different ligand affinities for $\mathrm{P} 2$ and $\mathrm{P} 1$ receptor subtypes are modulated by local factors obtained from ectonucleotides and ADA on the nucleotide and adenosine concentration. In vivo data supports in vitro evidence that the reduction of the intratumour adenosine concentration and the targeting of the $\mathrm{P} 2 \mathrm{X} 7$ receptor have a potent antitumor effect. Therefore, investigating the purinergic signaling in cancer opens promising perspectives for the development of innovative therapeutics [16].

Purinergic signaling has been focused on the tumor-associated immune response; nucleotides and nucleosides have strong direct effects on the tumor cells themselves. Stimulation of P2Y receptors (P2Y1 and P2Y2) promotes growth, therefore, depending on the expressed $\mathrm{P} 2 \mathrm{Y}$ receptor subtypes, the accumulation of ATP in the tumor microenvironment is likely to promote tumor growth. In addition to $\mathrm{P} 2 \mathrm{Y}$ receptors, $\mathrm{P} 2 \mathrm{X} 7$ plays a role in tumor growth. It is a long-standing observation that most malignant tumors over-express P2X7 [17]. It is known that this receptor mediates a strong cytotoxic response [18]. Therefore, why a tumor should overexpress a "suicide" receptor is determined. However, cytotoxicity is most commonly triggered by pharmacological (i.e., near millimolar) ATP doses. In contrast, the activation of $\mathrm{P} 2 \mathrm{X} 7$ by the endogenously released ATP produces a trophic, growthpromoting effect [19].

Nucleotides and nucleosides in airway surface fluid regulate mucociliary clearance (MCC) activities, the primary natural defense mechanism that removes foreign particles and pathogens from airway surfaces. These effects in the airways are mainly mediated by two purinergic receptor subtypes, the Gq-coupled ATP/UTPsensing P2Y2 receptor and the Gs-conjugated A2b adenosine receptor. Activation of the $\mathrm{A} 2 \mathrm{~b}$ receptor results in cyclic AMP-dependent activation of the Cin 1 channel of the cystic fibrosis transmembrane regulator (CFTR) and stimulation of the ciliary pulse frequency. Agonist activation of the $\mathrm{P} 2 \mathrm{Y} 2$ receptor promotes the inhibition of CFTR-dependent and CFTR-independent $\mathrm{Cl}$ secretion, ciliary beating and mucin secretion as well as $\mathrm{Na}^{+}$absorption [20].

The phenomenon about the process reveals the participation of a biological cascade. In this context, adenosine agonists and ATP-sensitive $\mathrm{K}^{+}$channel (KATP) openers mimic some protective effects of the preconditioning process. Furthermore, these effects are reversed by adenosine antagonists and KATP blockers; this suggests that the release of adenosine and activation of KATP channels through adenosine $\mathrm{Al}$ receptors may constitute an early step in ischemic cerebral preconditioning [21].

Activation of the adenosine receptor, protein kinase C (PKC) and ATP-sensitive potassium (KATP) channel is known to trigger preconditioning. The data provides direct evidence that the KATP channel, rather than the adenosine receptor, is the effector downstream of PKC in initiating PKC-mediated preconditioning. Both the adenosine receptor and the KATP channel are required to promote the actual protective effect during continuous hypoxia [22]. The possibility of joining the biological stage of protective event involvement of adenosine A1 receptors and KATP channels, associated with cross-tolerance between KA-induced epileptic tolerance or KA-induced epilepsy and global ischemia, is evaluated [23].

\section{Classification of the $P 1$ and $P 2$ receptors}

The antinociceptive effects of adenosine via preconceptional P1 (A1) purinoceptors in the spinal cord and the pain-enhancing effects of adenosine with P1 (A2) 
purinoceptors in the environment have shown great interest in the development of $\mathrm{P} 1$ agonists and antagonists and P2X antagonists as potential analgesic drugs [24].

Purinergic receptors are divided into adenosine receptors (P1) and nucleotide receptors (P2). The receptors for nucleotides are also divided into two main groups: ligand-gated ion channels (P2X) and G-protein-associated receptors (P2Y). Upon vascular injury, platelets are collected at the site of injury to form a hemostatic plug. Abnormal activation of platelets leads to thrombosis, resulting in greater paralysis and a risk of myocardial infarction. The importance of ADP in hemostasis and thrombosis greatly underscores the significance of understanding the function of these receptors that would enable development of potent and safe antithrombotic drugs. This makes ADP receptors antagonize or interfere. Purinergic receptors are shown in Figure 2.

The molecular mechanisms of platelet activation caused by ADP are now evident. The separation and interactions of a unique $\mathrm{P} 2 \mathrm{~T}$ receptor concept into three components (i.e., P2Y1, P2Y12 and P2X1 receptors) helped to explain the intracellular and physiological effects of ADP on platelets. The interaction of signaling events under P2Y1 and P2Y12 receptors is a new physiological response and may be a general mechanism of $\alpha 1 b \beta 3$ integrin activation by all physiological agonists. It is also shown to be a mechanism of activation for another platelet integrin $\alpha \mathrm{V} \beta 3$ [25].

Results from this observation include a fourth $\mathrm{P} 2$ receptor subtype on platelets and $\mathrm{P} 2 \mathrm{Y} 12$ receptor binding to other $\mathrm{G}$ proteins. The precise signaling mechanisms and pathways mediated by these three $\mathrm{P} 2$ receptor subtypes will provide a better understanding of the molecular mechanisms of ADP-mediated physiological responses in platelets and, in general, agonist-induced platelet activation [26].

Two types of purinergic receptors were distinguished: P1 purines are the most sensitive to adenosine and AMP, competitively blocked by methylxanthines; P2 purinoceptors are most sensitive to ATP and ADP, and quinidine is blocked (although not competitive) by 2-substituted imidazoline, 2,2'-pyridylisatogen and apamine, and their use leads to the production of prostaglandins. Adenosine reduces the heart rate and contraction force of the atrium and the ventricles of most species. It disrupts conduction in the atrioventricular node and has a particularly strong effect on the sinoatrial pacemaker. These effects are blocked by methylxanthines and strengthened by dipyridamole. ATP is also a contractility potent inhibitor of the heart of most species but initially has a positive inotropic effect on the frog's heart, followed by inhibition (possibly due to adenosine after rapid disintegration of ATP). Adenyl compounds allow the expansion of coronary vessels. ATP and ADP are the most potent, and adenosine and AMP are partially about $25 \%$, whereas inosine, adenine and hypoxanthine are almost inactive. Adenosine acts on the presynaptic $\mathrm{P} 1$ purinoceptors, reducing the release of noradrenaline and acetylcholine from the adrenergic and cholinergic nerve terminals. These effects are blocked by methylxanthines. Adenosine probably induces

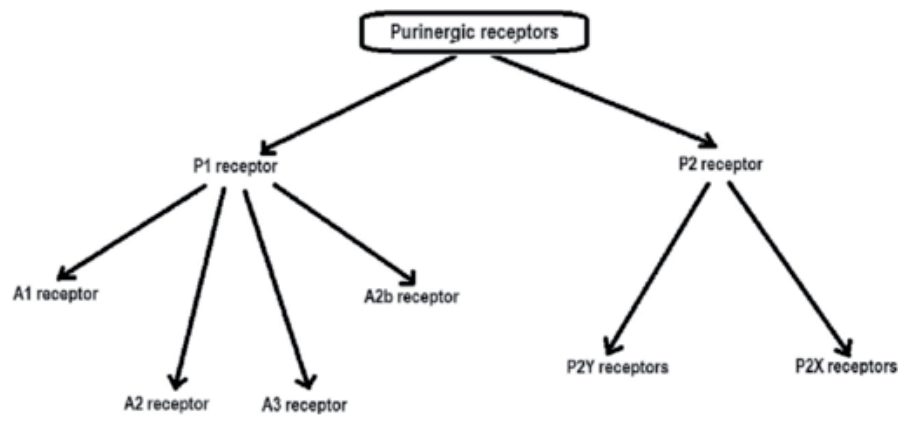

Figure 2.

Purinergic receptors [2]. 
adenylate cyclase in the three main regions of the heart (i.e., heart muscle, vascular smooth muscle and nerve terminals), causing changes in cAMP accumulation and a reduction in $\mathrm{Ca}^{2+}$ flux. The mechanism of action of ATP is unknown. There is strong evidence for a physiological role for adenyl compounds in the regulation of coronary blood flow. The concentration of adenosine, ischemia-induced ATPs acting on the P1 purinorecceptors, acting on vasoconstriction of vasodilatation from cardiac hyperactivity, may be increased by the release of intranural purinergic nerves and acting on $\mathrm{P} 2$ purinoseptors. Some purinergic nerves affect sinoatrial pacemaker activity, and adenosine may be a physiological presynaptic modulator of cardiothoracic activity of both adrenergic and cholinergic nerves [27]. ATP and other purine nucleotides and nucleosides have strong regulatory (similar to neurotransmitter) effects attributed to interaction with a specific plasma membrane receptor 1 . To date, receptor mechanisms underlying purinergic activation have been poorly characterized. One problem was the variability of excited effects in different tissues [28]. It was suggested that most of the effects could be explained if two different receptors, called P1 and P2, have different properties for agonists and antagonists. The receptor mechanisms in the parotid gland have been extensively studied. ATP causes a significant increase in membrane conductivity, radioactive $\mathrm{Rb}$ flow and amylase secretion. The effects of ATP are similar to those induced by acetylcholine (ACh) and $\alpha$-adrenergic agonists but are still present when cholinergic and adrenergic blocking agents are used. The latency and return potential of the effects induced by ATP can be compared to those of autonomic agonists. General structures of different classes of P2X7 antagonists are shown in Figures 3 and 4.

Since the sequence of action of the nucleotide sequence was ATP > ADP > AMP, adenosine had no effect, and the response could be blocked by quinidine, but not by theophylline [29]. Activation of P2Y1 and P2Y12 receptors by secreted ADP induced by agonists such as thrombin, thromboxane and collagen is the main mechanism of platelet activation. $\mathrm{P} 2 \mathrm{X} 1$ receptors also contribute to the change of platelet shape and enhance calcium mobilization. Cloning of the P2Y12 receptor and knockout in

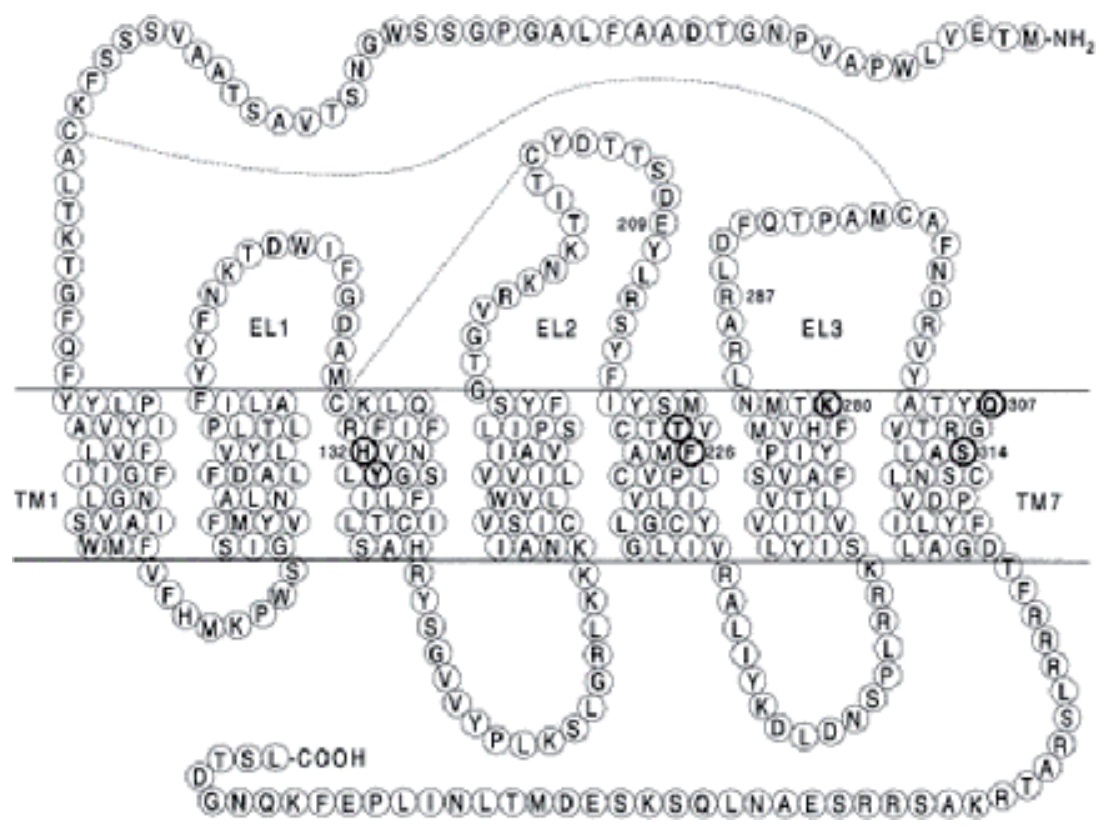

Figure 3.

General structures of different classes of $\mathrm{P}_{2} \mathrm{X}_{7}$ antagonists [2]. 
<smiles>[R]C1=N[C@H](c2ccccc2)[C@H](c2ccccc2)N1</smiles>

Diaryl imidazolidines<smiles>[R]c1c2c(c[n+]3c([R20])c(OC)ccc13)CCc1cc(OC)c(OC)cc1-2</smiles>

Dihydrodibenzo[a,g]quinolizinium<smiles>[R]C(=O)OC[C@H]1CN([R2])c2cn(CCc3ccccc3)nc2C(=O)N1</smiles>

Pyrazolodiazepine<smiles>[R]NC(=O)C1CCC(=O)N1[R]</smiles>

Pyroglutamic acid<smiles>[R2]Cn1nnnc1[R7]</smiles>

Tetrazole<smiles>[R]C(=O)Cc1c(C)nc(-c2ccccc2)n1[R2]</smiles>

Imidazoles<smiles>[R]NC(=O)Cc1c(C)nn([R])c1C</smiles>

Pyrazole acetamide

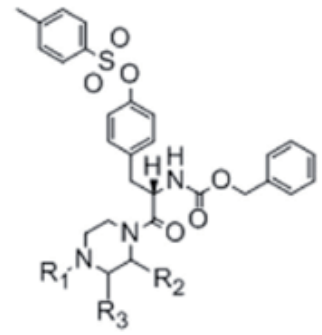

Tyrosine

Figure 4 .

General structures of different classes of $\mathrm{P}_{2} \mathrm{X}_{7}$ antagonists [2].

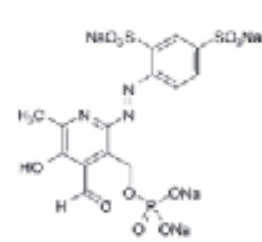

PPADS Tetrasodium sait

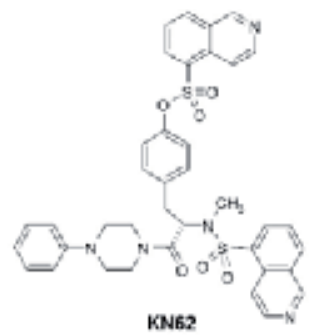

KN62

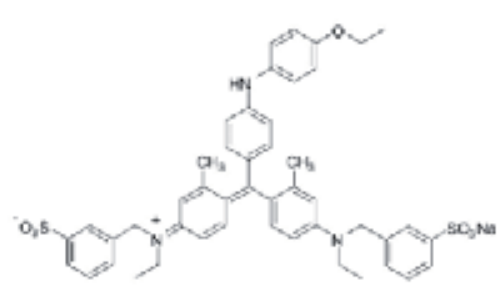

Brilliant Elue G

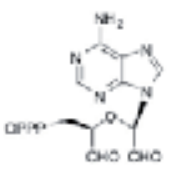

oxidizec ATP

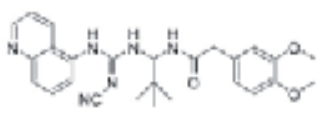

A-7 70003

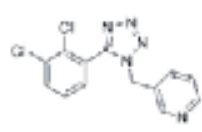

A-438070

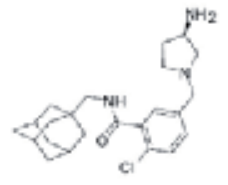

G5K314181A

Figure 5.

Chemical structures of literature $P_{2} X_{7}$ receptor antagonists [2].

subsequent mice promises a better understanding of downstream signaling events. Interestingly, mouse platelets missing from the P2Y1 receptor may enter partial deposition with high ADP concentrations [30]. Chemical structures of literature P2X7 receptor antagonists are shown in Figure 5. 


\section{Functions of the purinergic receptors in metabolism}

\subsection{Functions of the purinergic receptors in the cardiac system}

Multiple $\mathrm{P} 2$ receptor subtypes are located in the microglia pain paths as both initiator and modulator. Activation of homomeric $\mathrm{P} 2 \mathrm{X} 3$ receptors probably contributes to some aspects of acute nociception and acute inflammatory pain. In contrast, activation of heteromeric $\mathrm{P} 2 \mathrm{X} 23$ receptors appears to modulate the duration of nociceptive sensitivity associated with nerve injury or chronic inflammation. In addition, $\mathrm{P} 2 \mathrm{X} 4, \mathrm{P} 2 \mathrm{X} 7$ and P2Y12 receptors can serve to protect nociceptive sensitivity through sensitization of other nociceptive receptors such as TRPV1 channels or complex neural-glial cell interactions under conditions of continuous nociceptive activation on microglia. P2X3, P2X4, P2X7 and P2Y12 receptor antagonists are used for neuropathic pain. The study is being investigated for orally biologically available $\mathrm{P} 2 \mathrm{X} 3$, $\mathrm{P} 2 \mathrm{X} 23, \mathrm{P} 2 \mathrm{X} 4, \mathrm{P} 2 \mathrm{X} 7$ and $\mathrm{P} 2 \mathrm{Y} 12$ receptor antagonists with molecules able to cross the blood-brain barrier and not be degraded in vivo during the pain treatment. In particular, the $\mathrm{P} 2 \mathrm{X} 7$ receptor has become the main target for inflammatory neuropathic pain and a number of selective $\mathrm{P} 2 \mathrm{X} 7$ receptor antagonists have been developed. There is also a review describing the recent advances in the development of adenosine receptor ligands as anti-inflammatory drugs [31]. Other therapeutic approaches, including the development of agents that control the expression of receptors and the selective inhibition of known ectonucleotides, as well as the development of agents that prevent the degradation of ATP, are considered. It is also expected the mechanisms underlying the transport of ATP to be understood, although it is clear that many different cell types secrete physiologically to ATP in response to mechanical deterioration, hypoxia and various agents. Hopefully, when this becomes clearer, agents will be developed that will increase or enhance the release of ATP, another useful pathway that stands out as a therapeutic strategy. In this context A134757, a novel adenosine kinase (AK) inhibitor, alleviated tactile allodynia by means of spinal action sites in peripheral nerve injury rats and added increased evidence that EC inhibitors may be useful analgesic agents [32]. Furthermore, human macrophages express purinic receptors with the rIFN-an modulated P2Z subtype [33].

Purinergic receptor expression in human dendritic cells is associated with the pharmacological and biochemical evidence that immature and mature cells express P2Y and P2X subtypes associated with intracellular $\mathrm{Ca}^{2+}$, membrane depolarization and secretion of inflammatory cytokines. ATP-activated $\mathrm{Ca}^{2+}$ mobilization is biphasic, which is rapidly released from intracellular stores and releases a second delayed flow in the plasma membrane. Prolonged exposure to ATP was toxic to dendritic cells (swollen, lost from typical dendrites, phase lents were exhibited, separated from substrate, and eventually died). These changes strongly elicited the expression of the cytotoxic receptor $\mathrm{P} 2 \mathrm{X} 7$ as confirmed by the ability of dendritic cells to become permeable to membrane impermeable dyes such as Lucifer's yellow or ethidium bromide. P2X7 receptor ligand 2 isolation, $3 \mathrm{z}$-(4-benzoylbenzoyl) -ATP was a better agonist, followed by an increase in $\mathrm{Ca}^{2+}$ and ATP-induced plasma membrane depolarization. ATP oxidized and the P2X7 antagonist KN-62, a covalent blocker of P2X receptors, inhibited both permeabilization and ATP-induced Ca ${ }^{2+}$ changes. The following purinoceptors were expressed by immature and mature dendritic cells: P2Y1, P2Y2, P2Y5 and P2Y11 and P2X1, P2X4 and P2X7. Finally, stimulation of matured cells with LPS by ATP induced IL-1 and TNF- $\alpha$ release. Therefore, these receptors can provide a new way of modulating dendritic cell function [34]. Glutamate is a well-known excitotoxic agent that can lead neurons and astrocytes to death when it is present as the primary mediator of stimulatory neurotransmission in the central nervous system and in extracellular milieu [35]. 
The ability to release this transmitter demonstrates the direct involvement of astrocytes in glutamatergic neuronal transmission and in the excitotoxic effect of glutamate [36]. Although this last problem has been proven, a large number of evidence suggests that astrocyte-derived glutamate has complex effects on neurons that play a modulator role in synaptic transmission. In the hippocampus, it modulates the excitability of the interneurons and strengthens the inhibitory transmission; it also acts on the stimulating axon terminals of the CA1 region to increase the probability of spontaneous glutamate release [37]. At the same time, astrocytic glutamate has a direct effect on hippocampal pyramidal neurons by activating extra-synaptic NMDARs and triggering episodic inward currents (SICs) characterized by slow kinetics. Interestingly, this NMDAR response may occur simultaneously in many CA1 neurons, and this increases the likelihood of synergistic neuronal activity [38].

The results show that activation of different purinergic receptors in the hippocampus are mediated by two types of glutamate release, each of which induces a different response in CA1 pyramidal neurons. In the first release, P2X7R is not included. This release of glutamate mediated for astrocytes evokes transient NMDAR-mediated responses (SICs) in CA1 pyramidal neurons, which represent a sign of astrocyte-neuron communication. In the second type of release, a receptor similar to P2X7 may be included. This phenomenon is enhanced under nonphysiological conditions, increasing the likelihood of contributing to the excitotoxic effect of glutamate in the brain.

The presence of a non-cholinergic, non-adrenergic component in the vertebrate autonomic nervous system is now well established. Evidences that ATP is a donor released from some of these nerves include

a. synthesis and storage of ATP

b.release of ATP from nerves when stimulated

c. externally applied ATP mimicking the action of the nerve-secreting donor

d.the presence of enzymes that inactivate ATP

e. exogenously administered ATP and drugs that produce similar blocking or enhancing effects on response to nerve stimulation.

A basis for distinguishing two types of purinergic receptors has been proposed based on four criteria: relative forces of agonists, competitive antagonists, changes in cAMP levels and stimulation of prostaglandin synthesis. P1 purinoceptors are therefore most susceptible to adenosine and are blocked in competition with methylxanthines, and their use leads to changes in cAMP accumulation; P2 purinoceptors are most sensitive to ATP, but, although not competitive, quinidine is blocked by 2-substituted imidazolines, 2,2'-pyridylisatogen and apamine, and their use leads to prostaglandin production. $\mathrm{P} 2$ purinoceptors mediate the response of smooth muscle to ATP released from purinergic nerves, while P1 purinogens mediate the presynaptic effects of adenosine on adrenergic, cholinergic and purinergic nerve terminals [39].

The discovery of a P2X purinoceptor (a ligand-gated ion channel triggered by ATP) that is selectively expressed by small-diameter sensory neurons has led to the investigation of ATP sources involved in the initiation of different types of nociception and pain types including sympathetic nerves, endothelial cells and tumor cells. To a lesser extent, ATP stimulates the sensory nerve endings in the skin, causes severe pain, and causes a significant increase in discharge from sensory neurons. 
The molecular structure of the PZX3 purinepeptor is associated with the nociceptor and is associated with the search for the PZX3 purinoceptor to identify selective antagonists (Xenopus oocytes and/or transfected cells can be expressed herein).

When defined, such antagonists can be tested in vitro models of different types of pain. It is clear that PZX3 purine receptors are not the only receptors involved in pain, so a synergy with receptors for other pain-modulating agents (such as bradykinin, histamine and S-hydroxytryptamine) should be investigated. ATP acts on receptors on sensory nerve terminals; it has been reported that ATP acts on the dorsal horn neurons in the spinal cord after release from a subpopulation of small primary afferent nerves in the pain pathways.

There are multiple P2 receptor-mediated mechanisms in which ATP can alter nociceptive sensitivity following tissue damage. Evidence from various experimental strategies, including genetic degradation studies and the development of selective antagonists, modulates pain in the activation of $\mathrm{P} 2 \mathrm{X}$ receptor subtypes, including P2X3, P2X2 / 3, P2X4 and P2X7 and P2Y (eg P2Y2) receptors. For example, administration of A-317491, a selective P2X3 antagonist, has been shown to effectively block both hyperalgesia and allodynia in different pathological painful animal models. Antisense oligonucleotides administered intrathecally to target P2X4 receptors reduce tactile allodynia following nerve damage. Selective antagonists for the P2X7 receptor also reduce sensitivity in animal models of inflammatory and neuropathic pain; This provides evidence that purinergic glial nerve interactions are important modulators of harmful sensory neurotransmission. In addition, activation of $\mathrm{P} 2 \mathrm{Y} 2$ receptors leads to the planning of polmodal transient receptor potential-1 receptors. Thus, ATP acts either directly on neurons (P2X3, P2X2/3 and $\mathrm{P} 2 \mathrm{Y}$ receptors) or directly on multiple purinergic receptors that are indirectly affected by neural-glial cell interactions (P2X4 and P2X7 receptors). The development of selective antagonists for some of these $\mathrm{P} 2$ receptors has greatly helped to investigate the nociceptive role of ATP. This perspective highlights some of the recent advances to identify selective $\mathrm{P} 2$ receptor ligands that enhance the investigation of ATP-related pain sensitivity modulation [40].

\subsection{Function of the purinergic receptors in the retina}

$\mathrm{P} 2 \mathrm{X}$ receptors are ligand-gated ion channels which are activated by adenosine triphosphate and expressed in a wide variety of tissues. The expression of various types of purinergic P2X receptors is shown in defined retinal ganglion cells (RGCs) of the adult rat retinas. The single-cell reverse transcription polymerase chain reaction (SC-RT-PCR) resulted in a positive amplification signal for all P2X receptor subunit mRNAs studied (P2X3X5, P2X7). Immunohistochemistry with antibodies specific to the $\mathrm{P} 2 \mathrm{X} 3,4$ receptor subunit showed the label of neurons in the ganglion cell layer and internal nuclear layer. The data suggest that extracellular ATP is directly effective on RGCs through several types of $\mathrm{P} 2 \mathrm{X}$ receptors and may provide neuromodulatory effects in the retinal information processing [41]. For example, in the retina, glutamate release from acetamides modulates the spike activity in ganglion cell that is most likely driven by mild stimulation with a presynaptic action [42].

\subsection{Function of the purinergic receptors in the heart}

Both the adenosine receptor and the ATP-responsive K (KATP) channel mediate the intact heart-protective effect of ischemic preconditioning. The data [43] provides direct evidence that the myositis KATP channel is effective downstream of the adenosine $\mathrm{Al}$ receptor in mediating direct preconditioning of cardiac myocytes. 
A study by Liang and Gross [44] showed that the functional opioid receptors were found in chick cardiac ventricular myocytes. The activation of the receptors by the nonselective opioid receptor agonist morphine can result in a PC-like effect. The protective effect of morphine in myocytes was probably mediated by the activation of the K1 (KATP) channel, which is sensitive to mitochondrial origin, ATP. However, the identity of the specific subtype of the said opioid receptor and the signaling pathway for mediating cardioprotective effect to the mitochondrial KATP channel from the receptor is unknown [45].

\subsection{Function of the purinergic receptors in cancer}

Reports documenting the activity of convergent ATP and its metabolites on cancer growth demonstrate a clear issue of how we can benefit from purifying cancer from purinergic signaling. Schematically, two paths are possible for the host and/ or the tumor side to interfere. The available evidence in several experimental tumor models clearly demonstrates that decreasing adenosine concentration inhibits tumor progression and prevents metastasis [46]. The concentration of adenosine in the tumor interstitium can be reduced by downregulation of CD39 and/or CD73 or by upregulation of CD26. Alternatively, ADA may be targeted to the tumor as a PEG-ADA conjugate [47]. Also, on the host side, the beneficial effect of ATP release is demonstrated by the ability to activate the P2X7/inflammatory axis including the immune cells [48]. Thus, a pharmacological strategy may be based on the administration of CD39 inhibitors with double beneficial effect to maintain adequate levels of ATP for immunostimulation and to prevent adenosine accumulation.

When the use of purinergic receptors as a novel treatment for non-melanoma skin cancers is investigated; purinergic receptors binding adenosine- $5^{\prime}$-triphosphate are expressed in human cutaneous keratinocytes. Previous studies in rat and human epidermis have proposed functional roles for purinergic receptors in the regulation of proliferation, differentiation and apoptosis. Immunohistochemical analysis of frozen sections in human basal cell carcinomas and squamous cell carcinomas for $\mathrm{P} 2 \mathrm{X}$ 5, P2X7, P2Y1, P2Y2 and P2Y4 receptors was performed with detailed analysis of the archive material of tumor subtypes in paraffin sections. Functional studies were performed using the human cutaneous squamous cell carcinoma cell line (A431), where purinergic receptor subtype agonists were applied to cells and changes in cell number were measured by a colorimetric assay. P2X 5 and P2Y2 receptors have been extensively expressed in basal cell carcinomas and squamous cell carcinomas. P2X7 receptors were expressed in the necrotic center of nodular basal cell carcinomas and in apoptotic cells in superficial multifocal and infiltrative basal cell carcinomas and squamous cell carcinomas. P2Y1 receptors were expressed only in tumors surrounding the stroma. $\mathrm{P} 2 \mathrm{Y} 4$ receptors were found in basal cell carcinomas but not in squamous cell carcinomas. P2X 5 receptors appear to be associated with differentiation. P2X7 receptor agonist benzoylbenzoyl-adenosine 5 accordingly-triphosphate and high concentrations of adenosine 5 (-tophosphate (1000) 5000 concentM) lead to a significant decrease in A431 cell number ( $\mathrm{p}<0.001)$, while P2Y2 receptor agonist uridine 5 triphosphate significantly induced proliferation $(\mathrm{p} .<0.001)$. It is shown that non-melanoma skin cancers express functional purinergic receptors and significantly reduce in vitro cell numbers of P2X7 receptor agonists [49].

\subsection{Function of the purinergic receptors in the fetal epidermis}

It is expressed the expression of $\mathrm{P} 2 \mathrm{X} 5, \mathrm{P} 2 \mathrm{X} 7, \mathrm{P} 2 \mathrm{Y} 1$ and $\mathrm{P} 2 \mathrm{Y} 2$ receptor subtypes in the 8-11-week human fetal epidermis associated with proliferative proliferation markers (proliferative cell nuclear antigen (PCNA) and Ki-67), keratinocyte differentiation 
(cytokeratin K10 and involucrin) and apoptosis marker (TdT-mediated dUTP-biotin nick end labeling (TUNEL) and anti-caspase-3). Immunohistochemistry showed that each of the four receptors was expressed in spatially distinct regions of the developing epidermis: the P2Y1 receptors were found in the basal layer, the P2X5 receptors were found mainly in the basal and intermediate layers, and both P2Y2 and P2X7 receptors were in the periderm. Colocalization assays have proposed different functional roles for these receptors. In fetal keratinocytes positive for PCY and Ki-67, P2Y1 receptors were found, indicating a role in proliferation. Double-labeled P2X5 receptors with differentiated fetal keratinocytes, which are positive for cytokeratin K10, show that they play a role in differentiation. It was expressed in periderm cells, positive for P2X7 receptors collozed with anti-caspase-3 antibody and also positive for TUNEL, suggesting a role in periderm cell apoptosis. $\mathrm{P} 2 \mathrm{Y} 2$ receptors have been found only in periderm cells and may play a role in the release of chloride and fluid into the amniotic fluid [50].

\subsection{Function of the purinergic receptors in the kidney}

Autocrine and paracrine signals in the kidney nephron have been a widely used hypothesis for decades. The lumen of the nephron is an ideal autocrine and paracrine signal microenvironment. Any agonist released from the glomerulus or released in the proximal tubule or other proximal segments is then retained in the nephron lumen and is present to interact with the lumen receptors. Similar signals in the renal interstitium are also possible and possible. In fact, for many autocrine and paracrine agonists, the receptors have been characterized on the lumen membrane and serosal membrane of many nephron segments. An important autocrine and paracrine agonist family in the kidneys are purinergic agonists. In addition to extracellular ATP, metabolites (ADP, 5'-AMP and adenosine) are released by renal epithelial cells. These compounds are also freely filtered in the glomerulus and are in the final urine. ATP and adenosine receptors are also expressed on the lumen and serosal side of many nephron segments. This review discusses purinergic signaling by nucleotide agonists from ATP release to ATP receptors to extracellular ATP mediated effects in renal epithelial function. These themes are the areas in which our

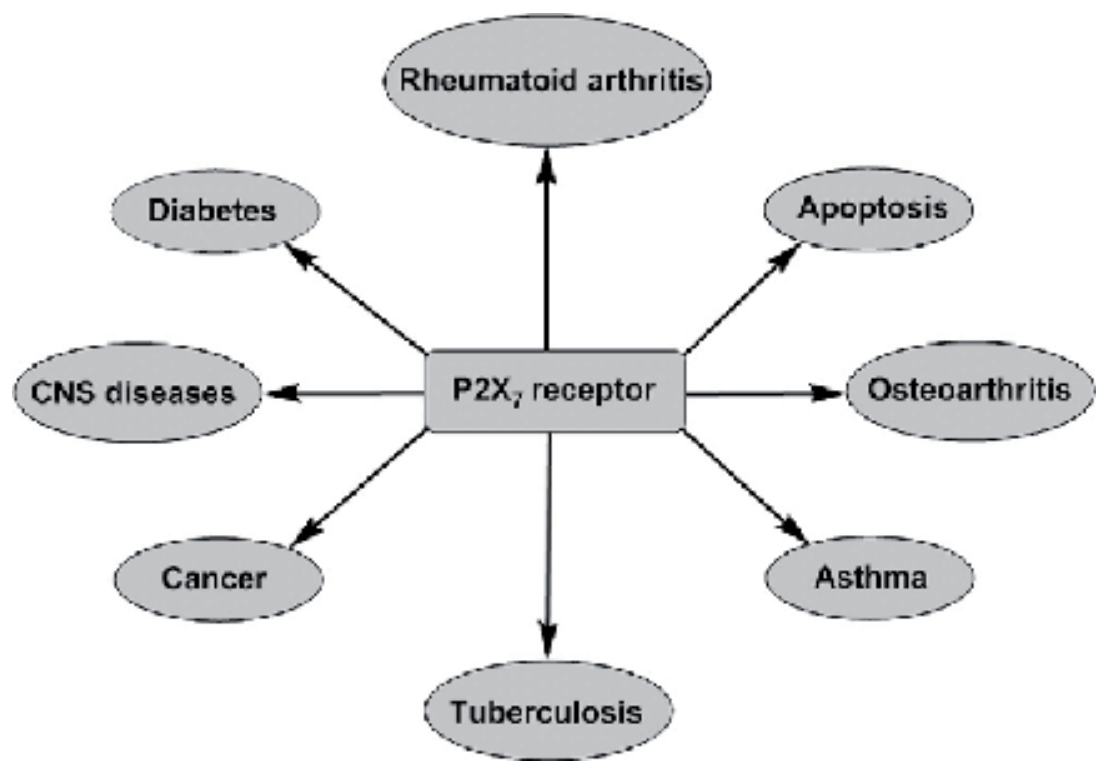

Figure 6.

$\mathrm{P}_{2} \mathrm{X}_{7}$ receptor and diseases [2]. 
laboratory focuses on normal and diseased epithelial cells in normal and polycystic kidneys and other tissues. The physiological roles of extracellular purinergic signals in the kidney and other tissues began to emerge [51]. $\mathrm{P} 2 \mathrm{X}_{7}$ receptor and diseases are shown in Figure 6.

\section{Conclusions}

Purinergic receptors are a family of newly characterized plasma membrane molecules in the field of signaling. As a result of many scientific studies, these receptors have been associated with many cellular functions including vascular reactivity, apoptosis and cytokine secretion; learning and memory, locomotor and feeding behavior and proliferation and migration of sleep neural stem cells. Activation of these receptors is partly due to the release of ATP (or UTP) from the cells, usually in the determination of cellular damage. Further studies are needed to better define the functions of purinergic receptors and to better understand the effect of extracellular micro-environment on their functions.

\section{Author details}

Eren Sarikaya

Van Yuzuncu Yil University, Van, Turkey

*Address all correspondence to: erensarikaya1@gmail.com

\section{IntechOpen}

(C) 2019 The Author(s). Licensee IntechOpen. This chapter is distributed under the terms of the Creative Commons Attribution License (http://creativecommons.org/licenses/ by/3.0), which permits unrestricted use, distribution, and reproduction in any medium, provided the original work is properly cited. (cc) BY 


\section{References}

[1] North RA, Barnard EA. Nucleotide receptors. Current Opinion in

Neurobiology. 1997;7(3):346-357. DOI: 10.1016/S0959-4388(97)80062-1. PMID: 9232809

[2] Mehta N, Kaur M, Singh M, Chand S, Vyas B, Silakari P, et al. Purinergic receptor $\mathrm{P}_{2} \mathrm{X}_{7}$ : A novel target for antiinflammatory therapy. Bioorganic \& Medicinal Chemistry. 2014;22(1):54-88. DOI: 10.1016/j.bmc.2013.10.054. PMID: 24314880

[3] Boyer JL, Lazarowski ER, Chen XH, Harden TK. Identification of a P2Ypurinergic receptor that inhibits adenylyl cyclase. The Journal of Pharmacology and Experimental Therapeutics. 1993;267(3):1140-1146. PMID: 8263774

[4] Lohmann K. Über die pyrophosphatfraktion im muskel. Die Naturwissenschaften. 1929;17(31): 624-625. DOI: 10.1007/BF01506215

[5] Abbracchio MP, Burnstock G, Verkhratsky A, Zimmermann $\mathrm{H}$. Purinergic signalling in the nervous system: An overview. Trends in Neurosciences. 2009;32(1):19-29. DOI: 10.1016/j.tins.2008.10.001. PMID: 19008000

[6] Dubyak GR. Signal transduction by P2-purinergic receptors for extracellular ATP. American Journal of Respiratory Cell and Molecular Biology. 1991;4(4):295-300. DOI: 10.1165/ ajrcmb/4.4.295. PMID: 1707633

[7] Dubyak GR, El-Moatassim C. Signal transduction via $\mathrm{P} 2$-purinergic receptors for extracellular ATP and other nucleotides. The American Journal of Physiology. 1993;265(3 Pt 1): C577-C606. DOI: 10.1152/ ajpcell.1993.265.3.C577. PMID: 8214015

[8] Scheepers A, Joost HG, Schürmann A. The glucose transporter families SGLT and GLUT: Molecular basis of normal and aberrant function. JPEN Journal of Parenteral and Enteral Nutrition. 2004;28(5):364-371. DOI: 10.1177/0148607104028005364. PMID: 15449578

[9] Cartier EA, Conti LR, Vandenberg CA, Shyng SL. Defective trafficking and function of KATP channels caused by a sulfonylurea receptor 1 mutation associated with persistent hyperinsulinemic hypoglycemia of infancy. Proceedings of the National Academy of Sciences of the United States of America. 2001;98(5):2882-2887. DOI: 10.1073/ pnas.051499698. PMID: 11226335

[10] Yee KK, Sukumaran SK, Kotha R, Gilbertson TA, Margolskee RF. Glucose transporters and ATP-gated $\mathrm{K}+$ (KATP) metabolic sensors are present in type 1 taste receptor 3 (T1r3)-expressing taste cells. Proceedings of the National Academy of Sciences of the United States of America. 2011;108(13):54315436. DOI: $10.1073 /$ pnas.1100495108. PMID: 21383163

[11] Kirsch GE, Codina J, Birnbaumer L, Brown AM. Coupling of ATP-sensitive $\mathrm{K}+$ channels to $\mathrm{A} 1$ receptors by $\mathrm{G}$ proteins in rat ventricular myocytes. The American Journal of Physiology. 1990;259(3 Pt 2):H820-H826. DOI: 10.1152/ajpheart.1990.259.3.H820. PMID: 2118729

[12] Bryan J, Crane A, Vila-Carriles WH, Babenko AP, Aguilar-Bryan L. Insulin secretagogues, sulfonylurea receptors and K(ATP) channels. Current Pharmaceutical Design. 2005;11(21):2699-2716. DOI: 10.2174/1381612054546879. PMID: 16101450

[13] Van Winkle DM, Chien GL, Wolff RA, Soifer BE, Kuzume K, Davis RF. Cardioprotection provided 
by adenosine receptor activation is abolished by blockade of the KATP channel. The American Journal of Physiology. 1994;266(2 Pt 2):H829-H839. DOI: 10.1152/ajpheart.1994.266.2.H829. PMID: 8141383

[14] Bienengraeber M, Alekseev AE, Abraham MR, Carrasco AJ, Moreau C, Vivaudou M, et al. ATPase activity of the sulfonylurea receptor: A catalytic function for the KATP channel complex. The FASEB Journal. 2000;14(13):1943-1952. DOI: 10.1096/fj.00-0027com. PMID: 11023978

[15] Di Virgilio F, Adinolfi E.

Extracellular purines, purinergic receptors and tumor growth. Oncogene. 2017;36(3):293-303. DOI: $10.1038 /$ onc.2016.206. PMID: 27321181

[16] Di Virgilio F. Purines, purinergic receptors, and cancer. Cancer Research. 2012;72(21):5441-5447. DOI: 10.1158/0008-5472.CAN-12-1600. PMID: 23090120

[17] Di Virgilio F, Ferrari D, Adinolfi E. P2X(7): A growth-promoting receptorimplications for cancer. Purinergic Signal. 2009;5(2):251-256. DOI: 10.1007/ s11302-009-9145-3. PMID: 19263244

[18] Di Virgilio F, Chiozzi P, Falzoni S, Ferrari D, Sanz JM, Venketaraman V, et al. Cytolytic P2X purinoceptors. Cell Death and Differentiation. 1998;5(3):191-199. DOI: 10.1038/ sj.cdd.4400341. PMID: 10200464

[19] Adinolfi E, Cirillo M, Woltersdorf R, Falzoni S, Chiozzi P, Pellegatti $P$, et al. Trophic activity of a naturally occurring truncated isoform of the $\mathrm{P} 2 \mathrm{X} 7$ receptor. The FASEB Journal. 2010;24(9):3393-3404. DOI: 10.1096/fj.09-153601. PMID: 20453110

[20] Lazarowski ER, Boucher RC. Purinergic receptors in airway epithelia. Current Opinion in Pharmacology.
2009;9(3):262-267. DOI: 10.1016/j. coph.2009.02.004. PMID: 19285919

[21] Heurteaux C, Lauritzen I, Widmann C, Lazdunski M. Essential role of adenosine, adenosine $\mathrm{Al}$ receptors and KATP channels in cerebral ischemic preconditioning. Proceedings of the National Academy of Sciences. 1995;92(10):4666-4670

[22] Liang BT. Protein kinase C-mediated preconditioning of cardiac myocytes: Role of adenosine receptor and KATP channel. The American Journal of Physiology. 1997;273(2 Pt 2):H847-H853. DOI: 10.1152/ajpheart.1997.273.2.H847. PMID: 9277502

[23] Plamondon $\mathrm{H}$, Blondeau $\mathrm{N}$, Heurteaux C, Lazdunski M. Mutually protective actions of kainic acid epileptic preconditioning and sublethal global ischemia on hippocampal neuronal death: Involvement of adenosine A1 receptors and $\mathrm{K}$ (ATP) channels. Journal of Cerebral Blood Flow and Metabolism. 1999;19(12):1296-1308. DOI:

10.1097/00004647-199912000-00002.

PMID: 10598933

[24] Burnstock G, Wood JN. Purinergic receptors: Their role in nociception and primary afferent neurotransmission. Current Opinion in Neurobiology. 1996;6(4):526-532. DOI: 10.1016/S09594388(96)80060-2. PMID: 8794102

[25] Paul BZ, Vilaire G, Kunapuli SP, Bennett JS. Concurrent signaling from Galphaq- and Galphai-coupled pathways is essential for agonistinduced alphavbeta 3 activation on human platelets. Journal of Thrombosis and Haemostasis. 2003;1(4):814-820. DOI: 10.1046/j.1538-7836.2003.00099.x. PMID: 12871420

[26] Burnstock G. Purinergic receptors in the heart. Circulation Research. 1980;46(6 Pt 2):I175-I182. PMID: 6247089 
[27] Kunapuli SP, Dorsam RT, Kim S, Quinton TM. Platelet purinergic receptors. Current Opinion in Pharmacology. 2003;3(2):175-180. DOI: 10.1016/S1471-4892(03)00007-9. PMID: 12681240

[28] Burnstock G. In: Straub RW, Bolis L, editors. Cell Membrane Receptors for Drugs and Hormones: A

Multidisciplinary Approach. New York: Raven; 1976. pp. 107-118

[29] Gallacher DV. Are there purinergic receptors on parotid acinar cells? Nature. 1982;296(5852):83

[30] Léon C, Hechler B, Freund M, Eckly A, Vial C, Ohlmann P, et al. Defective platelet aggregation and increased resistance to thrombosis in purinergic $\mathrm{P} 2 \mathrm{Y}$ (1) receptornull-null mice. The Journal of Clinical Investigation. 1999;104(12):1731-1737. DOI: 10.1172/JCI8399. PMID: 10606627

[31] Akkari R, Burbiel JC, Hockemeyer J, Müller CE. Recent progress in the development of adenosine receptor ligands as antiinflammatory drugs. Current Topics in Medicinal Chemistry. 2006;6(13):1375-1399. DOI: 10.2174/15680266106061375. PMID: 16918456

[32] Zhu CZ, Mikusa J, Chu KL, Cowart M, Kowaluk EA, Jarvis MF, et al. A-134974: A novel adenosine kinase inhibitor, relieves tactile allodynia via spinal sites of action in peripheral nerve injured rats. Brain Research. 2001 Jun;905(1-2):104-110. DOI: 10.1016/S0006-8993(01)02512-4. PMID: 11423084

[33] Falzoni S, Munerati M, Ferrari D, Spisani S, Moretti S, Di Virgilio F. The purinergic $\mathrm{P} 2 \mathrm{Z}$ receptor of human macrophage cells. Characterization and possible physiological role. The Journal of Clinical Investigation. 1995;95(3):1207-1216. DOI: $10.1172 /$ JCI117770. PMID: 7883969
[34] Ferrari D, La Sala A, Chiozzi P, Morelli A, Falzoni S, Girolomoni G, et al. The $\mathrm{P} 2$ purinergic receptors of human dendritic cells: Identification and coupling to cytokine release. The FASEB Journal. 2000;14(15):2466-2476 DOI: 10.1096/fj.00-0031com

[35] Choi ES, Clegg DO. Identification and developmental expression of a chicken calsequestrin homolog. Developmental Biology. 1990;142(1):169-177. DOI: 10.1016/ 0012-1606(90)90160-K. PMID: 2227093

[36] Bezzi P, Carmignoto G, Pasti L, Vesce S, Rossi D, Rizzini BL, et al. Prostaglandins stimulate calciumdependent glutamate release in astrocytes. Nature. 1998;391(6664): 281-285. DOI: $10.1038 / 34651$. PMID: 9440691

[37] Fiacco TA, McCarthy KD.

Intracellular astrocyte calcium waves in situ increase the frequency of spontaneous AMPA receptor currents in CA1 pyramidal neurons. The Journal of Neuroscience. 2004;24(3):722-732. DOI: 10.1523/JNEUROSCI.2859-03.2004.

PMID: 14736858

[38] Fellin T, PascualO, GobboS, PozzanT, Haydon PG, Carmignoto G. Neuronal synchrony mediated by astrocytic glutamate through activation of extrasynaptic NMDA receptors. Neuron. 2004;43(5):729-743. DOI: 10.1016/j. neuron.2004.08.011. PMID: 15339653

[39] Burnstock G. Purinergic nerves and receptors. Progress in Biochemical Pharmacology. 1980;16:141-154. PMID: 6108568

[40] Donnelly-Roberts D, McGaraughty S, Shieh CC, Honore P, Jarvis MF. Painful purinergic receptors. Journal of Pharmacology and Experimental Therapeutics. 2008;324(2):409-415. DOI: 10.1124/ jpet.106.105890. PMID: 18042830 
[41] Wheeler-Schilling TH, Marquordt K, Kohler K, Guenther E, Jabs R. Identification of purinergic receptors in retinal ganglion cells. Brain Research. Molecular Brain Research. 2001;92(1-2):177-180. DOI: 10.1016/ S0169-328X(01)00160-7. PMID: 11483255

[42] Newman EA, Zahs KR. Modulation of neuronal activity by glial cells in the retina. The Journal of Neuroscience. 1998;18(11):4022-4028. DOI: 10.1523/ JNEUROSCI.18-11-04022.1998. PMID: 9592083

[43] Liang BT. Direct preconditioning of cardiac ventricular myocytes via adenosine A1 receptor and KATP channel. The American Journal of Physiology. 1996;271(5 Pt 2): H1769-H1777. DOI: 10.1152/ ajpheart.1996.271.5.H1769. PMID: 8945890

[44] Liang CT, Gross GJ. Direct preconditioning of cardiac myocytes with Opioid receptors and KATP channels. Circulation Research. 1999;84:1396-1400

[45] Huh J, Gross GJ, Nagase H, Liang BT. Protection of cardiac myocytes via $\delta(1)$-opioid receptors, protein kinase $C$, and mitochondrial K(ATP) channels. American Journal of Physiology. Heart and Circulatory Physiology. 2001;280(1):H377-H383. DOI: 10.1152/ ajpheart.2001.280.1.H377. PMID: 11123254

[46] Stagg J, Divisekera U, Duret H, Sparwasser T, Teng MW, Darcy PK, et al. CD73-deficient mice have increased antitumor immunity and are resistant to experimental metastasis. Cancer Research. 2011;71(8):2892-2900. DOI: 10.1158/0008-5472.CAN-10-4246. PMID: 21292811

[47] Sauer AV, Brigida I, Carriglio N, Hernandez RJ, Scaramuzza S, Clavenna D, et al. Alterations in the adenosine metabolism and CD39/CD73 adenosinergic machinery cause loss of Treg cell function and autoimmunity in ADA-deficient SCID. Blood. 2012;119(6):1428-1439. DOI: $10.1182 /$ blood-2011-07-366781. PMID: 22184407

[48] Michaud M, Martins I, Sukkurwala AQ, Adjemian S, Ma Y, Pellegatti P, et al. Autophagy-dependent anticancer immune responses induced by chemotherapeutic agents in mice. Science. 2011;334(6062):1573-1577. DOI: $10.1126 /$ science.1208347. PMID: 22174255

[49] Greig AV, Linge C, Healy V, Lim P, Clayton E, Rustin MH, et al. Expression of purinergic receptors in non-melanoma skin cancers and their functional roles in A431 cells. The Journal of Investigative Dermatology. 2003;121(2):315-327. DOI: 10.1046/j.1523-1747.2003.12379.x. PMID: 12880424

[50] Greig AV, Linge C, Cambrey A, Burnstock G. Purinergic receptors are part of a signaling system for keratinocyte proliferation, differentiation, and apoptosis in human fetal epidermis. The Journal of Investigative Dermatology. 2003;121(5):1145-1149. DOI: 10.1046/j.1523-1747.2003.12567.x. PMID: 14708618

[51] Schwiebert EM. ATP release mechanisms, ATP receptors and purinergic signalling along the nephron. Clinical and Experimental Pharmacology \& Physiology. 2001;28(4):340-350. DOI: 10.1046/j.1440-1681.2001.03451.x. PMID: 11339211 


\title{
Chapter 3
}

\section{Purinergic Signaling and Dental Orofacial Pain}

\author{
Xiuxin Liu
}

\begin{abstract}
Pain is a common complaint of patients in the dental clinic. Patient with dental orofacial pain usually presents with hyperalgesia and allodynia. Its management has been a challenge, especially in the status of chronic pain or neuropathic pain. Purinergic signaling is dictated by ATP release, purinergic receptors activation, and sequential hydrolysis of ATP. Purinergic signaling participates in nociception processing in the sensory nerves by control of pain signal transduction, modulation, and sensitization. Since purinergic receptors are preferentially expressed in trigeminal nerves, purinergic singling may play a crucial role in the development of dental orofacial pain. In this chapter, we overview the expressions of purinergic receptors as well as the machinery for ATP release, ATP degradations, and adenosine generation in trigeminal nerves. Specifically, the roles of ATP signaling in dental orofacial pain generation and central sensitization via activation of $\mathrm{P} 2$ receptors and adenosine signaling in analgesia via activation of $\mathrm{P} 1$ receptors in trigeminal nerves are updated. We also discuss the affection of ecto-nucleotidases, the major enzymes responsible for extracellular ATP degradation and adenosine generation in trigeminal nerves that drive the shift from ATP-induced pain to adenosine-induced analgesia. This chapter provides advanced outlines for purinergic signaling in trigeminal nerves and unveils potential therapeutic targets for the management of dental orofacial pain.
\end{abstract}

Keywords: trigeminal nerves, orofacial pain, dentine hypersensitivity, central sensitization, analgesia, antinociception, dental pulp, P1 receptor, $\mathrm{P} 2$ receptor, ecto-nucleotidases, NTPDases

\section{Introduction}

Pain is an unpleasant sensation of subjects to harmful or potential harmful stimulations. Trigeminal nerves mediate orofacial somatosensory sensations, including dental orofacial pain. The primary trigeminal ganglia nociceptive neurons send axonal fibers innervating orofacial tissues as well as forming synapses with secondary nociceptive neurons in the brainstem. Noxious stimuli, biological insults, or pain mediators released following tissue injury and inflammations activate the nociceptors resulting in the nociceptive transduction in peripheral sensory nerves. The pain signal is conducted and further transmitted to the secondary and higher level nociceptive neurons via synaptic transmission in the brain. Nociception also depends on the condition and status of the sensory nervous system. Pain signal processing can be facilitated with maladaptive plasticity or neuropathy changes in 
the nociceptive pathway that result in pain sensitization or neuropathic pain. These changes include nociceptive sensitization, malfunctioned inhibition, and circuitlevel rewiring/aberrant processing [1] in both the peripheral and central nociceptive nerves. As peripheral or central sensitization occurs, slight noxious stimulation or even non-noxious stimulation induces severe pain, a phenomenon that is called hyperalgesia or allodynia, respectively. In sensitization condition, patients may also present with spontaneous and neuropathic pain without apparent stimulus. In contrast to the pain from extra-orofacial regions, dental orofacial pain is usually accompanied by the presence of hyperalgesia, allodynia. Dental orofacial pain patients often experience more severe pain and are typically emotional-distracted. Besides, patients with dental orofacial pain are prone to develop spontaneous pain, referred pain, and neuropathic pain [2].

For the past decades, studies strongly suggest a key modulatory role of purinergic signaling in pain generation and sensitization in the nociceptive nerves [3-7]. ATP induces pain via activation of $\mathrm{P} 2 \mathrm{X}$ receptors in peripheral sensory nerve fibers. ATP is also involved in cross-talk between the primary and secondary nociceptive neurons as well as with astrocytes and microglia. Since ATP and its metabolites are pain mediators and participate in pain signal processing via activation of various purinergic receptors ( $\mathrm{P} 1$ and $\mathrm{P} 2$ receptors) in the nociceptive sensory nerves [5, 8-10], one putative explanation for the unique properties in dental orofacial pain is due to the different existence or expression of purinergic signaling in trigeminal nerves. Indeed, it has been observed that purinergic receptors are preferentially expressed in trigeminal nociceptive neurons compared with that in dorsal root ganglions $[11,12]$. Purinergic signaling depends on ATP release, purinergic receptors (P1, P2X, and P2Y) activation, and extracellular enzymatic ATP degradation and adenosine generation. Therefore, identification of the machinery components for purinergic signaling in the trigeminal nociceptive pathway will provide promising insight to understand the underlying nociceptive mechanisms for the pathogenesis of dental orofacial pain.

In this chapter, we overview the expression of purinergic receptors and machinery for ATP release, ATP degradation, adenosine generation in the trigeminal nociceptive nerves, and discuss the role of purinergic signaling in the pathogenesis of dentin hypersensitivity and dental orofacial pain. Understanding the role of purinergic signaling in the nociceptive mechanisms for pain signal transduction, transmission, sensitization, and modulation in trigeminal nerves will reveal multiple targets for developing more effective drugs and therapies for the management of dental orofacial pain.

\section{Purinergic signaling and pain}

\subsection{ATP initiates pain signal via activation of peripheral $\mathrm{P} 2 \mathrm{X}$ receptors}

ATP has been recognized as a neuronal transmitter and modulator in synaptic transmission for decades [13]. ATP and its metabolites are also important pain mediators and modulators in pain signal processing [5, 8-10]. It has been proposed that ATP released from various cell types is implicated in initiating the pain signal by acting on purinoceptors on sensory nerve terminals [14]. Purinoreceptors responsible for pain transduction belong to P2X receptor family, a group of ligandgated non-selective cation channels using ATP as a native agonist. Upon binding to P2X receptors, ATP opens the pore of channels permeable to $\mathrm{Na}^{+}, \mathrm{K}^{+}$, and $\mathrm{Ca}^{2+}$ that depolarize the membrane potential, enhance the excitability and induce spikes in nociceptive neurons. So far, seven distinct P2X receptor subunits (P2X1-P2X7) 
have been isolated and cloned (North 2002). A total of 14 functional homo- or heterotrimers $\mathrm{P} 2 \mathrm{X}$ receptors (P2X1-P2X7, P2X1/2, P2X1/4, P2X1/5, P2X2/3, $\mathrm{P} 2 \mathrm{X} 2 / 6$, P2X4/6, and possibly $\mathrm{P} 2 \mathrm{X} 4 / 7$ ) assembled from different subunits had been reported [15].

Using in situ hybridization immunohistochemistry (ISHH), mRNA expression for $\mathrm{P} 2 \mathrm{X} 2,3,4,5$, and 6 receptors had been detected in naive dorsal root ganglia (DRG) neurons, in which $\mathrm{P} 2 \mathrm{X} 2$ and $\mathrm{P} 2 \mathrm{X} 3$ receptors were expressed preferentially by C-fiber neurons. In contrast, the majority of P2X 5 and P2X6 receptors were preferentially expressed by A-fiber neurons [16]. Specifically, expression of P2X receptors is also detected in nociceptive primary sensory neurons, peripheral nociceptive nerve fibers, and their free endings extending throughout the epidermis. Two types of P2X receptors (P2X2 and P2X3) have been particularly examined in DRG presumably nociceptive neurons [17]. P2X3 receptors appear to be exclusively expressed in a subgroup of sensory neurons that are likely to be nociceptive neurons [18]. Nociceptive neurons fall into nerve growth factor (NGF) sensitive group and glial cell-line derived neurotrophic factor (GDNF) sensitive group. It turned out that the vast majority of $\mathrm{P} 2 \mathrm{X} 3$ positive neurons overlap with GDNF subgroup of nociceptive neurons [19]. P2X3 receptors are peripherally axonal transported and have been identified in the free end of the nerve fibers in a variety of tissues including tongue, skin, and viscera (e.g., bladder) $[17,19]$. Co-localization studies suggest that many, but not all, DRG cells that express P2X2 receptors also express P2X3 receptors [17]. Furthermore, electrophysiological and pharmacological studies had demonstrated that the application of ATP or its analogs to DRG neurons results in depolarization or inward currents mediated by $\mathrm{P} 2 \mathrm{X}$ receptors activation.

The selective expression of $\mathrm{P} 2 \mathrm{X} 3$ and $\mathrm{P} 2 \mathrm{X} 2$ receptors within the nociceptive nerves has inspired a variety of approaches to elucidate the potential role of ATP as a pain mediator. ATP elicits excitatory inward currents in nociceptive small diameter sensory ganglion cells. Interestingly, these inward currents resemble the currents evoked by ATP on recombinantly expressed heteromeric $\mathrm{P} 2 \mathrm{X}(2 / 3)$ channels as well as homomultimers consisting of P2X2 and P2X3 [8, 14, 18, 20]. It had been observed that ATP and its analogs produce spike activity when applied to peripheral nociceptive terminals [8]. In in vivo pain behavioral animal models, the algogenic effects of ATP in normal conditions and models of peripheral sensitization had been confirmed. In humans, local skin delivery of ATP induces dosage-dependent pain sensation. Furthermore, it has been shown that ATP-induced algogenic responses depends on capsaicin-sensitive neurons and is augmented in the presence of inflammatory mediators. Since ATP is released in the vicinity of peripheral nociceptive terminals under a variety of conditions such as tissue injury or inflammation, the existence of purinergic signaling in peripheral sensory nervous free ends strongly links the tissue damage and inflammation to pain perception [9].

\subsection{Purinergic signaling is involved in central sensitization}

Noxious stimulation to the nociceptive nerves induces pain sensation in the brain. Acute pain is a warning signal for the individual to survive in response to tissue injuries or diseases. However, in nociceptive sensitization statuses, such as in chronic pain or neuropathic pain, nociception no longer relates to or depends on external noxious stimulation, and slight noxious or even no-noxious stimulation or non-stimulation at all can induce severe pain. The central sensitization theory proposed that neuronal plasticity occurred in the sensory nerve circuits that enhance the sensitivity to noxious stimuli or even turn the innocuous slight touching to pain [21]. Pain sensitization can also be induced by nerve injury (deafferentation, compression, and constriction) or neuropathy changes resulting from physical, 
chemical, metabolic, or biological insults to the sensory nerves. Besides, it has been proposed the pain signal itself that is accompanied with releasing of proinflammatory cytokines, neuronal transmitters, and modulators in nociceptive neuronal circuits participate in plasticity changes and induce central sensitization [22].

Synaptic neuronal transmission is accompanied with large amount of ATP release. Accumulated evidence suggests that ATP signaling play an essential role in the development and maintenance of central sensitization (Figure 1) [3-7]. In the somatosensory nerves, $\mathrm{P} 2 \mathrm{X}$ receptors are expressed in DRG nociceptive neurons and then transferred to central axonal terminals as well as peripheral free ends. For example, immunoreactivity to P2X3 subunits is detected in lamina IIi in spinal cord dorsal horn and is disappeared after axotomy or following destruction of IB4-positive afferent fibers [17]. Immunoreactivity to P2X1 and P2X2 subunits are also located on the central terminals of primary afferent neurons that innervate superficial lamina of the spinal cord dorsal horn [17]. The presence of P2X receptor subunits at the central terminals of primary afferent neurons raises the possibility that ATP may act on central terminals of primary afferent neurons to either modulate or directly evoke the release of neuronal transmitters such as glutamate and neuropeptides. Activation of central terminal P2X receptors will depolarize the membrane potential and induce $\mathrm{Ca}^{2+}$ influx that will enhance the release of glutamate and substance $\mathrm{P}$, and subsequently increase the secondary nociceptive neuron responses and dorsal horn nociceptive output. In neuropathic pain condition, an increase in the number of $\mathrm{P} 2 \mathrm{X}$ receptors positive DRG neurons is observed following sciatic nerve injury by chronic constriction [23]. Specifically, an increase of $\mathrm{P} 2 \mathrm{X} 3$ receptor immunoreactivity is detected in the dorsal horn ipsilateral side of the injured nerve indicating the upregulation of $\mathrm{P} 2 \mathrm{X}$ receptors at the central terminals of primary afferent neurons. P2X receptor expression is also upregulated following tissue injury or inflammation within the spinal cord. The upregulation of P2X receptor expression on the central terminals of primary afferent neurons would sensitize the responses to ATP, which in turn may facilitate $\mathrm{P} 2 \mathrm{X}$ receptor-mediated nociceptive modulation.

Activation of homomeric, as well as heteromeric $\mathrm{P} 2 \mathrm{X} 2 / 3$ receptors, appears to modulate longer lasting nociceptive sensation associated with nerve injury or chronic inflammation [1]. P2X3 receptor function is highly sensitive to soluble factors like neuropeptides and neurotrophins and is controlled by transduction mechanisms, protein-protein interactions, and discrete membrane compartmentalization. Recent findings have demonstrated that $\mathrm{P} 2 \mathrm{X} 3$ receptors interact with the synaptic scaffold protein calcium/calmodulin-dependent serine protein kinase (CASK) in a state-dependent fashion, indicating that CASK plays a crucial role in the modulation of $\mathrm{P} 2 \mathrm{X} 3$ receptor stability and efficiency [24]. Activation of $\mathrm{P} 2 \mathrm{X} 3$ receptors within CASK/P2X3 complex has essential consequences for neuronal plasticity and possibly for the release of neuromodulators and neurotransmitters. Better understanding the interaction machinery for $\mathrm{P} 2 \mathrm{X} 3$ receptors and their integration with other receptors and channels on pre- and postsynaptic membranes is proposed to be essential to unveil the process of nociceptive neuronal sensitization.

Multiple other purinoceptor subtypes participate in pain processing. In neuropathic pain, activation of purinergic receptors on microglia is thought to maintain nociceptive sensitization through neural-glial cell interactions [3]. Microglia expresses several P2 receptor subtypes, and of these the P2X4, 7, and P2Y12 receptor subtypes have been implicated in neuropathic pain. It has been shown that activation of P2X4, 7, and P2Y12 receptors expressed on microglia is critically involved in neuropathic pain arising from peripheral nerve injury [25], while blocking these receptor with antagonists reduces neuropathic pain [3]. The P2X4 receptor has emerged as the core microglia-neuron signaling pathway. In response 
to peripheral nerve injury, $\mathrm{P} 2 \mathrm{X} 4$ receptors are upregulated in spinal cord microglia [26]. Activation of this receptor causes the release of brain-derived neurotrophic factor (BDNF) which causes disinhibition of pain-transmission neurons in spinal lamina I. Several mechanisms have recently been implicated in the upregulation of $\mathrm{P} 2 \mathrm{X} 4$ receptors including CCL21, interferon $\gamma$, tryptase, fibronectin, and the activation of $\mu$-opioid receptors. Activation of $\mathrm{P} 2 \mathrm{X} 4$ receptors leads to an influx of extracellular $\mathrm{Ca}^{2+}$ activating p38 MAPK that leads to SNARE-dependent release of BDNF from the microglia. BDNF is a crucial microglia-neuron signaling molecule that causes disinhibition of nociceptive dorsal horn neurons by disrupting intracellular $\mathrm{Cl}^{-}$homeostasis of inhibitory interneurons [27-29]. Activation of P2X7 or P2Y12 receptors is also through signals of p38 MAPK. p38 MAPK signaling drives the release of interleukin- $1 \beta$ and cathepsin $S$, which contributes to the maintenance of mechanical hypersensitivity in the spinal cord. P2Y12 receptor expression is also upregulated in microglia, and activation of these receptors is involved in neuropathic pain. Recent studies have demonstrated that inhibition of microgliaexpressed P2 receptors (P2X4, P2X7 or P2Y12) by the pharmacological blockade, antisense knockdown or genetic deletion suppresses both mechanical allodynia and thermal hyperalgesia in nerve-injured rats [30, 31]. Conversely, intrathecal administration of the $\mathrm{P} 2 \mathrm{Y} 12$ receptor agonist 2Me-SADP elicits pain behaviors in naïve rats that mimic those observed in nerve-injured rats [30].

\subsection{Adenosine induces antinociception by activation of $\mathrm{P} 1$ receptors}

In contrast to the algogenic effects of ATP, adenosine, the metabolite of ATP, induces antinociception via activation of $\mathrm{P} 1$ receptors. $\mathrm{P} 1$ receptors are $\mathrm{G}$ proteincoupled metabotropic receptors. Four subtypes of $\mathrm{P} 1$ receptors (A1, A2A, A2B, and A3) have been cloned in the nervous system [32].

A1 receptor is detected in the peripheral sensory nerve fibers [33]. Local delivery of adenosine induces analgesia and blocking A1 receptors abolishes adenosineinduced antinociception in various inflammatory pain models [34]. In addition, it has been shown that adenosine also mediates the analgesic mechanism of acupuncture via peripheral A1 receptors [35]. Adenosine also produces antinociception via activation of A1 receptors in the spinal cord [33]. Intraspinal injection of adenosine or A1 receptor agonists induced antinociception in both inflammatory and neuropathic pain animal models. It has been proposed that the underlying mechanism for adenosine-induced antinociception is related to potassium channel activationinduced cell membrane hyperpolarization [36]. Activation of pre- or postsynaptic A1 receptor triggers cAMP/PKA, PLC/IP3/DAG, and nitric oxide/cGMP/PKG pathways $[33,37]$ that induce analgesia by reducing presynaptic vesicle release and postsynaptic excitability [36]. Indeed, it has been demonstrated that A1 receptor activation decreased the excitatory neurotransmitter release in synaptosomes isolated from the spinal cord dorsal horns [38, 39].

Endogenous adenosine also mediates antinociception by A2A, A2B, or A3 receptors expressed in nociceptive neurons, astrocytes, or immune cells [40, 41]. Considering the extensive involvements of glial cells (microglia and astrocytes) in central sensitization and chronic pain [42], activation of adenosine receptors on microglia and astrocytes are potentially involved in the antinociceptive mechanism of adenosine in the nervous system [43]. Additionally, adenosine may also mediate the antinociception by enhancing GABA inhibition and blocking neuroinflammation via activation of $A 3$ receptors [44]. Collectively, these studies suggest the possibility of treating chronic pain by targeting specific adenosine receptor subtypes in anatomically defined regions with agonists or with ecto-nucleotidases that control the generation of adenosine. 


\subsection{Ecto-nucleotidases drive the shift from ATP-induced pain to adenosine-induced antinociception}

Purinergic signaling depends on ATP release, purinergic receptor action, and sequential hydrolysis of ATP to ADP and nucleoside adenosine [45]. Because of their dynamic catalytic activities under physiological conditions, ecto-nucleotide diphosphatases (Ecto-NTPDases) are the major enzymes responsible for the hydrolysis of extracellular ATP and ADP. Four members of ecto-NTPDse family (NTPDase1, 2, 3, and 8) have been cloned. Three of which (i.e., NTPDase1, 2, and 3) are expressed in the nervous system [46]. NTPDase1 and 3 hydrolyze both ATP and ADP, while NTPDase2 primarily hydrolyzes ATP with minimal ADP hydrolytic activity [47]. Extracellular AMP is further hydrolyzed to adenosine by ecto-5'-nucleotidase (CD73) $[47,48]$ and a transmembrane isoform of prostatic acid phosphatase (PAP) $[47,48]$ in the nervous system. By control of ATP degradation and adenosine generation, these ecto-nucleotidases affect nociception by terminating ATP-induced pain and pain sensitization and promoting adenosine-mediated analgesia.

ATPase activity had been detected in dorsal root ganglion (DRG) and spinal cord using enzymatic histochemistry staining. Nucleotidase activity is robust in spinal cord dorsal horn nociceptive lamina suggesting that nucleotide hydrolysis would play a role in nociceptive processing. In DRG, extensive staining revealed ectoATPase activity in a subset of neurons and non-neuronal cells. The mRNA expression and immunoreactivity for NTPDase1-3, but not NTPDase8, was detected in lumbar DRG and spinal cord. Immunoreactivity for NTPDase3 that closely matches the distribution of ecto-ATPase activity labels DRG central projections in the dorsal root and superficial dorsal horn, as well as intrinsic spinal neurons concentrated in lamina II. It has been reported that NTPDase3 is located in nociceptive and non-nociceptive neurons of DRG, in the dorsal horn of the spinal cord, and the free nerve endings in the skin [49]. These data suggest that NTPDase3 would be a negative regulator for nociceptive signaling [50]. However, studies from NTPDase3 knockout mouse show that deletion of NTPDase3 does not impair ATP hydrolysis in primary somatosensory neurons or dorsal spinal cord. Also, NTPDase3 (-/-) mice did not differ in nociceptive behaviors when compared with wild-type mice. These observations suggest the existence of multiple ecto-nucleotidases acting redundantly to hydrolyze nucleotides [49].

Even though the manipulation of adenosine transport or degradation can induce antinociception [51], extracellular adenosine level is mainly controlled by extracellular AMP hydrolysis. Indeed, it has been shown that extracellular AMP hydrolysis provides the major source for endogenous adenosine in the nervous system that is essential to maintain a tonic activation of adenosine receptors in the nociceptive neurons of the spinal cord [52]. Two ecto-nucleotidases have been identified to be responsible for extracellular AMP hydrolysis in the spinal cord [48]. Ecto-5'-nucleotidase (CD73) is a membrane-anchored protein that hydrolyzes extracellular adenosine $5^{\prime}$-monophosphate (AMP) to adenosine in different tissues. CD73 was detected in peptidergic and nonpeptidergic nociceptive neurons in DRG and afferent terminals in lamina II of spinal cord. In addition, CD73 was also located on epidermal keratinocytes, cells of the dermis, and on nociceptive terminals in the epidermis [52]. Besides CD73, prostatic acid phosphatase (PAP) also functions as an ecto-nucleotidase and generates extracellular adenosine. PAP is expressed in nociceptive dorsal root ganglia (DRG) nociceptive neurons, it had been shown that PAP inhibits noxious thermal sensitivity and sensitization that is associated with chronic pain through sustained activation of the adenosine A1 receptor [53]. 
Knockout of CD73 and/or PAP reduced adenosine generation and enhanced nociception in animal models following inflammation and nerve injury [52]. It has been found that AMP hydrolysis was nearly abolished in DRG neurons and lamina II of the spinal cord from PAP/CD73 double knockout (dKO) mice. Likewise, the antinociceptive effects of AMP were reduced in PAP/CD73 dKO mice. Adenosine was maximally produced from AMP within seconds in wild-type (WT) mice but was significantly reduced in $\mathrm{dKO}$ mice indicating $\mathrm{PAP}$ and $\mathrm{CD} 73$ generate rapidly adenosine in lamina II. Besides, it has shown the existence of spontaneous low-frequency adenosine transients in lamina II in wild-type mice, while knockout of PAP and CD73 abolished the spontaneous adenosine transit suggesting these ecto-nucleotidases rapidly hydrolyze endogenously released nucleotides to adenosine, and there exists tonic activation of A1 receptors. Field potential recordings in dorsal horn lamina II and behavioral studies indicated that adenosine converted by these enzymes acts through the A1 receptor to inhibit excitatory neurotransmission. PAP and CD73 injected spinally produced long-lasting adenosine $\mathrm{A} 1$ receptor-dependent antinociceptive effects in inflammatory and neuropathic pain models [54]. Furthermore, it has been noted that following peripheral nerve injury CD73, PAP, as well as enzymatic ecto-AMPase activities were reduced in dorsal horn lamina II. Collectively, these evidences indicate that PAP and CD73 are the predominate ecto-nucleotidases that generate adenosine in the nociceptive circuits (Figure 1) [48].

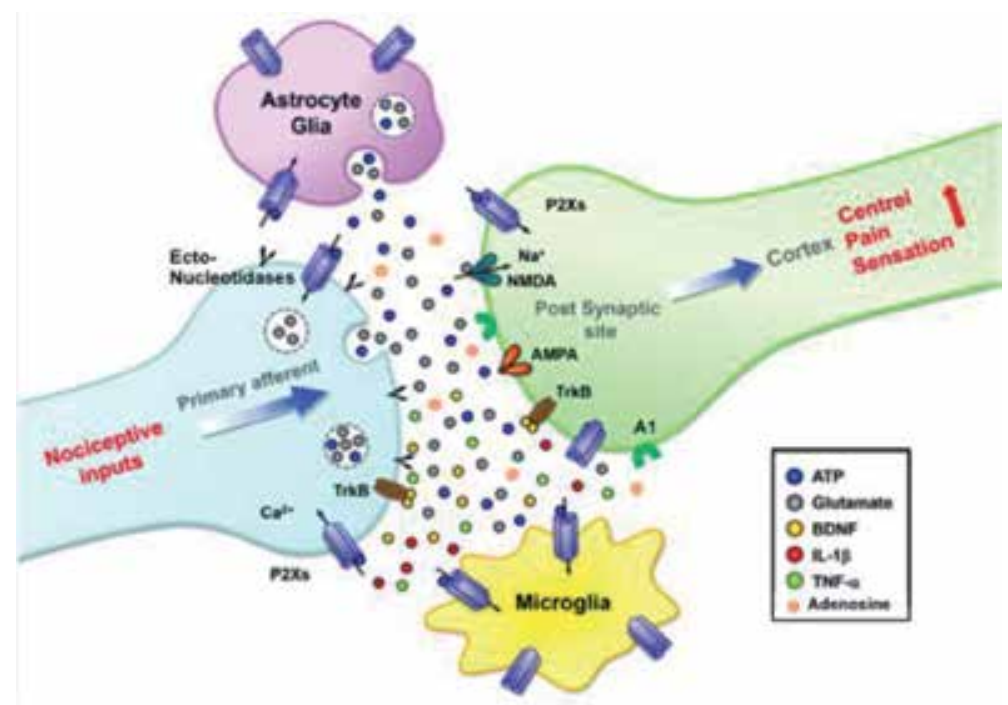

Modified from Kuan and Shyu, Mol Brain. 2016; 9: 58.

Figure 1.

Schematic illustrates purinergic signaling responsible for the pain signal transmission and sensitization at the nociceptive synapses. (1) Primary nociceptive inputs promote glutamate and ATP co-release and synergistically cause non-selective permeability to $\mathrm{Ca}^{2+}, \mathrm{Na}^{+}$, and $\mathrm{K}^{+}$cations via $\mathrm{P}_{2} \mathrm{X}_{3}$ receptor, leading to postsynaptic activation of NMDA or AMPA receptors and further contributing astrocytic glutamate and ATP co-release into the extracellular milieu which result in the pain signal transmission in the nociceptive synapses. (2) Activation of $\mathrm{P}_{2} \mathrm{X}_{4} / 7$ receptors expressed on astrocytes and microglia induces a local inflammatory response with release of cytokines including IL-1 $\beta, B D N F$, and $T N F-\alpha$, which will lead to sensitization in pain signal transduction and conduction as well as synaptic transmission caused by enhanced excitatory and reduced inhibitory driving. (3) Activation of A1 receptor triggers multiple intracellular cAMP/PKA, PLC/IP3/DAG, and nitric oxide/ cGMP/PKG signaling and induces analgesia by reducing both presynaptic vesicle release and postsynaptic excitability. Adenosine may also mediate antinociception by activation of $A 2 A, A 2 B$, or $A 3$ receptors expressed on nociceptive neurons, astrocytes, or immune cells. (4) Ecto-nucleotidases (NTPDase3/CD73) are specifically expressed in primary nociceptive neurons and localized at presynaptic terminals that will drive the shift from $A T P$-induced pain to adenosine-mediated analgesia by control of extracellular ATP extracellular hydrolysis in the nociceptive pathway [99]. 


\section{ATP signaling and dentin hypersensitivity}

\subsection{Dentin hypersensitivity}

Dentin hypersensitivity (DHS) is defined as a short, sharp pain that arises from exposed dentin in response to various environmental stimuli [55-57]. Dentin exposure can be caused by physical, chemical, pathological, biological challenges, and/or developmental abnormalities that result in dental and or periodontal damage or defects. In patients with DHS, gentle touch, mild cold or hot, chemical (acidic or sweet fruits, foods, and drinks) or air-flow stimulation to the exposed dentine can induce similar short, sharp pain. DHS can affect the quality of patient's daily activities such as eating, drinking, speaking, and tooth brushing. In some cases, more severe DHS can become a constant annoyance and induce psychological and emotional distractions $[55,57]$. Even though DHS is a common problem, the underlying nociceptive transduction mechanism still remains elusive, and no universally accepted or highly reliable desensitizing agents or treatment are available in dental practice.

\subsection{Hydrodynamic theory}

It is generally regarded that DHS is associated with dentin exposure, especially the exposure of open dentinal tubules, and dental pulp nerve responsiveness to external environmental stimuli [58]. Several theories have been proposed for the pathogenesis of DHS. The most widely accepted one is the hydrodynamic theory that is introduced by Brannstrom in 1964 [59]. It stated that environmental mechanical, thermal, or chemical changes cause the movements of fluid within dentinal tubules that stimulate the terminals of pulpal nerve fibers located at the dentin tubule inlets, thereby induces transient acute pain. The hydrodynamic theory highlights the notion that several different stimuli can evoke similar responses via dentin tubule fluid movements. The intra-dental myelinated A $\beta$ fibers and some $A \sigma$ fibers that send terminals into the dentin tubules are thought to respond to the fluid movements resulting in the characteristic short, sharp pain of DHS. However, A $\beta$ fibers usually mediate slight touching sensation with a lower threshold to mechanical stimulation, while A $\sigma$ fibers mediate pain, but they exhibit high threshold to noxious stimulation. How the essentially non-noxious dentin tubule fluid movements induce the nociceptive transduction in dental pulpal nerve fibers remains an enigma. Recently, the hydrodynamic theory has been challenged by emerging evidence suggesting that odontoblasts might play an essential role in the nociceptive transduction of DHS [60-62].

\subsection{The machinery for ATP signaling in dental pulp}

Odontoblasts locate at the outermost layer of the dental pulp and send odontoblastic processes to the dentin tubules. Therefore, odontoblasts are the first dental pulp cells to detect external stimuli in dentin exposure. Though a physical synaptic structure is absent, dental pulp nerve fibers are closely approached to the odontoblasts and tightly entangle these cells. This finding could provide a mechanism to explain how signals are transmitted to adjacent nerve endings through chemical mediators released from the odontoblasts. That is, a paracrine cell-cell communication is involved in signal transmission as opposed to classic neural synapses. Since purinergic $\mathrm{P} 2 \mathrm{X} 3$ receptors are expressed in dental pulp nerve fibers [63] and activation of $\mathrm{P} 2 \mathrm{X}$ receptors in peripheral nerve fibers induces pain [9]. ATP has 
been proposed as a promising candidate that participates in cell-cell communication within the dental pulp that would be associated with pain transduction mechanism of DHS [64].

For the past decades, chemo-, mechano-, and or thermo-sensitive channels such as connexin, pannexin, TRPV1-4, TRPM3, KCa, TREK-1, beta-ENa(+) C, and ASIC2 channels have been identified in odontoblasts [60, 65-70]. Activation of these channels depolarizes the membrane potential that induces ATP release via vesicles release or channel opening in odontoblasts. Interestingly, mechanicas well as depolarization-sensitive ATP permeable channel such as connexin 43 and pannexins had been detected in odontoblastic processes inserting into dentinal tubules $[60,64]$. Indeed it has been shown that mechanical and or thermal stimulation that mimics dentin hypersensitivity in clinic induces ATP release from odontoblasts $[65,66,71]$. Besides, mechanical stimulation-induced ATP release and ATP-mediated signal transmission from odontoblasts to trigeminal neurons have been demonstrated in vitro using co-culture models comprising of odontoblasts and trigeminal neurons $[68,72]$. The existence of autocrine/ paracrine mechanisms for ATP-involved purinergic signaling in cultured odontoblast-like stem cells is also confirmed [73]. Furthermore, external mechanical and thermal stimulation that mimics dentin hypersensitivity induces ATP release in a tooth perfusion model, while pharmacological blocking connexin and pannexin channels abolished external stimulation-induced ATP release in dental pulp [66]. Based on the above observations, we proposed that, as illustrated in Figure 2, external stimulation-induced mechanosensitive responses and ATP release from odontoblasts and subsequently activation of purinergic receptors in dental pulpal nerves may represent a novel explanation as to how odontoblasts participate in a mechanosensory mechanism leading to the pain transduction in DHS $[60,74]$.

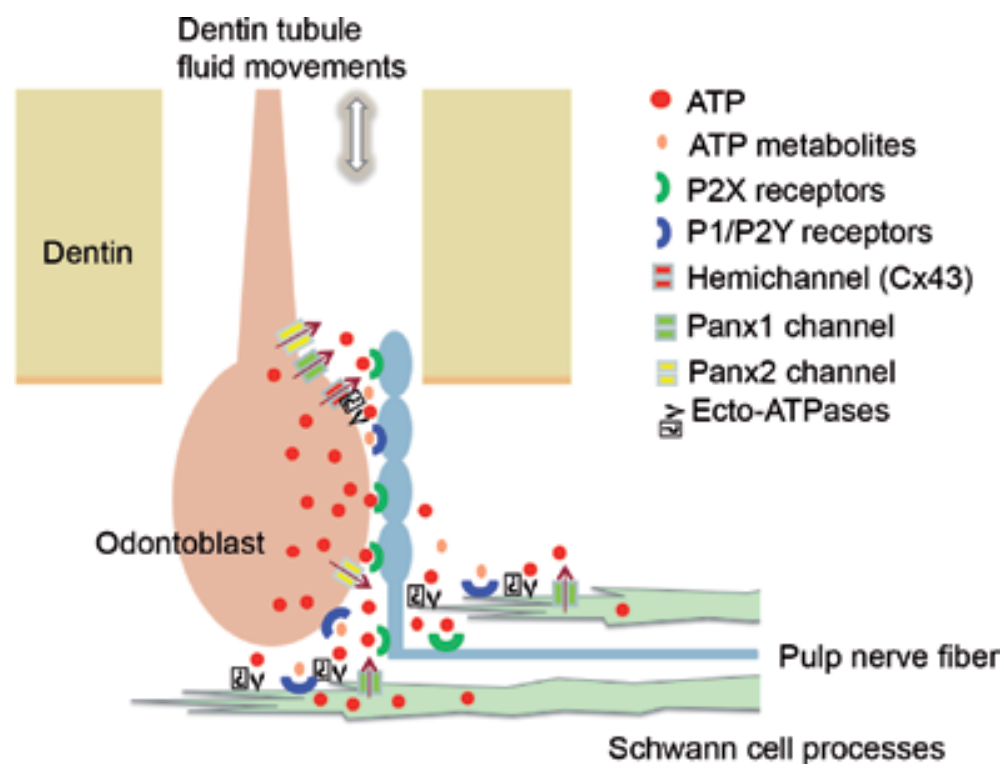

Figure 2.

A novel hypothesis for nociception transduction in DHS. External stimulation-induced dentin tubule fluid movements induces ATP release via pannexin/connexin channels in OBs (odontoblasts), ATP then activate $P_{2} X$ receptors on adjacent nerve fibers to trigger the transduction of pain. ATP signaling is terminated by ectoATPases in OBs and Schwann's cells. 


\subsection{Purinergic signaling and dentin hypersensitivity}

Dentin-odontoblasts-nerve terminal complex represents the essential components for the process of stimulation transducing and nociceptive transduction from environmental changes to pain impulse in DHS. External stimuli promote ATP release from odontoblasts through mechanic or depolarization-sensitive channels, which then initiates pain signaling via activation of $\mathrm{P} 2 \mathrm{X} 3$ receptors in dental pulp nerve fibers. Functional ecto-nucleotidases in odontoblasts, dental pulp nerve fibers, and Schwann cells that surround the nerve fibers modulate pain transmission by control of the local concentration of extracellular ATP and adenosine. ATP and its metabolites may also activate the $\mathrm{P} 2 \mathrm{Y}$ and $\mathrm{P} 1$ receptors via a paracrine mechanism to trigger intracellular $\mathrm{Ca}^{2+}$ signals that further promote ATP release in odontoblasts and regulate the expression of ATP permeable channels, purinergic receptors, and ecto-nucleotidases.

The existence of mechanical-sensitive ATP permeable connexin/pannexin channels and ATP singling in dentin-odontoblast-nerve fiber complex provides a clue to explain the unique characteristic of DHS, that is, the "all" or "none" property. In patients with DHS, a common phenomenon is that external environmental stimulation induces either one sharp pain or no pain at all. A self-activated propagation of ATP signaling and calcium response in gap junction coupled cells as well as in tissues or organs was demonstrated [75]. For example, a local mechanical stimulation induces connexin/pannexin channel opening, and then result in ATP release, ATP then activates the P2X/P2Y receptors in adjacent cells inducing intracellular $\mathrm{Ca}^{2+}$ increase and/or cell depolarization that further promote connexin/pannexin channels opening and ATP release in further beyond adjacent cells until all the cells are activated. Since odontoblasts express connexin 43 and are functionally connected via gap junction as a syncytium $[60,76]$, stimulation from locally exposed dentin tubules will induce a response in the whole dental pulp odontoblasts. With this mechanism, external stimulation will cause the full dental pulp odontoblast activation and evoke the typical "all" or "none" short, sharp pain in patients with DHS.

The existence of ecto-ATPase activity in dental pulp nerve fibers as well as in the odontoblast layer [60] may provide mechanisms to terminate ATP-induced pain in DHS. Studies have shown that NTPDase2 is expressed in odontoblasts as well as in Schwann's cells that encapsulate the dental pulp nerve fibers. While NTPDase3 is expressed in dental pulp nociceptive nerve fibers. The presence of these enzymes in dental pulp provides machinery responsible for ATP degradation that may provide a mechanism to terminate the pain signaling induced by purinergic receptor activation in DHS. While the existence of ecto-AMPase enzymatic activities and expression of CD73 in nociceptive nerve fibers and odontoblasts [64] will hydrolyze AMP to adenosine, the latter will activate the A1 receptors and hyperpolarize the terminals of the dental pulp nerve fibers via opening the potassium channels that will help to stop any lingering of pain impulses in nerve fibers.

\section{Purinergic signaling and dental orofacial pain}

\section{1 $\mathrm{P} 2 \mathrm{X}$ receptors in trigeminal nerves}

Activation of $\mathrm{P} 2 \mathrm{X}$ receptors in peripheral nociceptive nerve fibers results in pain transduction. Interestingly it has been observed that purinergic $\mathrm{P} 2 \mathrm{X}$ receptors are preferentially expressed in trigeminal nociceptive neurons [11,12] suggesting that purinergic signaling might play a unique role in the generation and development of dental orofacial pain. Previous studies have shown expression of $\mathrm{P} 2 \mathrm{X} 3$ receptors 
in dental pulp nerve fibers, including the iB4 positive nociceptive fibers [63]. Furthermore, it had been demonstrated that activation of $\mathrm{P} 2 \mathrm{X} 3$ and $\mathrm{P} 2 \mathrm{X} 2 / 3$ receptors in dental pulp is sufficient to elicit nociceptive behavioral as well as trigeminal brainstem neuronal activity [77]. Functional homomeric P2X3 receptor and heteromeric $\mathrm{P} 2 \mathrm{X}(2 / 3)$ receptor are highly expressed on nociceptive trigeminal neurons, their contribution toward the pain mechanism in dental orofacial pain has been well established [78, 79]. Using real-time reverse transcription-PCR analysis, besides $\mathrm{P} 2 \mathrm{X} 3$, mRNA expression for $\mathrm{P} 2 \mathrm{X} 1$ and $\mathrm{P} 2 \mathrm{X} 4$ was also detected in trigeminal ganglion neurons. Indeed, application of $\mathrm{P} 2 \mathrm{X}$ receptors agonists, ATP, $\alpha, \beta$-methylene ATP, or $\beta, \gamma$-methylene ATP induced neuronal $\mathrm{Ca}^{2+}$ influx and a series of selective antagonists for P2X1, P2X3, or P2X4 receptors inhibited these $\mathrm{Ca}^{2+}$ influx responses. Interestingly, expression of purinergic receptors ( $\mathrm{P} 2 \mathrm{X} 1,3$, and 5$)$ in trigeminal ganglion is upregulated in response to dental pulp inflammation-induced pain suggesting that these receptors may participate in the peripheral pain sensitization [80]. Expression of P2X receptors in trigeminal ganglion is also upregulated by oral facial deep tissue inflammation $[11,12]$. In addition, application of $\mathrm{P} 2 \mathrm{X}$ receptor agonist $\alpha \beta$-meATP to rat tooth pulp induces central sensitization in medullary nociceptive neurons, and this sensitization response can be blocked by dental pulp application of the P2X $(1,2 / 3,3)$ receptor antagonist TNP-ATP as well as by medullary application of TNP-ATP. These results suggest that the activation of peripheral $\mathrm{P} 2 \mathrm{X}$ receptors in orofacial tissues plays a critical role in producing central sensitization in medullary trigeminal subnucleus caudalis (TSNC) nociceptive neurons [81]. Therefore, trigeminal ganglion neurons preferentially express functional $\mathrm{P} 2 \mathrm{X} 1,2 / 3$, 4 receptors, and activation of these receptors attributes to generation and sensitization of dental orofacial pain [78].

Involvement of $\mathrm{P} 2 \mathrm{X}$ receptor activation in dental orofacial pain had been demonstrated in various animal models. In the carrageenan-induced TMJ inflammatory hyperalgesia model, the $\mathrm{P} 2 \mathrm{X} 1,3$, and 2/3 receptor antagonist TNP-ATP, but not the selective $\mathrm{P} 2 \mathrm{X} 7$ receptor antagonist A-438079, significantly reduced the pain behavior. These findings indicate that $\mathrm{P} 2 \mathrm{X} 3$ and $\mathrm{P} 2 \mathrm{X} 2 / 3$ receptors would be potential targets for the development of new analgesics to control TMJ inflammatory pain [82]. Interestingly, it has been found that the number of $\mathrm{P} 2 \mathrm{X} 3$ receptor positive cells is increased in the small cell group in trigeminal ganglia, whereas there was no change in medium or large cell groups after TMJ CFA-injection. Retrograde tracing confirmed that TMJ-innervated neurons in TG exhibited $\mathrm{P} 2 \mathrm{X} 3$ receptors. These observations provided evidence to support that $\mathrm{P} 2 \mathrm{X} 3$ receptor play an essential role in orofacial pain induced by TMJ arthritis [83]. Pharmacological and immunohistochemical studies revealed that the $\mathrm{P} 2 \mathrm{X} 3$ receptor also plays an essential role in the heat hyperalgesia observed in the infraorbital nerve (IoN) ligation-induced neuropathic pain model [84]. In an oral cancer pain model, injection of squamous cell carcinoma cells into the lower gingiva produces mechanical allodynia and thermal hyperalgesia. It has been observed that expression of $\mathrm{P} 2 \mathrm{X}$ receptor, calcitonin gene-related peptide (CGRP)-, substance P (SP)-, and capsaicin receptor (TRPV1)immunoreactive cells are strikingly upregulated in the small cell group of trigeminal ganglia (TGs) after tumor cell inoculation [85].

Whereas there is ample evidence that purinergic $\mathrm{P} 2$ receptors in trigeminal glial cells are altered after peripheral nerve injury, there is very little information about the changes of $\mathrm{P} 2$ receptors in TG satellite glial cells (SGCs), although it is well established that SGCs are endowed with P2 receptors. In submandibular inflammation with the injection of complete Freund's adjuvant, there was a marked increase in the sensitivity of SGCs to ATP, with a threshold decreasing from 5 $\mu \mathrm{M}$ to $10 \mathrm{nM}$. A similar result was observed in the intact trigeminal ganglion after infraorbital nerve axotomy. It had been demonstrated that the increased 
after-inflammation response was mediated predominantly by $\mathrm{P} 2 \mathrm{X}$ receptors. The enhanced responses to ATP after inflammation are primarily due to $\mathrm{P} 2 \mathrm{X} 2$ and or $\mathrm{P} 2 \mathrm{X} 5$ receptors, with a possible contribution of $\mathrm{P} 2 \mathrm{X} 4$ receptors. It has been proposed that the over 100-fold augmented sensitivity of SGCs to ATP may contribute to the development of chronic pain status in dental orofacial pain [86].

\section{2 $\mathrm{P} 2 \mathrm{Y}$ receptors in trigeminal nerves}

Little is known about P2Y receptor expression in trigeminal nerves and their role in dental orofacial pain. It had been demonstrated that UTP, an agonist of P2Y2/ P2Y4 receptors, significantly decreased the mean threshold potentials for evoking action potentials and induced a striking increase in the mean number of spikes in TG neurons [87]. Because of its vital role in the control of neuronal spike onset, fast inactivating transient $\mathrm{K}^{+}$channels (IA) is a key regulator of membrane excitability in sensory neurons. It has been shown that UTP significantly inhibited IA and the expression of Kv1.4, Kv3.4, and Kv4.2 subunits in TG neurons. The P2Y receptor antagonist suramin could reverse these effects. Furthermore, in ION-CCI (chronic constriction injury of the infraorbital nerve) induced neuropathic pain model, when blocking P2Y2 receptors with suramin or injection of P2Y2 receptor antisense oligodeoxynucleotides led to a long time- and dose-dependent reverse of allodynia [87]. Blocking P2Y2 receptors is accompanied with a significant increase in Kv1.4, Kv3.4, and Kv4.2 subunit expression and decrease in phosphorylated ERK expression in trigeminal ganglia. These data suggest activation of P2Y2 receptors leads to upregulation of ERK-mediated phosphorylation and decline of the expression of I(A)-related $\mathrm{Kv}$ channels in trigeminal ganglion neurons, which might reveal potential alternative targets for the treatment of trigeminal neuropathic pain [87].

Other type of $\mathrm{P} 2 \mathrm{Y}$ receptors are also involved in the development of dental orofacial pain. Administration of the P2Y1, 12, and 13 receptor agonist, 2-(methylthio) adenosine 5 '-diphosphate trisodium salt hydrate (2-MeSADP), in naïve rats induced neuropathic pain in the tongue, as demonstrated in lingual nerve crush rats, while co-administration of P2Y receptor antagonists (MRS2395) to naïve MRS2395 rats did not result in hypersensitivity of the tongue. P2Y12 receptor had been detected in satellite cells of the trigeminal ganglia. In an orofacial pain model after lingual nerve crush, expression of $\mathrm{P} 2 \mathrm{Y} 12$ receptors was enhanced in $\mathrm{pERK} 1 / 2$-immunoreactive cells encircling trigeminal ganglion neurons. Administration of a selective P2Y12 receptor antagonist, MRS2395, attenuated tongue hypersensitivity to mechanical and heat stimulation and suppressed the increase in the relative numbers of calcitonin gene-related peptide (CGRP)-immunoreactive neurons and neurons encircled by pERK1/2-immunoreactive cells. These results suggest that intercellular communication between activated satellite cells and CGRP-immunoreactive neurons via P2Y12 receptors contributes to the development of orofacial neuropathic pain [88].

\subsection{Purinergic signaling in trigeminal subnucleus caudalis (TSNC)}

Besides purinergic receptors expressed in the central afferent terminals of primary trigeminal nociceptive neurons, multiple $\mathrm{P} 2 \mathrm{X}, \mathrm{P} 2 \mathrm{Y}$, and $\mathrm{P} 1$ receptors are also detected in the secondary nociceptive neurons, astrocytes, and microglia in TSNC. Since pain signal synaptic transmission is accompanied by a large amount of ATP release in TSNC. Activation of purinergic receptors expressed in presynaptic afferent terminals, secondary nociceptive neurons, astrocytes, and microglia in TSNC would play an essential role for the development of central sensitization [77]. Studies have shown that extracellular ATP acting on presynaptic purinergic receptors ( $\mathrm{P} 2 \mathrm{X} 2 / 3$ and $\mathrm{P} 2 \mathrm{X} 3$ subunits) participate in central sensitization of dental orofacial 
pain. Application of inflammatory irritant mustard oil (MO) to the tooth pulp produced a long-lasting allodynia and hyperalgesia. Intrathecal administration of the selective $\mathrm{P} 2 \mathrm{X} 1, \mathrm{P} 2 \mathrm{X} 3$, and $\mathrm{P} 2 \mathrm{X} 2 / 3$ receptor antagonist, TNP-ATP, significantly and reversibly attenuated the $\mathrm{MO}$-induced central sensitization. While the administration of the selective $\mathrm{P} 2 \mathrm{X} 1, \mathrm{P} 2 \mathrm{X} 3$, and $\mathrm{P} 2 \mathrm{X} 2 / 3$ receptor agonist, alpha, beta-methylene ATP (alpha, beta-meATP, i.t.) produced abrupt and significant neuroplastic changes in TSNC nociceptive neurons, followed by neuronal sensitization as evidenced by the ineffectiveness of a second application of alpha, beta-meATP and subsequent $\mathrm{MO}$ application to the pulp. These results suggest that $\mathrm{P} 2 \mathrm{X} 3$ and possibly also the $\mathrm{P} 2 \mathrm{X} 2 / 3$ receptor subtypes in TSNC play a crucial role for the initiation and maintenance of central sensitization in brainstem nociceptive neurons [89]. Tooth pulp application of mustard oil (MO) induced a significant increase in glutamate release in TSNC. Intrathecal administration of apyrase or TNP-ATP (a P2X1, P2X3, P2X2/3 receptor antagonist) alone significantly reduced the $\mathrm{MO}$-induced glutamate release in the TSNC. Furthermore, the suppressive effects of apyrase on glutamate release were reduced by DPCPX (an adenosine A1 receptor antagonist) [89].

It had been reported that $\mathrm{P} 2 \mathrm{X} 3$ receptor expressed in astrocytes in the TSNC participates in the development of craniofacial neuropathic pain induced by chronic constriction of the infraorbital nerve (CCI-ION) [90]. The number of P2X3-positive fine astrocytic processes and the density of $\mathrm{P} 2 \mathrm{X} 3$ receptors in these processes was increased significantly in CCI-ION model and administration of MPEP, a specific mGluR5 antagonist, alleviated the mechanical allodynia and abolished the increase of $\mathrm{P} 2 \mathrm{X} 3$ receptor expression in the fine astrocytic processes. Specific glial cell populations become activated in both trigeminal ganglia and brainstem in CFA-injection induced temporomandibular joint (TMJ) inflammation pain model. CFA-injected animals exhibited ipsilateral mechanical allodynia that is accompanied by a substantial increase of GFAP-positive satellite glial cells and activation of resident macrophages in the trigeminal ganglia. The activated microglial cells were also observed in the ipsilateral TSNC [91]. In dental pulp, MO injection induced central sensitization model, it has been demonstrated that continuous intrathecal (i.t.) superfusion of the potent P2X7 receptor antagonists brilliant blue G or periodate-oxidized ATP could significantly attenuate the central sensitization. Specifically, central sensitization could be induced by superfusion of ATP and even more effectively produced by the P2X7 receptor agonist benzoylbenzoyl ATP. Consistent with the report that P2X7 receptors are mostly expressed on microglia, superfusion of the microglial blocker minocycline abolished the MO-induced central sensitization. These novel findings suggest that activation of $\mathrm{P} 2 \mathrm{X} 7$ receptors in microglia cells may be involved in the development of central sensitization in acute dental orofacial pain [92].

Microglial P2Y12 receptor is also reported to be involved in the central sensitization of orofacial pain [93]. In a tongue cancer, pain model produced by squamous cell carcinoma (SCC) cell inoculation, microglia were strongly activated in TSNC, and administration of MRS2395 or minocycline reversed the associated nociceptive behavior and microglial activation in SCC-inoculated rats. The increased activity of TSNC wide dynamic range nociceptive neurons was also recorded in SCC-inoculated rats. These findings suggest that SCC inoculation results in strong activation of microglia via $\mathrm{P} 2 \mathrm{Y} 12$ receptor signaling in the TSNC that is associated with the increased excitability of TSNC nociceptive neurons and the development of central sensitization.

\subsection{Adenosine signaling and dental orofacial pain}

Purinergic P1 receptor signaling may also exist in trigeminal nerves and affects nociception processing. In 12 healthy female volunteers randomized, double-blind, 
placebo-controlled, cross-over trial, the effect of A1 receptor agonist GR79236 on trigeminal nociception processing was investigated. Activation of A1 receptor with GR79236 inhibits trigeminal nociception in humans [94]. In a model of trigeminovascular nociceptive transmission, the superior sagittal sinus (SSS) was stimulated electrically, and the responding nociceptive units were recorded. It has been shown that intravenous administration of the highly selective adenosine A1 receptor agonist, GR79236 had a dose-dependent inhibitory effect on SSS-evoked trigeminal nociceptive activity. Selective adenosine A1 receptor antagonist DPCPX abolished the neuronal inhibitory effect of GR79236 [95]. In another animal experiment, adenosine decreased the amplitude of glutamatergic excitatory postsynaptic currents and increased the unpaired-pulse ratio suggesting that adenosine acts presynaptically to reduce glutamate release from primary afferents. Besides, the adenosine-induced inhibition of excitatory postsynaptic currents was impaired by a selective A1 receptor antagonist, DPCPX, and was mimicked by a selective A1 receptor agonist CPA. These findings suggest that presynaptic A1 receptors decrease action potential-dependent glutamate release from primary trigeminal afferents onto TSNC neurons, and thus adenosine A1 receptors could be a potential target for the treatment of pain of orofacial tissues [96].

\subsection{Ecto-nucleotidases in trigeminal nerves and orofacial pain}

By the control of ATP degradation and adenosine generation, ecto-nucleotidases drive the shift from ATP-induced nociception to adenosine-induced analgesia [97]. Since ATP induces pain and pain sensitization via activation of P2X receptors and adenosine mediates analgesia via activation of $\mathrm{P} 1$ receptors, existence of ecto-nucleotidases and their enzymatic activities in the trigeminal nociceptive pathway will affect the development and maintenance of dental orofacial pain. Recently we have demonstrated the expression and central terminal localization of ecto-nucleotidases (NTPDase3/CD73) in the trigeminal ganglia nociceptive neurons $[64,98]$. Considering the pivotal role of purinergic singling in the pathogenesis of neuropathic pain and the preference expression and upregulation of purinergic receptors in the trigeminal nervous system, ecto-nucleotidase expression, and localization in trigeminal nerves might participate in the development of orofacial neuropathic pain.

Using histochemistry staining, ecto-ATPase and AMPase activities were detected in dental pulp odontoblast layer, Raschkow's nerve plexus, and nerve bundles. Interestingly, in inflammatory dental pulp with pulpitis, enzymatic ecto-ATPase activity was significantly upregulated. Specifically, using immunohistochemistry and immunofluorescence staining, NTPDase2 is expressed in Shwann's cells that encapsulate the $A \beta$ and A $\sigma$ fibers, while that NTPDase 3 and CD73 are detected in nociceptive nerve fibers in dental pulp $[60,64,98]$.

Trigeminal ganglia contain both primary sensory neurons and satellite glial cells. Satellite glial cells encapsulate the ganglia neurons and are gap junction channel connected. Via intercellular interaction satellite glia cells affect neuronal excitability and impulse conduction in TG neurons. The ecto-ATPase activity was detected in TG cells. Specifically, NTPDase3 is expressed in TG neurons, including the nociceptive neurons, while NTPDase 2 is expressed in TG satellite glial cells that encapsulated the TG neurons $[60,64,98]$. In addition, ecto-AMPases activity is also detected in TG cells and TG nerve fibers. It reveals that CD73 is expressed in TG neurons, including the nociceptive neurons [64]. By control of extracellular ATP degradation and adenosine generation, these enzymes would play a crucial role in orofacial pain signal processing by affecting the excitability, inhibition, and interaction of TG neurons. 
TG nociceptive neurons project central nerve fibers to the brainstem and form synapses with the secondary nociceptive neurons in the nociceptive lamina of the TSNC. It has been well established that the nociceptive lamina in the brainstem or spinal cord is a pivotal region for pain signaling transmission, inhibition, modulation, and sensitization. Interestingly, striking ecto-ATPase and ecto-AMPase activities were detected in brainstem TSNC nociceptive lamina. Immunohistochemistry studies confirmed the existence of immunoreactivity for NTPDase 3 and CD73 in the nociceptive lamina. Furthermore, it has been demonstrated that incubation with specific anti-NTPDase 3 or anti-CD73 antibodies, significantly reduced ecto-ATPase and acto-AMPase activities in TNSC nociceptive lamina, respectively $[64,98]$. These findings suggest that NTPDase 3 and CD73 are the major enzymes responsible for ATP degradation and adenosine generation in TSNC nociceptive lamina. Since the neuronal plasticity and central sensitization mainly occurs at the central nociceptive lamina in neuropathic pain, the presence of NTPDase 3 and CD73 in TNSC nociceptive lamina may also participate in the central sensitization mechanism in orofacial neuropathic pain.

The characteristic staining patterns for NTPDase3 and CD73 in the nociceptive lamia of TSNC indicate the presynaptic localization of these enzymes [64, 98]. This observation suggests that NTPDase 3 and CD73 are produced at TG nociceptive neurons and then are transferred to the central presynaptic membranes along the afferent trigeminal nerves. Disruption of ecto-nucleotidase expression and presynaptic localization caused by biological, chemical, or physical trigeminal insults such as virus infection, nerve fiber differentiation, and physical constriction//compression may attribute to pathogenesis mechanism in trigeminal neuralgia and other orofacial neuropathic pain $[64,98]$.

\section{Conclusion}

Purinergic signaling plays essential role in pain signal processing in the nociceptive pathway from peripheral to central nerves. Via activation of P2X, P2Y, and P1 receptors, ATP and its metabolites induced purinergic signaling participates in the nociceptive transduction, conduction, transmission, modulation, sensitization, and development of neuropathic pain. Ecto-nucleotidases are the predominant enzymes responsible for extracellular ATP degradation and adenosine generation that play essential role to drive the shift from ATP-induced pain to adenosine-induced analgesia. In order to identify the role of purinergic signaling in dental orofacial pain, the existence of purinergic signaling and their regulation in the trigeminal nociceptive pathway has yet to be identified.

Several ion channels and receptors that are prominent in craniofacial nociceptive mechanisms have been identified on trigeminal primary afferent neurons. Many of these receptors and channels exhibit unusual distributions compared with extracranial regions. For example, expression of the ATP receptor P2X3 is strongly implicated in nociception and is more abundant on trigeminal primary afferent neurons than analogous extracranial neurons. P2X3 receptors are often co-expressed with the nociceptive neuropeptides CGRP and SP in trigeminal ganglia neurons. Co-expression of $\mathrm{P} 2 \mathrm{X} 3$ receptor and other nociceptors (TRPV1, and ASIC3) in trigeminal neurons imply the existence of functional complexes that allow craniofacial nociceptive neurons to respond synergistically to altered ATP and other pain mediators. These observations indicate that trigeminal P2X3 receptor expression pattern differs markedly from dorsal root ganglion that may provide a clue to explain the unique properties of dental orofacial pain. Different expression and or regulation of purinergic signaling in the trigeminal nociceptive pathway may 
attribute to a nociceptive mechanism of dentin hypersensitivity and dental orofacial pain. Identification of the underlying nociceptive mechanism will unveil potential targets for better treatment and management of dental orofacial pain.

\section{Author details}

Xiuxin $\mathrm{Liu}^{1,2}$

1 Department of Pharmacology and Physiology, Eastman Institute for Oral Health, University of Rochester School of Medicine and Dentistry, Rochester, New York, USA

2 Department of Dentistry, Atlanta VA Medical Center, Decatur, Georgia, USA

*Address all correspondence to: xiuxin_liu@urmc.rochester.edu; xiuxin.liu@va.gov

\section{IntechOpen}

(C) 2019 The Author(s). Licensee IntechOpen. This chapter is distributed under the terms of the Creative Commons Attribution License (http://creativecommons.org/licenses/ by/3.0), which permits unrestricted use, distribution, and reproduction in any medium, provided the original work is properly cited. (cc) BY 


\section{References}

[1] West SJ, Bannister K, Dickenson AH, Bennett DL. Circuitry and plasticity of the dorsal horn-Toward a better understanding of neuropathic pain. Neuroscience. 2015;300:254-275

[2] Falace DA, Reid K, Rayens MK. The influence of deep (odontogenic) pain intensity, quality, and duration on the incidence and characteristics of referred orofacial pain. Journal of Orofacial Pain. 1996;10(3):232-239

[3] Inoue K. Purinergic signaling in microglia in the pathogenesis of neuropathic pain. Proceedings of the Japan Academy. Series B, Physical and Biological Sciences. 2017;93(4):174-182

[4] Han JS, Adwanikar H, Li Z, Ji G, Neugebauer V. Facilitation of synaptic transmission and pain responses by CGRP in the amygdala of normal rats. Molecular Pain. 2010;6:10

[5] Burnstock G. Purinergic receptors and pain. Current Pharmaceutical Design. 2009;15(15):1717-1735

[6] Kuner R. Central mechanisms of pathological pain. Nature Medicine. 2010;16(11):1258-1266

[7] Bele T, Fabbretti E. P2X receptors, sensory neurons and pain. Current Medicinal Chemistry. 2015;22(7):845-850

[8] Hamilton SG. ATP and pain. Pain Practice: The Official Journal of World Institute of Pain. 2002;2(4):289-294

[9] Hamilton SG, McMahon SB. ATP as a peripheral mediator of pain. Journal of the Autonomic Nervous System. 2000;81(1-3):187-194

[10] Kukulski F, Levesque SA, Sevigny J. Impact of ectoenzymes on $\mathrm{p} 2$ and p1 receptor signaling. Advances in Pharmacology. 2011;61:263-299
[11] Ambalavanar R, Dessem D.

Emerging peripheral receptor targets for deep-tissue craniofacial pain therapies. Journal of Dental Research. 2009;88(3):201-211

[12] Ambalavanar R, Moritani M, Dessem D. Trigeminal P2X3 receptor expression differs from dorsal root ganglion and is modulated by deep tissue inflammation. Pain. 2005;117(3):280-291

[13] Burnstock G. Historical review: ATP as a neurotransmitter. Trends in Pharmacological Sciences. 2006;27(3):166-176

[14] Burnstock G, Wood JN. Purinergic receptors: their role in nociception and primary afferent neurotransmission. Current Opinion in Neurobiology. 1996;6(4):526-532

[15] Kobayashi K, Yamanaka H, Noguchi K. Expression of ATP receptors in the rat dorsal root ganglion and spinal cord. Anatomical Science International. 2013;88(1):10-16

[16] Kobayashi K et al. Differential expression patterns of mRNAs for $\mathrm{P} 2 \mathrm{X}$ receptor subunits in neurochemically characterized dorsal root ganglion neurons in the rat. The Journal of Comparative Neurology. 2005;481(4):377-390

[17] Vulchanova L et al.

Immunohistochemical study of the $\mathrm{P} 2 \mathrm{X} 2$ and $\mathrm{P} 2 \mathrm{X} 3$ receptor subunits in rat and monkey sensory neurons and their central terminals. Neuropharmacology. 1997;36(9):1229-1242

[18] Chen CC et al. A P2X purinoceptor expressed by a subset of sensory neurons. Nature. 1995;377(6548):428-431

[19] Bradbury EJ, Burnstock G, McMahon SB. The expression of P2X3 
purinoreceptors in sensory neurons: effects of axotomy and glial-derived neurotrophic factor. Molecular and Cellular Neurosciences. 1998;12(4-5):256-268

[20] Wirkner K, Sperlagh B, Illes P. $\mathrm{P} 2 \mathrm{X} 3$ receptor involvement in pain states. Molecular Neurobiology. 2007;36(2):165-183

[21] Woolf CJ. Central sensitization: implications for the diagnosis and treatment of pain. Pain. 2011;152 (3 Suppl):S2-S15

[22] Opree A, Kress M. Involvement of the proinflammatory cytokines tumor necrosis factor-alpha, IL-1 beta, and IL- 6 but not IL- 8 in the development of heat hyperalgesia: effects on heatevoked calcitonin gene-related peptide release from rat skin. The Journal of Neuroscience: The Official Journal of the Society for Neuroscience. 2000;20(16):6289-6293

[23] Novakovic SD et al. Immunocytochemical localization of $\mathrm{P} 2 \mathrm{X} 3$ purinoceptors in sensory neurons in naive rats and following neuropathic injury. Pain. 1999;80(1-2):273-282

[24] Fabbretti E. ATP P2X3 receptors and neuronal sensitization. Frontiers in Cellular Neuroscience. 2013;7:236

[25] Inoue K, Koizumi S, Tsuda M, Shigemoto-Mogami Y. Signaling of ATP receptors in glia-neuron interaction and pain. Life Sciences. 2003;74(2-3):189-197

[26] Tsuda M et al. P2X4 receptors induced in spinal microglia gate tactile allodynia after nerve injury. Nature. 2003;424(6950):778-783

[27] Coull JA et al. BDNF from microglia causes the shift in neuronal anion gradient underlying neuropathic pain. Nature. 2005;438(7070):1017-1021
[28] Coull JA et al. Trans-synaptic shift in anion gradient in spinal lamina I neurons as a mechanism of neuropathic pain. Nature. 2003;424(6951):938-942

[29] Keller AF, Beggs S, Salter MW, De Koninck Y. Transformation of the output of spinal lamina I neurons after nerve injury and microglia stimulation underlying neuropathic pain. Molecular Pain. 2007;3:27

[30] Kobayashi K et al. P2Y12 receptor upregulation in activated microglia is a gateway of $\mathrm{p} 38$ signaling and neuropathic pain. The Journal of neuroscience : the official journal of the Society for Neuroscience. 2008;28(11):2892-2902

[31] Tozaki-Saitoh H et al. P2Y12 receptors in spinal microglia are required for neuropathic pain after peripheral nerve injury. The Journal of Neuroscience: The Official Journal of the Society for Neuroscience. 2008;28(19):4949-4956

[32] Sawynok J. Adenosine receptor targets for pain. Neuroscience. 2015

[33] Lima FO et al. Direct blockade of inflammatory hypernociception by peripheral A1 adenosine receptors: involvement of the NO/cGMP/ PKG/KATP signaling pathway. Pain. 2010;151(2):506-515

[34] Maes SS, Pype S, Hoffmann VL, Biermans M, Meert TF. Antihyperalgesic activity of nucleoside transport inhibitors in models of inflammatory pain in guinea pigs. Journal of Pain Research. 2012;5:391-400

[35] Goldman N et al. Adenosine A1 receptors mediate local anti-nociceptive effects of acupuncture. Nature Neuroscience. 2010;13(7):883-888

[36] Patel MK, Pinnock RD, Lee K. Adenosine exerts multiple 
effects in dorsal horn neurones of the adult rat spinal cord. Brain Research. 2001;920(1-2):19-26

[37] Chen JF, Lee CF, Chern Y. Adenosine receptor neurobiology: overview. International Review of Neurobiology. 2014;119:1-49

[38] Li X, Eisenach JC. Adenosine reduces glutamate release in rat spinal synaptosomes. Anesthesiology. 2005;103(5):1060-1065

[39] Santicioli P, Del Bianco E, Tramontana M, Maggi CA. Adenosine inhibits action potential-dependent release of calcitonin generelated peptide- and substance P-like immunoreactivities from primary afferents in rat spinal cord. Neuroscience Letters. 1992;144(1-2):211-214

[40] Feoktistov I, Biaggioni I. Role of adenosine A(2B) receptors in inflammation. Advances in Pharmacology. 2011;61:115-144

[41] Borea PA et al. The A3 adenosine receptor: history and perspectives. Pharmacological Reviews. 2015;67(1):74-102

[42] Ji RR, Berta T, Nedergaard M. Glia and pain: is chronic pain a gliopathy? Pain. 2013;154(Suppl 1):S10-S28

[43] Paterniti I et al. Selective adenosine A2A receptor agonists and antagonists protect against spinal cord injury through peripheral and central effects. Journal of Neuroinflammation. 2011;8:31

[44] Ford A et al. Engagement of the GABA to KCC2 signaling pathway contributes to the analgesic effects of A3AR agonists in neuropathic pain. The Journal of Neuroscience: The Official Journal of the Society for Neuroscience. 2015;35(15):6057-6067
[45] Robson SC, Sevigny J,

Zimmermann H. The E-NTPDase family of ectonucleotidases: Structure function relationships and pathophysiological significance. Purinergic Signalling. 2006;2(2):409-430

[46] Belcher SM et al. Immunolocalization of ecto-nucleoside triphosphate diphosphohydrolase 3 in rat brain: implications for modulation of multiple homeostatic systems including feeding and sleep-wake behaviors.

Neuroscience. 2006;137(4):1331-1346

[47] Zimmermann H, Braun N.

Extracellular metabolism of nucleotides in the nervous system. Journal of Autonomic Pharmacology. 1996;16(6):397-400

[48] Street SE et al. PAP and NT5E inhibit nociceptive neurotransmission by rapidly hydrolyzing nucleotides to adenosine. Molecular Pain. 2011;7:80

[49] McCoy E et al. Deletion of ENTPD3 does not impair nucleotide hydrolysis in primary somatosensory neurons or spinal cord. F1000Research. 2014;3:163

[50] Vongtau HO, Lavoie EG, Sevigny J, Molliver DC. Distribution of ecto-nucleotidases in mouse sensory circuits suggests roles for nucleoside triphosphate diphosphohydrolase- 3 in nociception and mechanoreception. Neuroscience. 2011;193:387-398

[51] Schmidt AP et al. Anti-nociceptive properties of the xanthine oxidase inhibitor allopurinol in mice: role of A1 adenosine receptors. British Journal of Pharmacology. 2009;156(1):163-172

[52] Sowa NA, Taylor-Blake B, Zylka MJ. Ecto-5'-nucleotidase (CD73) inhibits nociception by hydrolyzing AMP to adenosine in nociceptive circuits. The Journal of Neuroscience: The Official Journal of the Society for Neuroscience. 2010;30(6):2235-2244 
[53] Sowa NA, Street SE, Vihko P, Zylka MJ. Prostatic acid phosphatase reduces thermal sensitivity and chronic pain sensitization by depleting phosphatidylinositol 4,5-bisphosphate. The Journal of Neuroscience: The Official Journal of the Society for Neuroscience. 2010;30(31):10282-10293

[54] Zylka MJ. Pain-relieving prospects for adenosine receptors and ectonucleotidases. Trends in Molecular Medicine. 2011;17(4):188-196

[55] Goh V, Corbet EF, Leung WK. Impact of dentine hypersensitivity on oral health-related quality of life in individuals receiving supportive periodontal care. Journal of Clinical Periodontology. 2016;43(7):595-602

[56] Kopycka-Kedzierawski DT et al. Management of dentin hypersensitivity by practitioners in The National Dental Practice-Based Research Network. Journal of the American Dental Association. 2017;148(10):728-736

[57] Lima TC et al. Oral health-related quality of life before and after treatment of dentin hypersensitivity with cyanoacrylate and laser. Journal of Periodontology. 2017;88(2):166-172

[58] Absi EG, Addy M, Adams D.

Dentine hypersensitivity. A study of the patency of dentinal tubules in sensitive and non-sensitive cervical dentine. Journal of Clinical Periodontology. 1987;14(5):280-284

[59] Brannstrom M. A hydrodynamic mechanism in the transmission of pain producing stimuli through the dentine. In: Sensory mechanisms in dentine. Anderson DJ, editor. Oxford: Pergamon Press; 1963;73-79

[60] Liu X et al. Expression of ectoATPase NTPDase2 in human dental pulp. Journal of Dental Research. 2012;91(3):261-267
[61] Magloire H et al. Topical review. Dental pain and odontoblasts: facts and hypotheses. Journal of Orofacial Pain. 2010;24(4):335-349

[62] Sole-Magdalena A et al. Molecular basis of dental sensitivity: The odontoblasts are multisensory cells and express multifunctional ion channels. Annals of Anatomy. 2018;215:20-29

[63] Alavi AM, Dubyak GR, Burnstock G. Immunohistochemical evidence for ATP receptors in human dental pulp. Journal of Dental Research. 2001;80(2):476-483

[64] Liu X, Ma L, Zhang S, Ren Y, Dirksen RT. CD73 controls extracellular adenosine generation in the trigeminal nociceptive nerves. Journal of Dental Research. 2017;96(4):671-677. DOI: $10.1177 / 0022034517697653$

[65] Egbuniwe O et al. TRPA1 and TRPV4 activation in human odontoblasts stimulates ATP release. Journal of Dental Research. 2014;93(9):911-917

[66] Liu X et al. External dentin stimulation induces ATP release in human teeth. Journal of Dental Research. 2015;94(9):1259-1266

[67] Okumura R et al. The odontoblast as a sensory receptor cell? The expression of TRPV1 (VR-1) channels. Archives of Histology and Cytology. 2005;68(4):251-257

[68] Shibukawa Y et al. Odontoblasts as sensory receptors: transient receptor potential channels, pannexin-1, and ionotropic ATP receptors mediate intercellular odontoblast-neuron signal transduction. Pflügers Archiv/ European Journal of Physiology. 2015;467(4):843-863

[69] Sole-Magdalena A et al. Human odontoblasts express transient 
receptor protein and acid-sensing ion channel mechanosensor proteins. Microscopy Research and Technique. 2011;74(5):457-463

[70] Son AR et al. Odontoblast TRP channels and thermo/mechanical transmission. Journal of Dental Research. 2009;88(11):1014-1019

[71] El Karim IA et al. Human odontoblasts express functional thermo-sensitive TRP channels: implications for dentin sensitivity. Pain. 2011;152(10):2211-2223

[72] Nishiyama A et al. Intercellular signal communication among odontoblasts and trigeminal ganglion neurons via glutamate. Cell Calcium. 2016;60(5):341-355

[73] Zhang S et al. Purinergic signaling modulates survival/proliferation of human dental pulp stem cells. Journal of Dental Research. 2018;98(2):242-249

[74] West NX, Lussi A, Seong J, Hellwig E. Dentin hypersensitivity: pain mechanisms and aetiology of exposed cervical dentin. Clinical Oral Investigations. 2013;17(Suppl 1):S9-S19

[75] Jorgensen NR, Geist ST, Civitelli R, Steinberg TH. ATP- and gap junction-dependent intercellular calcium signaling in osteoblastic cells. The Journal of Cell Biology. 1997;139(2):497-506

[76] Ikeda H, Suda H. Rapid penetration of lucifer yellow into vital teeth and dye coupling between odontoblasts and neighbouring pulp cells in the cat. Archives of Oral Biology. 2006;51(2):123-128

[77] Adachi K et al. Purinergic receptors are involved in tooth-pulp evoked nocifensive behavior and brainstem neuronal activity. Molecular Pain. 2010;6:59
[78] Kuroda $\mathrm{H}$ et al. Expression of $\mathrm{P} 2 \mathrm{X}(1)$ and $\mathrm{P} 2 \mathrm{X}(4)$ receptors in rat trigeminal ganglion neurons. Neuroreport. 2012;23(13):752-756

[79] Staikopoulos V, Sessle BJ, Furness JB, Jennings EA. Localization of $\mathrm{P} 2 \mathrm{X} 2$ and $\mathrm{P} 2 \mathrm{X} 3$ receptors in rat trigeminal ganglion neurons. Neuroscience. 2007;144(1):208-216

[80] Chen Y, Zhang L, Yang J, Zhang L, Chen Z. LPS-induced dental pulp inflammation increases expression of ionotropic purinergic receptors in rat trigeminal ganglion. Neuroreport. 2014;25(13):991-997

[81] Cherkas PS, Dostrovsky JO, Sessle BJ. Activation of peripheral P2X receptors is sufficient to induce central sensitization in rat medullary dorsal horn nociceptive neurons. Neuroscience Letters. 2012;526(2):160-163

[82] Teixeira JM et al. Involvement of temporomandibular joint $\mathrm{P} 2 \mathrm{X} 3$ and $\mathrm{P} 2 \mathrm{X} 2 / 3$ receptors in carrageenaninduced inflammatory hyperalgesia in rats. European Journal of Pharmacology. 2010;645(1-3):79-85

[83] Shinoda M, Ozaki N, Asai H, Nagamine K, Sugiura Y. Changes in $\mathrm{P} 2 \mathrm{X} 3$ receptor expression in the trigeminal ganglion following monoarthritis of the temporomandibular joint in rats. Pain. 2005;116(1-2):42-51

[84] Shinoda M et al. P2X3 receptor mediates heat hyperalgesia in a rat model of trigeminal neuropathic pain. The Journal of Pain: Official Journal of the American Pain Society. 2007;8(7):588-597

[85] Nagamine K et al. Mechanical allodynia and thermal hyperalgesia induced by experimental squamous cell carcinoma of the lower gingiva in rats. The Journal of Pain: Official 
Journal of the American Pain Society. 2006;7(9):659-670

[86] Kushnir R, Cherkas PS, Hanani M. Peripheral inflammation upregulates $\mathrm{P} 2 \mathrm{X}$ receptor expression in satellite glial cells of mouse trigeminal ganglia: a calcium imaging study. Neuropharmacology. 2011;61(4):739-746

[87] Li N et al. Inhibition of $\mathrm{G}$ proteincoupled $\mathrm{P} 2 \mathrm{Y} 2$ receptor induced analgesia in a rat model of trigeminal neuropathic pain. Molecular Pain. 2014;10:21

[88] Sugawara S et al. Interaction between calcitonin gene-related peptide-immunoreactive neurons and satellite cells via P2Y12 R in the trigeminal ganglion is involved in neuropathic tongue pain in rats. European Journal of Oral Sciences. 2017;125(6):444-452

[89] Kumar $\mathrm{N}$ et al. Involvement of ATP in noxious stimulus-evoked release of glutamate in rat medullary dorsal horn: a microdialysis study. Neurochemistry International. 2012;61(8):1276-1279

[90] Mah W et al. A role for the purinergic receptor $\mathrm{P} 2 \mathrm{X} 3$ in astrocytes in the mechanism of craniofacial neuropathic pain. Scientific Reports. 2017;7(1):13627

[91] Villa G et al. Temporomandibular joint inflammation activates glial and immune cells in both the trigeminal ganglia and in the spinal trigeminal nucleus. Molecular Pain. 2010;6:89

[92] Itoh K et al. Central sensitization of nociceptive neurons in rat medullary dorsal horn involves purinergic P2X7 receptors. Neuroscience. 2011;192:721-731

[93] Tamagawa $\mathrm{T}$ et al. Involvement of microglial P2Y12 signaling in tongue cancer pain. Journal of Dental Research. 2016;95(10):1176-1182
[94] Giffin NJ et al. Effect of the adenosine $\mathrm{A} 1$ receptor agonist GR79236 on trigeminal nociception with blink reflex recordings in healthy human subjects. Cephalalgia: An International Journal of Headache. 2003;23(4):287-292

[95] Goadsby PJ, Hoskin KL, Storer RJ, Edvinsson L, Connor HE. Adenosine A1 receptor agonists inhibit trigeminovascular nociceptive transmission. Brain: A Journal of Neurology. 2002;125(Pt 6):1392-1401

[96] Choi IS, Cho JH, Jang IS. A(1) receptors inhibit glutamate release in rat medullary dorsal horn neurons. Neuroreport. 2011;22(14):711-715

[97] Street SE, Zylka MJ. Emerging roles for ectonucleotidases in pain-sensing neurons. Neuropsychopharmacology: Official Publication of the American College of Neuropsychopharmacology. 2011;36(1):358

[98] Ma L, Trinh T, Ren Y, Dirksen RT, Liu X. Neuronal NTPDase3 mediates extracellular ATP degradation in trigeminal nociceptive pathway. PLoS One. 2016;11(10):e0164028

[99] Kuan YH, Shyu BC. Molecular Brain. 2016;9:58 


\title{
The Role of Purinergic Signaling in the Pathophysiology of Perinatal Hypoxic-Ischemic Encephalopathy
}

\author{
Tagore M. Morais-Lima, Joana C. Vicentini,
} Anael V.P. Alberto, Pedro H.M. de Freitas, Caio M. Perret, Natiele C. da Silva Ferreira, Deepaneeta Sarmah, Bharati Sinha, Gopika Das, Pallab Bhattacharya, Xin Wang, Luiz A. Alves and Renato Rozental

\begin{abstract}
Perinatal hypoxic-ischemic encephalopathy (HIE), known as birth asphyxia, remains a major contributor to poor neurodevelopmental outcomes including cerebral palsy and seizures. One striking feature of HIE injury is a delayed progression of neuronal degeneration that spreads over time from the most severely damaged areas outward into neighboring undamaged regions. There is increasing evidence that these lesions act as sites of origin for waves of spreading depression (SD), a wave of neuronal and glial depolarization, that progressively enlarge the brain lesions. While the pathophysiology of SD is still under debate, there is increasing evidence that purinergic receptors in conjunction with connexin and pannexin 1 channels are necessary for sustained propagation of the waves and neuroinflammation. This review intends to discuss the relative contribution of purinergic signaling and connexin and pannexin 1 channels to trigger and spread SD waves leading to the development of progressive brain lesions under conditions of perinatal HIE.
\end{abstract}

Keywords: spreading depression, gap junctions, hypoxic-ischemic encephalopathy, purinergic signaling

\section{Introduction}

Perinatal hypoxic-ischemic encephalopathy (HIE), also known as birth asphyxia, is a neurological syndrome that affects newborns worldwide, causing life lasting sequelae and not only impacting individual lives but also economy and public health systems [1, 2]. It is estimated that HIE occurs between 1 and 8 per 1000 newborns, although this number can be widely more expressive accordingly to the region, especially in low-income countries [3, 4]. Besides, HIE is considered to be the third major cause of neonatal mortality, accountable for $23 \%$ of newborn deaths and averaging about 1 million children annually $[5,6]$. In consonance, the morbidity is not far behind: HIE accounts for $10 \%$ of all cerebral palsy cases, 
compromising the quality of life of these patients and their families [7-9]. In this scenario, understanding the factors and mechanisms involved in HIE etiology is crucial to the development of new therapeutic strategies and improvement of mortality and morbidity rates.

Over the last years, several studies emerged intending to explain the pathophysiology of HIE [10-13]. The gaps in these topics are highlighted as particular priorities among the many critical areas that remain to be integrated. It is a consensus that the primary event for HIE burden is a global reduction of blood flow to the fetal brain during pregnancy or birth process [13]. This ischemic-hypoxic insult may result from various maternal or fetal conditions such as umbilical cord prolapse, rupture of the uterus and placental insufficiency $[1,14,15]$. One of the most intriguing features of HIE, however, is not even the ischemic injury per se, but the ability of the initial lesion to expand to previously undamaged areas (i.e., secondary lesions) [16]. Much of this process remains undefined and saving perilesional regions at risk, termed penumbra, challenges physicians and scientists. In this context, increasing evidence supports extracellular ATP and purinergic receptors as significant players in HIE pathophysiology and, consequently, a unique addition as interventional targets for the limited repertoire of drugs currently available as therapeutic approaches for HIE [17-19].

Purinergic receptors are a class of ligand-gated receptors divided into two groups $\mathrm{P} 1$ and $\mathrm{P} 2$, responsive to nucleosides and nucleotides, respectively. P1 receptors have four members described (A1, A2A, A2B e A3) [20-22]. On the other hand, P2 receptors are subdivided into two families $\mathrm{P} 2 \mathrm{Y}$ and $\mathrm{P} 2 \mathrm{X}$. Both $\mathrm{P} 2 \mathrm{Y}$ receptors and the P1 receptors are G coupled protein receptors (GPCRs), and the P2X receptors are ionotropic receptors. Those receptors are expressed in various systems in the organism, as the vascular system, the immune system, the gastrointestinal system, the renal system, and the central nervous system (CNS) [20-22]. Specifically, in the CNS, it is believed that some purinergic receptors could play essential roles in ischemia decreasing the symptoms and the extent of brain damage [23, 24].

Along with purinergic signaling, there are strong pieces of evidence in the literature correlating spreading depression (SD), a phenomenon characterized by self-sustained waves of depolarization of a sizeable population of cells, and hypoxic-ischemic insults $[25,26]$. HIE-mediated SDs erupt in the brain, encumbering tissue structure and function, and raising fascinating-and still unansweredquestions concerning their initiation (i.e., genesis) and propagation. Even more ominously, erupting SDs accelerate tissue damage following HIE or traumatic brain injury (TBI) [27, 28]. Studies by many authors, including our group [29], suggest that lesions act as a site of origin to these waves, which slowly propagate through the brain surface [30]. So far, the role of glia (astrocytes and microglia) in initiation, propagation, and recovery of SD is poorly understood [31, 32]. Although there is evidence that SD has an impact on astrocytes and microglia [31, 32], the consequences of their activation need to be further explored. Considering SD as an electrochemical event, ionic changes in the extracellular medium are important to the genesis and maintenance of propagated SDs. In this regard, recent studies present pannexins and connexins paved the way for sustainable SD propagation [26]. Hence, HIE detains a multifactorial mechanism, compelling not only purinergic signaling but also spreading depression, connexins, pannexins and many other biological processes yet to be defined.

This article intends to review the aspects and empirical evidence made on HIEmediated brain injury through the functional interaction between purinergic signaling, connexins, pannexins, and SDs. To the best of our knowledge, this is the first review to discuss the functional interplay among purinergic signaling and the above 
The Role of Purinergic Signaling in the Pathophysiology of Perinatal Hypoxic-Ischemic... DOI: http://dx.doi.org/10.5772/intechopen.86425

mentioned "players" as key elements to trigger and to either support or to interrupt the propagation of waves of SD within the HIE's penumbra. Understanding the underlying mechanisms of HIE is expected to develop more effective neuroprotective approaches during the highly prevalent condition of perinatal hypoxic distress.

\section{Purinergic signaling}

Since the first description of the physiological effects of purines and pyrimidines, by Drury and Szent-Györgyi in 1929, several pieces of evidence increased the discussion on their activity in the context of the CNS [23, 24, 33-35]. This novel family of receptors is virtually expressed in all human cells types, including neurons and glial cells at central nervous system, hence raising the several hypotheses on their role in the context of a myriad of neurological disorders, such as, neurodegenerative diseases, traumatic brain injury, CNS tumors, epilepsy, psychiatric disorders, and ischemic encephalopathy [36, 37].

The early 1970s classification of the novel receptor family-then called purinoreceptors-proposed by Geoffrey Burnstock is considered to be one of the first steps to current comprehension and systematic research of purinergic receptors, which stratifies them into two groups, taking in consideration their molecular characteristics and downstream signaling [38].

The adenosine-activated receptors, or P1 receptors, present four subtypes (A1, A2A, A2B, and A3), each of these consisting of seven folds of transmembrane protein domains (TM1-TM7) linked to an N-terminal extracellular domain and a C-terminal intracellular domain. In contrast, P2 receptors are subdivided into two families: metabotropic P2Y receptors and ionotropic P2X receptors. Among several other mammal species, humans present eight members of the metabotropic P2Y, (described as P2Y1, P2Y2, P2Y4, P2Y6, P2Y11, P2Y12, P2Y13, and P2Y14), and seven members of the ionotropic P2X receptors, numbered P2X1 to P2X7 [22, 39-42].

The P1A2A and P1A2B molecules are Gs-protein-coupled receptors, therefore stimulating adenylate cyclase and leading to downstream production of cyclic adenosine $3^{\prime}, 5^{\prime}$-monophosphate (cAMP) second signaling, once they are bound to their active ligand. On the other, hand P1A1 and P1A3 subtypes molecules are $\mathrm{Gi}$ protein-coupled receptors, leading to adenylate cyclase inhibition and cAMP degradation. In addition, some of the $\mathrm{A} 2 \mathrm{~B}$ receptor isoforms may also be associated with $\mathrm{Gq}$ domains, leading to a phospholipase $\mathrm{C}$ and inositol triphosphate second signaling pathways [42] (Figure 1).

Metabotropic P2Y receptors are $G$ protein-coupled receptors activated by different nucleotide types, including ATP, ADP, UTP, UDP, and UDP-glucose. Similarly to P1 receptors, the seven transmembrane domain/ns, three extracellular and three intracellular loops, and C-terminal intracellular and extracellular $\mathrm{N}$-terminal ends are found in their structure. P2Y1, P2Y2, P2Y4, P2Y6, and P2Y11 receptors are associated with Gq protein, leading to an increase of the intracellular calcium through the internal stores culminating in a protein kinase $\mathrm{C}$ activation, whereas P2Y12, P2Y13, and P2Y14 are coupled to Gi protein, inhibiting adenylate cyclase and cyclic AMP [39]. Concerning the ionotropic P2X receptors, they are non-selective cation channels modulated by ATP [43]. Once activated these receptors act as transmembrane channels, allowing the flow of mono and divalent cations, such as, $\mathrm{K}^{+}, \mathrm{Ca}^{2+}$, and $\mathrm{Na}^{+}$accordingly to their gradient $[44,45]$. Although some data in this context is found to be controversial, it is important to mention that some subtypes as $\mathrm{P} 2 \mathrm{X} 2, \mathrm{P} 2 \mathrm{X} 4$, and $\mathrm{P} 2 \mathrm{X} 7$ are described to open a non-selective transmembrane pore, if submitted to high concentrations or prolonged exposure 

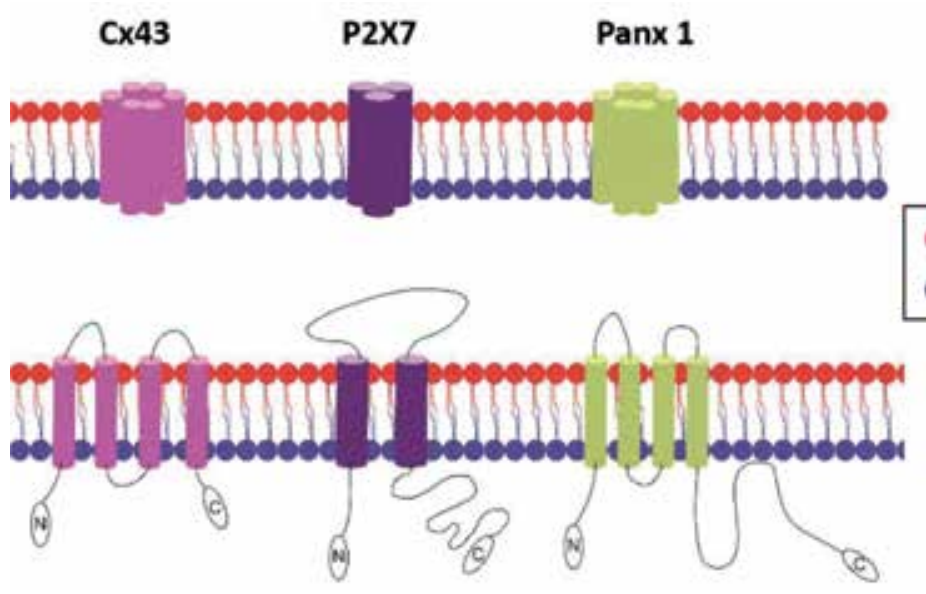

Extracellular layer Intracellular layer

Figure 1.

Structural features of $C_{4} 43, P_{2} X_{7}$ and Panx1. Each functional $P_{2} X_{7}$ receptor is a trimer, with the three protein subunits arranged around a cation-permeable channel pore. The subunits all share a common topology, possessing two plasma membrane spanning domains (TM1 and TM2), a large extracellular loop with the ATP binding site, and containing 10 similarly spaced cysteines and glycosylation sites, and intracellular carboxyl $(C)$ and amino termini (N). (Left) Connexin 43 (Cx43) and pannexin 1 (Panx1) (right) share similar membrane topology, with four $\alpha$-helical transmembrane domains (M1-M4) connected by two extracellular loops and one cytoplasmic loop, where both amino $\mathrm{NH}_{2}(\mathrm{~N})$ and carboxy COOH-termini $(C)$ are intracellular. However, different from connexins, the pannexins possess an extracellular glycosylation site which impedes gap junction formation by these channels. Upper panel_-(left) a Cx hemichannel (HC) and pannexon (right) are formed by connexins and pannexins, respectively, that oligomerize laterally.

to their ligand. In this condition, these receptors allow the passage of molecules up to $900 \mathrm{Da}$, which includes organic ions and most of the frequently used fluorescent dyes [46-48] (Table 1). P2X receptors present two transmembrane domains connected by an extracellular loop, besides a C-terminal and an N-terminal domain in the intracellular milieu [56]. They are capable of homotrimeric and heterotrimeric assemble [57, 58] (Figure 1).

As suggested before, the ischemic CNS context, purinergic receptors might represent an important molecular target to restrain the condition's irreversible

\begin{tabular}{llll}
\hline Channel & Blockers & Dye & Permeability \\
\hline \multirow{2}{*}{ P2X7 } & BBG, oATP and AZ11645373 [49] & Iodide propidium (+) & - \\
\cline { 2 - 4 } & $\begin{array}{l}\text { A-438079, AZ11645373 and } \\
\text { probenecid [50] }\end{array}$ & $\begin{array}{l}\text { Ethidium bromide (+) and } \\
\text { Lucifer yellow (-) }\end{array}$ & - \\
\cline { 2 - 4 } & A-740003, PPADS and BBG [51] & Yo-Pro-1 (+) & - \\
\hline \multirow{2}{*}{$\begin{array}{l}\text { Hennexin } \\
\text { Hemichannel }\end{array}$} & $\begin{array}{l}\text { Heptanol, octanol, CBX, La }{ }^{3+}, \\
\text { FFA and AGA [52] }\end{array}$ & Lucifer yellow (-) & - \\
\cline { 2 - 4 } & CBX and Gap26 [53] & Ethidium bromide $(+)$ & - \\
\cline { 2 - 4 } & CBX and mefloquine [54] & Iodide propidium $(+)$ & - \\
\hline CBX, FFA, AGA and NFA [55] & Not used & - \\
\hline Pannexin & ${ }^{10}$ Panx [50, 53] & Ethidium bromide $(+)$ & No change \\
\hline
\end{tabular}

Nomenclature:-, decreased permeability/no permeability. BBG, brilliant blue G; oATP, periodate-oxidized adenosine triphosphate; CBX, carbenoxolone; AGA, 18alpha-glycyrrhetinic acid; FFA, flufenamic acid; PPADS, pyridoxalphosphate-6-azophenyl-2',4'-disulfonic acid; NFA, niflumic acid. The (+) and (-) indicates valency of the dye used.

Table 1.

$P_{2} X_{7}$, connexins and pannexins antagonists blocked the permeability to anionic and cationic dyes. 
burden. In this scenario, ATP and adenosine are released to the extracellular space after injury through vesicles from neurons, besides exocytosis and membrane channels including $\mathrm{ABC}$ transporters, pannexin 1, calcium homeostasis modulator 1 (CALHM1) channels and P2X7 pore in glial cells [59]. Estimated extracellular ATP concentrations have been described to reach up to $700 \mathrm{nM}$ after ischemic events leading to tissue necrosis, whereas adenosine levels can reach up to $1000 \mathrm{nM}$ [17], due to ectonucleotidases' activity, which catabolizes AMP and generates adenosine consequently. These extracellular concentrations of adenosine and ATP after ischemic events are high enough to activate $\mathrm{P} 1$ and $\mathrm{P} 2$ receptors [60].

Even though purinergic receptors in the CNS are believed to play different roles during HIE, while the protective role of adenosine P1A1 receptors during ischemia is well accepted, through the reduction of infarct volume and improvement of neurological functions [61, 62], P2 receptors activation have been associated with inflammation, neurodegeneration and cell death $[45,63]$. The evidence supporting an "adenosine neuroprotection" dates from 1997, when Halle and cols reported that pretreatment with 2-amino-3-benzothiophene (PD 81,273) - to increase adenosine binding to P1A1 receptors-conferred neuroprotection following HIE [24]. As expected, the neuroprotection afforded by adenosine is antagonized by theophylline (dimethylxanthine), an inhibitor of phosphodiesterase (PDE) isoenzymes, which break down cyclic nucleotides in the cell and leads to increased concentrations of [cAMP]i and [cyclic 3',5' guanosine monophosphate] I [64, 65], antagonizing P1A1 and P1A2 receptors at therapeutic concentrations [23]. Along the same line, Ådén et al. (2003) reported that the absence of P1A2A receptors (P1A2A KO mice) aggravated brain damage after neonatal HI [62].

All mammalian cell types express multiple $\mathrm{P} 2$ receptor subtypes, each of which presenting variable affinities for purine and pyrimidine nucleotides [66]. In the neonatal HI CNS, Wang et al. (2009) suggested that P2X7 downregulation in oligodendrocyte precursor cells confers neuroprotection [67], while the use of P2X7 antagonists, such as, A-438079 and JNJ-47965567, can antagonize the occurrence of seizures. In this context, P2X7 could represent a novel and effective therapeutic target in the condition mentioned above [68]. There is accumulating evidence that P2X1, P2X2, P2X3, P2X4 and $\mathrm{P} 2 \mathrm{X} 5$ are potentially involved in direct neuronal death $[69,70]$ and that $\mathrm{P} 2 \mathrm{X} 7$ are expressed in glial cells [71]. It remains a matter of debate whether neurons express P2X7.

\section{Connexins}

Connexins are a family of trans-membrane proteins related to several functions, such as, intercellular communication and tissue differentiation. These proteins are best known for being the assembling subunits of connexons, a hexameric structure composed of six units of connexins [72-74]. The apposition of connexons in adjacent cells forms intercellular conduits named gap junctions (GJs), which allow the transfer of small molecules, ions and second messengers between cells [75]. The connexins family comprises 21 genes in the human genome [76], and their genetic expression varies according to the tissue and extracellular conditions. It is noteworthy that several cell types can express more than one type of connexin simultaneously $[73,77]$. Connexins isoforms possess very similar and conserved structures, consisting of two extracellular loops, four transmembrane domains, one cytoplasmic loop, the C-terminus and the N-terminus [78]. When six units of identical connexins assemble, the resulting connexon is termed homomeric, whereas a connexon formed of different types of connexins is named heteromeric. Following the same rule, gap junctions are homotypic if derived from two identical connexons or heterotypic when two different connexons assemble [73] (Figure 1). 
Among all connexins isoforms, connexin $43(\mathrm{Cx} 43)$ is the more widely expressed, being present in more than 30 different tissues [77]. Predominantly found in astrocyte's membrane, novel studies suggest important participation of $\mathrm{Cx} 43$ connexons and GJs in the pathophysiology of several diseases [73, 79-82]. In the field of CNS hypoxic-ischemic insults, including neonatal asphyxia, some groups argue that GJs allows redistribution of nutrients, such as, glucose, and ATP [19], hence providing neuroprotection in this context. On the other hand, a myriad of studies presents $\mathrm{Cx} 43$ hemichannels as protagonists in processes of brain blood barrier disruption, calcium disbalance and mitochondrial dysfunction [83-85]. In addition, Cx43 may play an important role in the propagation of SD waves, possibly promoting the expansion of the initial injury to previously undamaged areas [26].

Under normal conditions, GJs may open or close accordingly to cell demands, while undocked connexons remain closed $[86,87]$. Nevertheless, in cell death scenarios, hemichannels may open, allowing molecules to flow through the cell membrane, from and into the extracellular space [84, 88-90]. The release of substances, such as, ATP, glutamate and nicotinamide adenine dinucleotide $\left(\mathrm{NAD}^{+}\right)$ in the extracellular medium promotes paracrine signaling to the surrounding cells, triggering cell death cascades and, consequently, expanding the primary injury [87].

Purinergic receptors in both neurons and glial cells can be activated from dying cell's ATP release, leading to calcium influx through the receptor channel [83]. An increase of intracellular calcium might induce or worsen mitochondrial dysfunction in the context of brain injury, which leads to both secondary energy deficit and apoptosis [83]. In addition, ATP can also activate pattern recognition receptors (PRR), highlighting NOD-like receptor protein-3 (NLRP3) [84]. Finally, P2X7 and $\mathrm{P} 2 \mathrm{X} 4$ receptors are involved in inflammasome activation and the secretion of proinflammatory molecules.

One of the most widely characterized approach intending to prevent the inflammatory responses of purinergic receptors activation is $\mathrm{Cx} 43$ blockade. However, the effects of $\mathrm{Cx} 43$ blockade are still controversial. Several in vitro and in vivo models in the literature resulted in a reduction of cell death, tissue swelling, and lesion spread $[91,92]$. In contrast, some groups described an association between Cx43 blockade, apoptosis and higher infarct volume $[93,94]$. This divergence may be explained by the limited pharmacologic agents and approaches described to promote $\mathrm{Cx} 43$ blockade. Currently, some of the most commonly used agents in the literature include $\mathrm{Cx} 43$ mimetic peptide, carbenoxolone, and octanol [19]. Once agents with greater specificity for $\mathrm{Cx} 43$ are established and their mechanisms are characterized, a better understanding of the role of $\mathrm{Cx} 43$ in pathological conditions such as HIE will be possible.

\section{Pannexins}

Pannexins are a class of monomeric proteins capable of forming cell membrane hemichannels, resembling structural and functional homology with the connexins as mentioned earlier. Likewise the formers, these molecules can assemble as oligomeric forms, namely pannexons. There are several different subtypes of pannexons in which pannexins can be assembled, depending on the cell type and physiologic condition of the cell surroundings. Among these, the three human isotypes are expressed virtually in all tissues: Panx1 (426 amino acids, $47.6 \mathrm{kDa}$ ), Panx2 (677 amino acids, $74.4 \mathrm{kDa}$ ) and Panx3 (392 amino acids, $44.7 \mathrm{kDa}$ ) [84, 95, 96].

The characterization of the assembled pannexin polymers upon cell membrane is still controversial since several groups suggest their action to be in the hemichannel fashion-such as connexins_-while other findings indicate their function to 
resemble full transmembrane channels between cells $[84,95,96]$. Despite the fact pannexins and connexins share several similar pharmacologic properties and expression patterns, unlike connexons, it is now believed that pannexons are not capable of forming functional gap junctions between neighbor cells and hence not being capable of promoting the connection between their cytoplasm [95, 97, 98].

Regarding molecular characterization, human pannexin isotypes share 50-60\% of membrane sequence similarity, and their extracellular C-terminal sequences are the most variable among them, defining their subtype characterization based on their pattern of glycosylation $[96,98]$. Novel structural studies of pannexin membrane characterization suggest that the physiologic interplay between Panx2 and other subtypes, and functional gap junction formation are very unlikely in experimental scenarios due to glycosylated domain ionic repulsion [97, 98]. Panx2 is believed to be exclusive to CNS cells, even though its molecular properties are not elucidated as well as Panx1 subtypes [95, 96] (Figure 1).

In contrast, Panx1 subtypes can be subdivided accordingly to their different expressed conformations, mostly determined by the several possible types of channel activation $[97,99]$. Recent studies suggest that in the absence of specific ligands, Panx1 is a Cl-selective channel expressed in astrocytes, oligodendrocytes, and microglia [100]. In contrast, once activated by $\mathrm{K}^{+}$ions, Panx1 can isomerize into a highly conductant non-selective channel $(500 \mathrm{pS})$, permeable to molecules such as ATP and other nucleotide polymers. Alternatively, voltage-activation of Panx1 opens a lower conductance conformation (50 Ps) [97, 99]. Nonetheless, it is important to mention that caspase activity, mechanical stretching, osmotic changes, purinergic receptor activation (such as $\mathrm{P} 2 \mathrm{X} 7$ bound to adenosine nucleotides), and other cell biomolecular survival pathways are indicated as panx1 activators $[19,43,101]$. Additionally, this suggests that tissue injury and cell death processes can mediate Panx1 activity and might explain one of the early mechanisms of ATP leakage through the cell membrane $[97,99]$ and intercellular activation through purinergic receptors, and coupling through functional gap junctions. The influence of extracellular ATP in astrocytes downstream signaling is further discussed in this review.

The evidence against the pannexin role as intercellular hemichannels is based on three major aspects of these protein characteristics. Firstly, their well-recognized function as ATP and other macromolecule releasers. In addition, their distribution is described mostly in the apical domains of ubiquitous cells, which makes hemichannel coupling very unlikely [95]. Lastly, the aforementioned glycosylated extracellular domain acts repealing the near plasmatic membrane and does not talk in favor of their gap junction formation [95-98].

Although it seems that hemichannel opening occurs only at the downhill of cell stress, Panx opening is also observed under physiological situations, such as, the glucocorticoid release throughout the circadian cycle and neuronal coordination under sleep pattern changing $[102,103]$. Panx1 role was also described in inflammasome formation and the release and cleavage of IL-1 $\beta[101,104]$, which might suggest a role in the triggering of early inflammatory response and cell death [105].

\section{Spreading depression}

In 1906, Sir William Gowers described migraine pathophysiology as an intense, yet slow activity of the cortical centers of the brain spreading as "ripples in a pond into which a stone is thrown"- "occupying $20 \mathrm{~min}$ or so in passing through center affected" leaving a state of "molecular disturbance of the structures" [106]. This phenomenon was confirmed and described 38 years later in rabbit's cerebral cortexes 
by Aristides Leão, who coined the term spreading depression (SD) [107], nowadays associated not only with migraine pathophysiology but also with several other neurological disorders, such as, traumatic brain injury, spinal cord injury, subarachnoid and intracranial hemorrhage, stroke and HIE [28, 108-111] (Figure 2).

Characterized as an intense change in ionic homeostasis and extracellular space (ECS) features, SD is an all-direction depression of neural activity that does not respect any tissue cellularity boundaries in the cortex $[30,112]$. Although it is described as a negative shift in DC moving a few millimeters per minute, SD also involves fast electrical events, as seen in a burst of activity at the wavefront, followed closely by the numbness of preview neuronal tissue [27, 28, 30, 113, 114]. SD used to be described by Professor Hiss Martins-Ferreira as an "electrical tsunami" spreading among a neuronal mass that encompasses dendritic swelling, gap junction channels assemble and opening, mitochondrial changes, up-regulation, and down-regulation of several other proteins of the CNS $[26,115,116]$.

\section{SD-Mediated Secondary Damage}

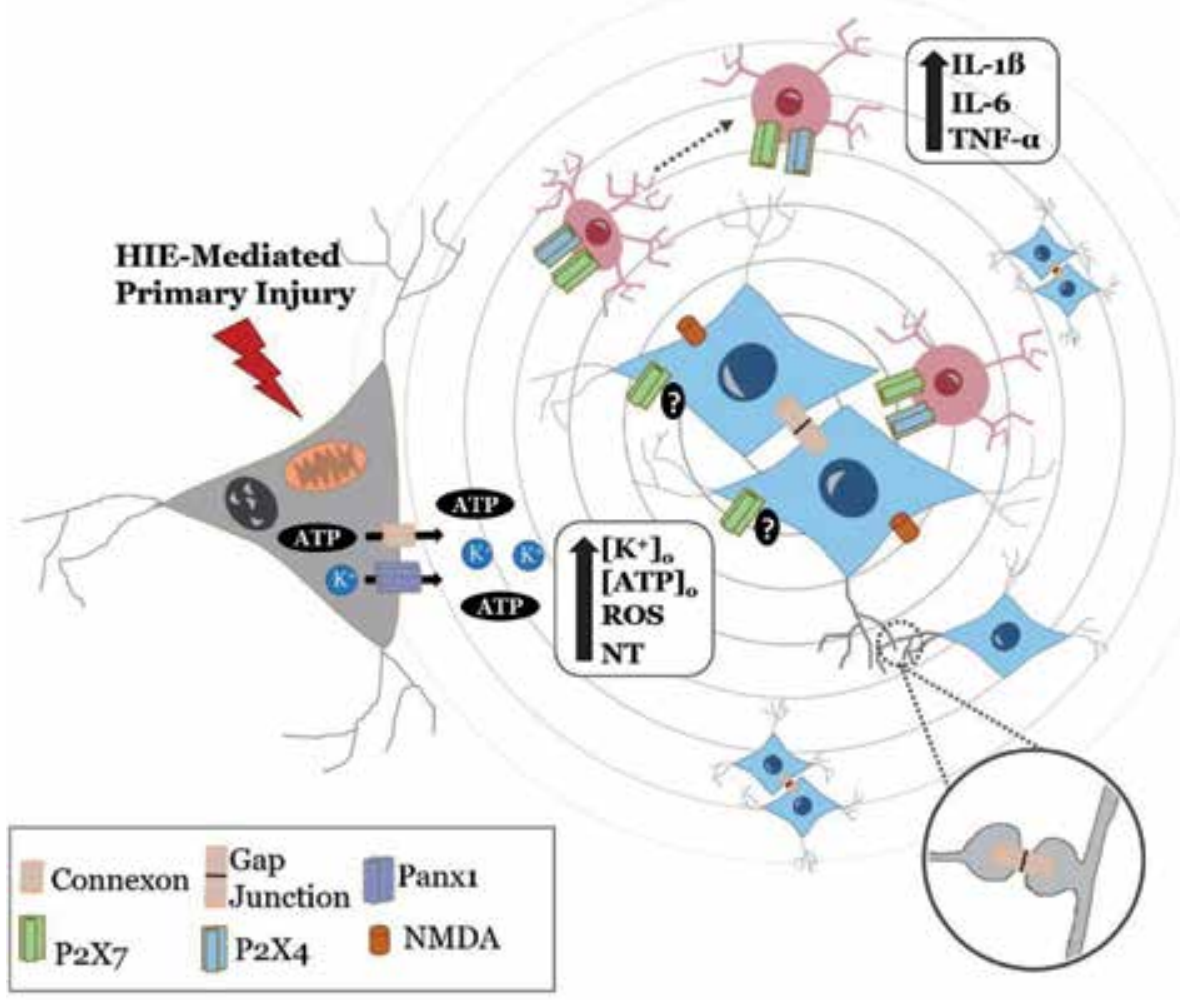

Figure 2.

Waves of Leão spreading depression (SD) and purinergic receptors. Three-step models have been proposed to explain genesis and propagation of SDs, a phenomenon believed to play a major role in the pathophysiology of HIE. Firstly, HIE-mediated primary injury leads to a surge in $\left[\mathrm{K}^{+}\right]$o, ATP, reactive oxygen species (ROS) and a number of neurotransmitters (NT) in the extracellular space through Cx hemichannels and Panx 1 opening in dying cells (gray cell). The upcoming activation of purinergic receptors at glia [71] and/or at neighboring neuron cell surfaces (blue cells) — a matter of debate (?)-triggering SD phenomenon. Besides, glutamate excitotoxicity is also triggered, leading to $\mathrm{Ca}^{2+}$ influx in the adjacent cells through NMDA receptors. Transmembrane ionic shifts during SD leads to a large drop in $\left[\mathrm{Na}^{+}\right] \mathrm{o},\left[\mathrm{Ca}^{2+}\right] \mathrm{o},\left[\mathrm{Cl}^{-}\right] \mathrm{o}$, simultaneously with the extracellular DC potential shift. Subsequently (third step), reentrant waves spread throughout the penumbra mediated by gap junctions, promoting secondary damage — via apoptosis_and lesion enlargement [30]. Electrotonic junctions in the neonatal cerebral cortex (see inset_-bottom) are mostly dendrodendriticalthough these same neurons can also be interconnected by chemical synapses [38]—and are believed to provide an important path for propagation of the waves [42]). Microglia (pink cell) is also activated via $\mathrm{P}_{2} \mathrm{X}_{4}$ and $\mathrm{P}_{2} \mathrm{X}_{7}$ receptors and releases proinflammatory cytokines. 
Among this complex electrochemical phenomenon that revolves in the CNS extracellular space, the intracellular spaces of neuronal-glial populations, and cellular coupling, many factors have been attributed as key players to its genesis and sustenance, such as, $\mathrm{Ca}^{2+}, \mathrm{K}^{+}$, and glutamate and purinergic receptors [30]. Highly increased $\mathrm{K}^{+}$concentration was demonstrated in SD scenarios, which lead to several experimental models intending to recapitulate SD waves through artificially increasing this ionic concentration on the cortical surface [29]. It was also observed that the levels of this ion in the ECS reaches typically a plateau, being trespassed once SD is elicited [117] and those higher amounts of $\mathrm{K}^{+}$deliverance increase wave frequencies. Moreover, the fast electrical burst at SD wavefront is possibly explained by high extracellular $\mathrm{K}^{+}$concentrations inducing high neuronal activity. Imaging studies assessing initial changes in $\mathrm{Ca}^{2+}$, glutamate, and $\mathrm{K}^{+}$concentrations at SD wavefront revealed earlier and more significant changes in $\mathrm{K}^{+}$, suggesting its role as the first responder in SD initiation and propagation [118] (Figure 2).

Astrocytic $\mathrm{Ca}^{2+}$ waves are also intrinsically related to $\mathrm{SD}$, sharing its "velocity of propagation and stimulation paradigms" initiation stimuli, refractory period, and signaling characteristics, which are postulated not only as involved with the initiation of SD, but also as fundamental for its propagation [30, 119-121]. However, $\mathrm{Ca}^{2+}$ waves are not a sine qua non player for SD genesis, as observed in a $\mathrm{Ca}^{2+}$ free medium, in ion chelating experimental contexts, in which SD genesis was not inhibited, albeit it caused a lower onset and faster recovery [119] (for further evidence against this $\mathrm{Ca}^{2+}$ role, see [122-124]). It is noteworthy that, gap junction blockers, purinergic blockers, ATP hydrolase inducers, and desensitization of the purinergic receptors were reported as potential $\mathrm{Ca}^{2+}$ wave inhibitors [30, 125-128].

The myriad of aforementioned cationic changes in SD scenarios implies in several anionics unbalances in the ECS, being $\mathrm{Cl}^{-}$the most affected inorganic anion [30]. Consequently, $\mathrm{Na}^{+}$follows the elicited $\mathrm{Cl}^{-}$influx, decreasing ECS tonicity leading to cell swelling and morphologic changes in dendritic spines [129]. The dendritic spines recovery depends on mitochondrial membrane potential integrity, an already impaired function in hypoxic-ischemic scenarios [130].

Glutamate concentration is not only found to be higher during and after SD but also its release to be synchronic and excitotoxic processes are triggered by NMDAr activation. Despite these events, the blockade of this neurotransmitter is not able to inhibit SD onset [131-133].

The roles of purinergic signaling in neurodegeneration following perinatal HIE contexts is also well documented. Levels of extracellular ATP in the brain increase during ischemia, activating both $\mathrm{P} 1$ and $\mathrm{P} 2$ receptors expressed on neural cells (neuronal and glial). Hence, extracellular ATP levels are postulated to be involved in the pathophysiology of post-ischemic inflammation and extent of brain injury $[17,45,81,83,134]$. Despite this factor is being considered to be one of the key players in triggering SD through Panx1 and Cx hemichannels in dying cells, the propagation of the waves requires the participation of gap junctional channels within the ischemic penumbra $[19,30,115,135]$. Therefore, the hypothesis of a functional interplay between $\mathrm{P} 2 \mathrm{X} 7$, Panx1, and $\mathrm{Cx}$, and its impact in the injury enlargement is very plausible in the context of the HI newborn cerebral cortex development $[19,104,130,136]$. In consonance with this conclusion, the blockade of genesis and propagation of SD through purinergic antagonists and GJ blockers may represent a viable therapeutic approach, not only to prevent post-HIE neonatal brain injury expansion, but also in other neurovascular disorders, including migraine, trauma, and ischemic stroke [19] (Figure 2).

Mitochondrial activity is fundamental to cell maintenance, carrying in itself an intricate and distinct pattern of protein, ionic and electrical activity [137-139]. Both oxygen and glucose deprivations unbalance the primary source of cellular 
ATP production through the disruption of mitochondrial oxidative phosphorylation chain [140-143]. This described powerhouse organelle failure generates a toxic $\left[\mathrm{Ca}^{2+}\right] \mathrm{i}$ increase, caspase activation, and ROS production, which induces necrotic features of the HIE-mediated primary injury $[142,143]$. We are lead to believe that this characteristic of cell membrane rupture is the main contributing path for $\mathrm{Cx}$ hemichannel opening; acting synergically with the Panx1 heightening of ATP and $\mathrm{K}^{+}$in ECS. Henceforth, we postulate this described cascade of hemichannel events to be the first step for SD genesis and propagation in HIE [95, 99, 136, 144]. The opening of these pores induces several other cell-signaling events, such as P2X7 activation and glutamate excitotoxic activity that is leading to significant $\mathrm{Ca}^{2+}$ concentration increase in the ECS. Ionic shifts and DC change is followed by gap junction-mediated spiral waves, promoting secondary SD-mediated injury [29] (Figure 2).

In conclusion, $\mathrm{Cx}$ hemichannels opening may elicit $\mathrm{Ca}^{2+}$ waves-responsible for the faster onset of SD-ATP, caspases, NO and other second signaling molecules flow, contributing to the bystander cell killing effect among coupled astroglial cells [145]. This highway-rail for SD waves intensifies its onset, as longs as $\left[\mathrm{Ca}^{2+}\right] \mathrm{i}$ augmentation is followed by $\mathrm{Cl}^{-}, \mathrm{Na}^{+}$influx, leading to ECS changes ("Chemical Tsunami”) [30]. Depolarizing wavefront will also elicit neuronal bursts, contributing to $\mathrm{K}^{+}$and ATP increase in the biophase [146]. The cited secondary injury appears to behave in a positive feedback-like fashion, into which further ionic and ATP release will lead to SD frequency increase and the ECS changes to mechanical panx1 activation.

\section{Biomarkers}

Inflammation plays a critical role in HIE $[147,148]$ by the complex interplay between neutrophils, lymphocytes, adhesion molecules, cytokines, and chemokines, causing injury in neurons, glial cells, and white matter. The blood-brain barrier is disrupted leading to egress of brain chemicals, normally only found in the CNS, and circulate peripherally. These chemicals can serve as important biomarkers that may help in disease risk stratification and clinical decision-making.

Hypoxia-ischemia induces activation of microglia and astrocytes [149, 150], resulting in secretion of inflammatory cytokines and chemokines that influence neuronal viability and recovery [149]. Following brain injury, purinergic P2 receptors and extracellular ATP play an important role in the microglial inflammatory response [151]. While $\mathrm{P} 2$ receptors are activated during oxygen-glucose deprivation (OGD) leading to microglia activation with cytokine release [70,152] and subsequent neuronal death, the enhanced expression of P2X4 mediates ATP induced amoeboid microglial cell activation for production of proinflammatory cytokines [153] in postnatal hypoxic rats. In particular, P2X7 expression is increased $24 \mathrm{~h}$ after neonatal hypoxia-induced seizures in mouse pups following global hypoxia and injection of P2X7 antagonist reduced the frequency of electrographic seizures and EEG abnormality [68]. Therefore, purinergic biomarkers have been proposed for both cerebral ischemia diagnosis and prognosis [45].

Microglia responds vigorously to hypoxic-ischemic attack and produce excess inflammatory cytokines [148]. Newborns with HIE have higher levels of interleukins IL-1, IL-6, IL-8, IL-10, tumor necrosis factor TNF- $\alpha$, transforming growth factor TGF- $\beta$ and monocyte chemoattractant protein MCP- 1 that correlate positively with brain injury severity [154-157]. IL-1 $\beta$ plays an important role in brain injury during ischemia [158]. The mechanism of brain damage induced by IL-1 $\beta$ involves the release of free radicals, enhancing the toxicity of excitatory amino acids and 
increasing vascular permeability resulting in secondary cerebral edema. Blood and cerebrospinal fluid (CSF) IL-1 $\beta$, IL-6, and TNF- $\alpha$ concentrations were found higher in HIE neonates compared to control group and a high CSF/serum ratio suggested cytokine production in the brain in addition to the systemic cytokines crossing the blood-brain barrier $[154,159]$. Therapeutic hypothermia (TH), a well established treatment for neonates with HIE $[8,10,157,159,160]$, has been shown to perform a role in the prevention of inflammatory process by maintaining proinflammatory IL-6 at low levels and anti-inflammatory IL-10 at high levels [160] (Figure 2).

\section{Discussion}

HIE remains one of the leading causes of neonatal deaths [5, 6]. Although multiple factors have been implicated in this disorder, the HIE underlying mechanisms are yet to be elucidated. To the best of our knowledge, we provide herein a summary of the described functional interplay among purinergic signaling, pannexins, connexins, and SD waves in HIE pathophysiology. Based on this interaction, the present work intends to review the current information on potential biomarkers on HIE diagnosis and prognosis.

SD waves spread across the cortex at rates of $2-5 \mathrm{~mm} / \mathrm{min}[30,107,161]$, accompanied by a slow negative extracellular voltage and ions movement depolarizing neurons and astrocytes followed by a period of electrical suppression of distinct neuronal populations. The propagation of the SD waves is more significant in fields enriched with dendrodendritic synapses [162], such as, those described in the inner plexiform layer of the retina [30]. At this time, there are no comprehensive reviews of SD, from genesis to sustained propagation for which gap junctions have been reported to be essential [30]. However, the fact that the temporal and spatial characteristics of intercellular $\mathrm{Ca}^{2+}$ waves in astrocytes are remarkably similar to those of SDs "contributed, in part, to the mischaracterization of this phenomena" $[30,113]$. Even though both events fail when gap junctions are blocked, the latest (i.e., $\mathrm{Ca}^{2+}$ waves) is neither antagonized by glutamate receptor blockers nor by purinergic receptor antagonists [30] (Tables 1 and 2).

Considering the role of spreading depression waves in HIE etiology, a new panel of biomarkers are being proposed to improve accuracy in diagnosis and prognosis, especially in the disease earlier stages or milder presentations. Unfortunately, ATP and adenosine, with short half-lives, do not offer good performance as biomarkers [174]. Recent studies have supported the use of proton magnetic resonance spectroscopy (MRS), a quantitative, noninvasive method of detecting energy metabolism disturbances in the neonate's brain as a marker in outcome prediction for HIE patients [175]. In these studies, it seems that the ratios including Lactate/Nacetylaspartate and $\mathrm{N}$-acetylaspartate/creatine could be a potential prognostic biomarker to evaluate neurodevelopmental outcomes [176, 177]. However, larger prospective multicenter studies with a standardized protocol for both measurement protocols and analysis methods are required to validate such protocols.

As discussed, cytokines are key players in the inflammatory mechanism, contribute to the progression of ischemic damage and are released by SD-activated glia. Waves of SD cause a considerable perturbation of the ionic environment in the brain, which are readily detected by microglia-although the role of microglial activation in SD-related neurological disorders remains a matter of debate. There is increasing evidence that supports that glia (astrocytes, oligodendrocytes and microglia) may play a key role in triggering SD waves. It is known that CNS microglia become activated due to the increase in extracellular ATP from the depolarization of neurons and glia, by propagated waves of SD and from the release 
Receptors $P_{1}$ and $P_{2}$ as Targets for Drug Therapy in Humans

\begin{tabular}{|c|c|c|c|}
\hline Channel & Model & Blocker(s) & Effects \\
\hline \multirow[t]{4}{*}{$\mathrm{P} 2 \mathrm{X} 7$} & In vivo $\mathrm{MCAO}$ (rat) & RB2 (10-100 mg/kg) & $\begin{array}{l}\text { RB2 improved neurological } \\
\text { score and reduced brain- } \\
\text { damaged area [163] }\end{array}$ \\
\hline & In vivo $4-\mathrm{VO}$ (rat) & $\begin{array}{l}\text { BBG and oATP }(1,5 \text { and } \\
10 \mu \mathrm{g}) \text { and } \mathrm{A}-438079(0.03 \text {, } \\
0.3 \text { and } 3 \mu \mathrm{g})\end{array}$ & $\begin{array}{l}\mathrm{P} 2 \mathrm{X} 7 \text { antagonists increased } \\
\text { neuronal survival and } \\
\text { improved behavioral deficits. } \\
\text { They reduced mortality, glial } \\
\text { activation, and cytokine } \\
\text { transcription [164]. }\end{array}$ \\
\hline & In vivo 4-VO (rat) & $\begin{array}{l}\text { BBG }(50 \mathrm{mg} / \mathrm{kg}) \text { and } \\
\text { A-740003 }(0.04 \mathrm{~mm} / \mathrm{kg})\end{array}$ & $\begin{array}{l}\text { P2X7 antagonist, BBG, } \\
\text { reduced cell death, microglial } \\
\text { microvesicle-like components, } \\
\text { expression of IL-1 } \beta, \mathrm{p}-38 \\
\text { phosphorylation and glial } \\
\text { activation. BBG and A- } 740003 \\
\text { improved memory functions } \\
{[165]}\end{array}$ \\
\hline & $\begin{array}{l}\text { In vivo carotid arteries } \\
\text { occlusion and post- } \\
\text { conditioning (mouse) }\end{array}$ & BBG (20-40 mg/kg) & $\begin{array}{l}\text { BBG abolished neuroprotective } \\
\text { effects produced by post- } \\
\text { conditioning, such as memory, } \\
\text { and motor performance } \\
\text { improvement [166] }\end{array}$ \\
\hline \multirow[t]{2}{*}{$\mathrm{P} 2 \mathrm{Y}$} & $\begin{array}{l}\text { Culture of rat primary } \\
\text { cortical neurons subjected } \\
\text { to OGD }\end{array}$ & N/A & Ischemic tolerance [167] \\
\hline & $\begin{array}{l}\text { Culture of astrocytes } \\
\text { exposed to sublethal OGD } \\
\text { and subsequent lethal OGD }\end{array}$ & N/A & Ischemic tolerance [168] \\
\hline \multirow[t]{3}{*}{ Connexin } & $\begin{array}{l}\text { Perinatal ischemia- } \\
\text { intrauterine hypoxia- } \\
\text { ischemia (rat) }\end{array}$ & Carbenoxolone (105 mg/kg) & $\begin{array}{l}\text { Decreased neuronal death, } \\
\text { apoptosis, histopathologic } \\
\text { damage and developmental } \\
\text { impact. Decreased clustering of } \\
\text { dying cells [169] }\end{array}$ \\
\hline & $\begin{array}{l}\text { Perinatal ischemia-bilateral } \\
\text { carotid ligation (sheep) }\end{array}$ & $\begin{array}{l}\text { Cx43 mimetic peptide } \\
(50 \mu \mathrm{mol} / \mathrm{kg})\end{array}$ & $\begin{array}{l}\text { Reduced seizure activity and } \\
\text { status epilepticus. Improved } \\
\text { neuronal and oligodendrocytes } \\
\text { survival [170] }\end{array}$ \\
\hline & $\begin{array}{l}\text { Neonate 7D hypoxia/ } \\
\text { ischemia-carotid ligation } \\
\text { and hypoxic chamber (rat) }\end{array}$ & $\begin{array}{l}\text { Cx43 mimetic peptide } \\
(25-50 \mu \mathrm{g} / \mathrm{kg})\end{array}$ & $\begin{array}{l}\text { Reduced infarct volume, } \\
\text { astrogliosis, glutamate release } \\
\text { and improved neurological } \\
\text { function [171] }\end{array}$ \\
\hline \multirow[t]{2}{*}{ Pannexin } & In vivo $4-\mathrm{VO}$ (rat) & Probenecid (2 mg/kg) & $\begin{array}{l}\text { Probenecid attenuated } \\
\text { neuronal death, cathepsin B } \\
\text { translocation in neurons and } \\
\text { glial reactivity [172] }\end{array}$ \\
\hline & In vivo $\mathrm{MCAO}$ (Mouse) & Probenecid $(1 \mathrm{mg} / \mathrm{ml})$ & $\begin{array}{l}\text { Probenecid reduced infarct } \\
\text { size, neurological deficit, } \\
\text { brain water content, astrocytic } \\
\text { activation and inhibited } \\
\text { HMGB1 and AQP4 expression } \\
\text { [173] }\end{array}$ \\
\hline
\end{tabular}

$M C A O$, middle cerebral arterial occlusion; 4-VO, four-vessel occlusion; $R B 2$, reactive blue 2; $B B G$, brilliant blue G; oATP, periodate-oxidized adenosine triphosphate; OGD, oxygen-glucose deprivation; N/A: not applied.

Table 2.

Key findings of $P_{2} X_{7}, P_{2} Y$, connexins and pannexins blockade in brain ischemia models. 
of chemicals through damaged plasma membranes of dying cells [178]. Activated microglia secrete pro-inflammatory mediators such as cytokines and develop phagocytic and major histocompatibility complex (MHC) class II-restricted antigen presenting characteristics. Although microglia express almost all $\mathrm{P} 2 \mathrm{X}$ members (P2X1, P2X4, P2X5, and P2X7), these receptors are expressed in different levels and contribute distinctly to neuroinflammation [148]. One of the central cytokines produced by these cells is IL-1 $\beta$, which plays essential roles in brain injury during ischemia, such as, IL-6 secretion $[89,179]$. In bone marrow-derived macrophages, P2X7 activation plays a significant role in the release of IL-1 $\beta$ [180]. In microglia, however, evidence suggests that other receptors, highlighting P2X4, may be protagonists along with P2X7 in IL-1 $\beta$ release [180]. Hence, despite the fact that purinergic biomarkers are not available, cytokines induced by P2X activation are measurable in serum and might be useful as diagnostic and prognostic indicators.

Although TH is a current standard therapy for neonatal HIE $[8,10,157,159,160]$, no serum biomarker is in current clinical use for this high-risk population. Using a serum panel of biomarkers rather than a single biomarker and combining them with acid-base values, Apgar score, clinical signs of encephalopathy, early EEG and MRI could help in identifying the infants with the highest risk of compromise. None of the proposed biomarkers, so far, has yet been established as clearly better than clinical evaluation of HIE for recruitment of infants at risk of adverse outcomes. Also, even though some of the putative biomarkers show good correlations with outcome, they do so only after the onset of the subsequent deterioration (e.g., 12 or $24 \mathrm{~h}$ or even later). In practice, this means that the search continues for a panel of biomarkers with high diagnostic and prognostic accuracy that can be identified early in the disease process to aid the bedside clinician in tailoring treatment to individual HIE newborns.

\section{List of abbreviations}

$\begin{array}{ll}\text { 4-VO } & \text { four-vessel occlusion } \\ \text { AGA } & \text { 18alpha-glycyrrhetinic acid } \\ \text { BBG } & \text { brilliant blue G } \\ \text { CALHM1 } & \text { calcium homeostasis modulator 1 } \\ \text { cAMP } & \text { cyclic adenosine monophosphate } \\ \text { CBX } & \text { carbenoxolone } \\ \text { CNS } & \text { central nervous system } \\ \text { CSF } & \text { cerebrospinal fluid } \\ \text { Cx } & \text { connexin } \\ \text { ECS } & \text { extracellular space } \\ \text { FFA } & \text { flufenamic acid } \\ \text { GJ } & \text { gap junction } \\ \text { GPCRs } & \text { G coupled protein receptors } \\ \text { HI } & \text { hypoxic-ischemia } \\ \text { HIE } & \text { hypoxic-ischemic encephalopathy } \\ \text { MCAO } & \text { middle cerebral arterial occlusion } \\ \text { MCP-1 } & \text { monocyte chemoattractant protein-1 } \\ \text { MHC } & \text { major histocompatibility complex } \\ \text { MRS } & \text { proton magnetic resonance spectroscopy } \\ \text { NFA } & \text { niflumic acid } \\ \text { oATP } & \text { periodate-oxidized adenosine triphosphate } \\ \text { OGD } & \text { oxygen-glucose deprivation }\end{array}$




$\begin{array}{ll}\text { Panx } & \text { pannexin } \\ \text { PDE } & \text { phosphodiesterase } \\ \text { PPADS } & \text { pyridoxalphosphate-6-azophenyl-2', } 4^{\prime} \text {-disulfonic acid } \\ \text { RB2 } & \text { reactive blue } 2 \\ \text { ROS } & \text { reactive oxygen species } \\ \text { SD } & \text { spreading depression } \\ \text { TBI } & \text { traumatic brain injury } \\ \text { TH } & \text { therapeutic hypothermia }\end{array}$




\section{Author details}

Tagore M. Morais-Lima ${ }^{1 \dagger}$, Joana C. Vicentini ${ }^{1 \dagger}$, Anael V.P. Alberto ${ }^{2}$, Pedro H.M. de Freitas ${ }^{1,3}$, Caio M. Perret ${ }^{1,3}$, Natiele C. da Silva Ferreira ${ }^{2}$, Deepaneeta Sarmah ${ }^{4}$, Bharati Sinha ${ }^{5,6}$, Gopika Das ${ }^{5}$, Pallab Bhattacharya ${ }^{4}$, Xin Wang ${ }^{5}$, Luiz A. Alves ${ }^{2}$ and Renato Rozental ${ }^{1,7,8 *}$

1 Centro de Ciências da Saúde, Instituto de Ciências Biomédicas, Universidade Federal do Rio de Janeiro, Rio de Janeiro, Brazil

2 Laboratório de Comunicação Celular, Fundação Oswaldo Cruz (Fiocruz), Institute Oswaldo Cruz, Rio de Janeiro, Brazil

3 Faculdade de Medicina, Programa de Anatomia Patológica, Universidade Federal do Rio de Janeiro, Rio de Janeiro, Brazil

4 Department of Pharmacology and Toxicology, National Institute of Pharmaceutical Education and Research (NIPER), Ahmedabad, India

5 Department of Neurosurgery, Harvard Medical School, Boston, MA, USA

6 Department of Pediatric Newborn Medicine, Brigham and Women's Hospital, Harvard Medical School, Boston, MA, USA

7 Centro de Desenvolvimento Tecnológico em Saúde (CDTS), Fundação Oswaldo Cruz (Fiocruz), Rio de Janeiro, Brazil

8 Department of Neuroscience, Albert Einstein College of Medicine, Bronx, NY, USA

*Address all correspondence to: renato.rozental@cdts.fiocruz.br

$\uparrow$ T.M.M-L and J.C. Vicentini contributed equally to this work.

\section{IntechOpen}

(C) 2019 The Author(s). Licensee IntechOpen. This chapter is distributed under the terms of the Creative Commons Attribution License (http://creativecommons.org/licenses/ by/3.0), which permits unrestricted use, distribution, and reproduction in any medium, provided the original work is properly cited. (cc) BY 


\section{References}

[1] Endorsement SOF. Neonatal encephalopathy and neurologic outcome, second edition. Pediatrics. 2014;133:e1482-e1488

[2] Centers for Disease Control and Prevention (CDC). Economic Costs Associated with Mental Retardation, Cerebral Palsy, Hearing Loss, and Vision Impairment-United States, 2003. MMWR Morbidity Mortal Weekly Report. 2004. Available from: https://www.cdc.gov/mmwr/preview/ $\mathrm{mmwrhtml} / \mathrm{mm} 5303 \mathrm{a} 4 . \mathrm{htm}$

[3] Dixon BJ, Reis C, Ho WM, Tang J, Zhang JH. Neuroprotective strategies after neonatal hypoxic ischemic encephalopathy. International Journal of Molecular Sciences. 2015;16:

22368-22401. Available from: http:// www.mdpi.com/1422-0067/16/9/22368

[4] Douglas-Escobar M, Weiss MD. Hypoxic-ischemic encephalopathy a review for the clinician. JAMA Pediatrics. 2015;169:397-403

[5] Lawn J, Shibuya K. No cry at birth: Global estimates of intrapartum stillbirth and intrapartum-related neonatal deaths. Bulletin of the World Health Organization. 2005;014506:409-418. Available from: http://www.who.int/bulletin/ volumes/83/6/409.pdf

[6] Bryce J, Boschi-Pinto C, Shibuya $\mathrm{K}$, Black RE. WHO estimates of the causes of death in children. Lancet. 2005;365:1147-1152

[7] Eunson P. The long-term health, social, and financial burden of hypoxic-ischaemic encephalopathy. Developmental Medicine and Child Neurology. 2015;57:48-50

[8] Maede Y, Tokuhisa T, Matsui T, Ibara S, Ishihara C, Minakami H. Outcome of infants with hypoxic ischemic encephalopathy treated with brain hypothermia. The Journal of Obstetrics and Gynaecology Research. 2014;41:229-237

[9] Strauss D, Brooks J, Rosenbloom L, Shavelle R. Life expectancy in cerebral palsy: An update. Developmental Medicine and Child Neurology. 2008;50:487-493

[10] Davidson JO, Wassink G, van den Heuij LG, Bennet L, Gunn AJ. Therapeutic hypothermia for neonatal hypoxic-ischemic encephalopathyWhere to from here? Frontiers in Neurology. 2015;6:198. Available from: https://www.frontiersin.org/ article/10.3389/fneur.2015.00198

[11] Wassink G, Gunn ER, Drury PP, Bennet L, Gunn AJ. The mechanisms and treatment of asphyxial encephalopathy. Frontiers in Neuroscience. 2014;8:1-11

[12] Volpe JJ. Neonatal encephalopathy: An inadequate term for hypoxicischemic encephalopathy. Annals of Neurology. 2012;72:156-166

[13] Ferriero DM. Neonatal brain injury. The New England Journal of Medicine. 2004;351:1985-1995

[14] Badawi N, Kurinczuk JJ, Keogh JM, Alessandri LM, O’Sullivan F, Burton $\mathrm{PR}$, et al. Intrapartum risk factors for newborn encephalopathy: The Western Australian case-control study. BMJ. 1998;317:1554-1558. Available from: http://www.ncbi.nlm.nih.gov/ pubmed/9836653\%0Ahttp://www. pubmedcentral.nih.gov/articlerender. fcgi?artid=PMC28733

[15] Harteman JC, Nikkels PGJ, Benders MJNL, Kwee A, Groenendaal F, De Vries LS. Placental pathology in full-term infants with hypoxic-ischemic neonatal encephalopathy and association with 
The Role of Purinergic Signaling in the Pathophysiology of Perinatal Hypoxic-Ischemic...

magnetic resonance imaging pattern of brain injury. The Journal of Pediatrics. 2013;163:968-975.e2. DOI: 10.1016/j. jpeds.2013.06.010

[16] Ramos-Cabrer P, Campos F, Sobrino $\mathrm{T}$, Castillo J. Targeting the ischemic penumbra. Stroke. 2011;42:7-11

[17] Melani A, Pugliese AM, Coppi E, Corradetti R, Pedata F, Dettori I, et al. Purinergic signalling in brain ischemia. Neuropharmacology. 2015;104:105-130. DOI: 10.1016/j.neuropharm.2015.11.007

[18] Burnstock G. An introduction to the roles of purinergic signalling in neurodegeneration, neuroprotection and neuroregeneration.

Neuropharmacology. 2016;104:4-17. DOI: 10.1016/j.neuropharm.2015.05.031

[19] de Freitas PHM, da Silva Ferreira NC, Fioravante-Rezende JG, de Menezes Santos L, Alves LA, Rozental R. Dispelling myths about connexins, pannexins and $\mathrm{P} 2 \mathrm{X} 7$ in hypoxicischemic central nervous system. Neuroscience Letters. 2019;695:76-85. Available from: http://www. sciencedirect.com/science/article/pii/ S0304394017309539

[20] North RA. Molecular physiology of P2X receptors. Physiological Reviews. 2015;82:1013-1067

[21] North RA, Jarvis MF. P2X receptors as drug targets. Molecular Pharmacology. 2013;83:759-769. Available from: http://molpharm.aspetjournals.org/ content/83/4/759.abstract

[22] von Kügelgen I, Hoffmann K. Pharmacology and structure of P2Y receptors. Neuropharmacology.

2016;104:50-61. Available from: https:// www.sciencedirect.com/science/article/ pii/S0028390815301532?via\%3Dihub

[23] Bona E, Ådén U, Gilland E, Fredholm BB, Hagberg H. Neonatal cerebral hypoxia-ischemia: The effect of adenosine receptor antagonists. Neuropharmacology. 1997;36:1327-1338. Available from: https:// www.sciencedirect.com/science/article/ pii/S0028390897001391?via\%3Dihub

[24] Halle JN, Kasper CE, Gidday JM, Koos BJ. Enhancing adenosine A1 receptor binding reduces hypoxicischemic brain injury in newborn rats. Brain Research. 1997;759:309-3012. Available from: http://www. sciencedirect.com/science/article/pii/ S0006899397003648

[25] Bari F, Tóth R, Makra P, Bálint AR, Krizbai IA, Farkas AE, et al. Largeconductance $\mathrm{Ca}^{2+}$-activated potassium channels are potently involved in the inverse neurovascular response to spreading depolarization. Neurobiology of Disease. 2018;119:41-52. DOI: 10.1016/j.nbd.2018.07.026

[26] Risher WC, Croom D, Kirov SA. Persistent astroglial swelling accompanies rapid reversible dendritic injury during stroke-induced spreading depolarizations. Glia. 2012;60:1709-1720

[27] Dreier JP. The role of spreading depression, spreading depolarization and spreading ischemia in neurological disease. Nature Medicine. 2011;17:439. DOI: $10.1038 / \mathrm{nm} .2333$

[28] Hartings JA, Shuttleworth CW, Kirov SA, Ayata C, Hinzman JM, Foreman $\mathrm{B}$, et al. The continuum of spreading depolarizations in acute cortical lesion development: Examining Leão's legacy. Journal of Cerebral Blood Flow and Metabolism. 2017;37:1571-1594. Available from: https://www.ncbi.nlm.nih.gov/ pubmed/27328690

[29] Yu Y, Santos LM, Mattiace LA, Costa ML, Ferreira LC, Benabou K, et al. Reentrant spiral waves of spreading depression cause macular degeneration in hypoglycemic chicken retina. Proceedings of the National Academy of Sciences of the United States of America. 2012;109: 
2585-2589. Available from: https://www. ncbi.nlm.nih.gov/pubmed/22308470

[30] Martins-Ferreira H, Nedergaard M, Nicholson C. Perspectives on spreading depression. Brain Research Reviews. 2000;32:215-234

[31] Shibata M, Suzuki N. Exploring the role of microglia in cortical spreading depression in neurological disease. Journal of Cerebral Blood Flow and Metabolism. 2017;37:1182-1191. Available from: https://www.ncbi.nlm. nih.gov/pubmed/28155572

[32] Seidel JL, Escartin C, Ayata C, Bonvento G, Shuttleworth CW. Multifaceted roles for astrocytes in spreading depolarization: A target for limiting spreading depolarization in acute brain injury? Glia. 2016;64:5-20. Available from: https://www.ncbi.nlm. nih.gov/pubmed/26301517

[33] Drury AN, Szent-Györgyi A. The physiological activity of adenine compounds with especial reference to their action upon the mammalian heart. The Journal of Physiology. 1929;68:213-237

[34] Silva CG, Métin C, Fazeli W, Machado NJ, Darmopil S, Launay P-S, et al. Adenosine receptor antagonists including caffeine alter fetal brain development in mice. Science Translational Medicine. 2013;5:197ra104

[35] Porkka-Heiskanen T, Strecker RE, Thakkar M, Bjørkum AA, Greene RW, McCarley RW. Adenosine: A mediator of the sleep-inducing effects of prolonged wakefulness. Science (80-). 1997;276:1265-1268

[36] Fields RD, Burnstock G. Purinergic signalling in neuron-glia interactions. Nature Reviews. Neuroscience.

2006;7:423

[37] Burnstock G. Purinergic signalling: Therapeutic developments.
Frontiers in Pharmacology. 2017;8:661. Available from: https://www. frontiersin.org/article/10.3389/ fphar.2017.00661

[38] Burnstock G. Discovery of purinergic signalling, the initial resistance and current explosion of interest. British Journal of Pharmacology. 2012;167:238-255

[39] Jacobson KA, Jayasekara MPS, Costanzi S. Molecular structure of P2Y receptors: Mutagenesis, modeling, and chemical probes. Wiley interdisciplinary reviews. Membrane transport and signaling. 2012;1:WMTS68

[40] Kawate T, Michel JC, Birdsong WT, Gouaux E. Crystal structure of the ATPgated P2X4 ion channel in the closed state. Nature. 2009;460:592

[41] Alves L, da Silva J, Ferreira D, Fidalgo-Neto A, Teixeira P, de Souza C, et al. Structural and molecular modeling features of P2X receptors. International Journal of Molecular Sciences. 14 Mar 2014;15(3):4531-4549. Available from: http://dx.doi.org/10.3390/ ijms150345312014

[42] Piirainen H, Ashok Y, Nanekar RT, Jaakola V-P. Structural features of adenosine receptors: From crystal to function. Biochimica et Biophysica Acta-Biomembranes. 2011;1808:1233-1244

[43] Alberto AVP, Faria RX, Couto CGC, Ferreira LGB, Souza CAM, Teixeira PCN, et al. Is pannexin the pore associated with the P2X7 receptor? Naunyn-Schmiedeberg's Archives of Pharmacology. 2013;386:775-787. DOI: $10.1007 /$ s00210-013-0868-x

[44] Hattori M, Gouaux E. Molecular mechanism of ATP binding and ion channel activation in $\mathrm{P} 2 \mathrm{X}$ receptors. Nature. 2012;485:207 
The Role of Purinergic Signaling in the Pathophysiology of Perinatal Hypoxic-Ischemic... DOI: http://dx.doi.org/10.5772/intechopen.86425

[45] Martín A, Domercq M, Matute C. Inflammation in stroke: The role of cholinergic, purinergic and glutamatergic signaling. Therapeutic Advances in Neurological Disorders. 2018;11:1756286418774267

[46] Virginio C, MacKenzie A, Rassendren FA, North RA, Surprenant A. Pore dilation of neuronal P2X receptor channels. Nature Neuroscience. 1999;2:315

[47] Suh B-C, Kim J-S, Namgung U, Ha H, Kim K-T. P2X7 nucleotide receptor mediation of membrane pore formation and superoxide generation in human promyelocytes and neutrophils. Journal of Immunology. 2001;166:6754-6763

[48] Kawate T, Robertson JL, Li M, Silberberg SD, Swartz KJ. Ion access pathway to the transmembrane pore in P2X receptor channels. The Journal of General Physiology. 2011;137:579-590

[49] Soares-Bezerra RJ, Ferreira NC, Alberto AV, Bonavita AG, Fidalgo-Neto AA, Calheiros AS, et al. An improved method for P2X7R antagonist screening. PLoS One. 2015;10(5):e0123089

[50] Bhaskaracharya A, Dao-Ung P, Jalilian I, Spildrejorde M, Skarratt KK, Fuller SJ, et al. Probenecid blocks human $\mathrm{P} 2 \mathrm{X} 7$ receptorinduced dye uptake via a pannexin-1 independent mechanism. PLoS One. 2014;9(3):e93058

[51] Honore P, Donnelly-Roberts D, Namovic MT, Hsieh G, Zhu CZ, Mikusa JP, et al. A-740003 [N-(1$\{$ [(cyanoimino) (5-quinolinylamino) methyl]amino -2,2-dimethylpropyl)2-(3,4-dimethoxyphenyl)acetamide], a novel and selective $\mathrm{P} 2 \mathrm{X} 7$ receptor antagonist, dose-dependently reduces neuropathic pain in the rat. The Journal of Pharmacology and Experimental Therapeutics. 2006;319(3):1376-1385
[52] Ye ZC, Wyeth MS, BaltanTekkok S, Ransom BR. Functional hemichannels in astrocytes: A novel mechanism of glutamate release. The Journal of Neuroscience. 2003;23(9):3588-3596

[53] Chever O, Lee CY, Rouach N. Astroglial connexin43 hemichannels tune basal excitatory synaptic transmission. The Journal of Neuroscience. 2014;34(34):11228-11232

[54] Voytenko LP, Lushnikova IV, Savotchenko AV, Isaeva EV, Skok MV, Lykhmus OY, et al. Hippocampal GABAergic interneurons coexpressing alpha7-nicotinic receptors and connexin-36 are able to improve neuronal viability under oxygenglucose deprivation. Brain Research. 2015;1616:134-145

[55] Lin JH, Lou N, Kang N, Takano T, Hu F, Han X, et al. A central role of connexin 43 in hypoxic preconditioning. The Journal of Neuroscience. 2008;28(3):681-695

[56] Burnstock G. Purinergic signalling: From discovery to current developments. Experimental Physiology. 2014;99:16-34

[57] Virginio C, North RA, Surprenant A. Calcium permeability and block at homomeric and heteromeric P2X2 and $\mathrm{P} 2 \mathrm{X} 3$ receptors, and $\mathrm{P} 2 \mathrm{X}$ receptors in rat nodose neurones. The Journal of Physiology. 1998;510:27-35

[58] Virginio C, Robertson G, Surprenant A, North RA. Trinitrophenylsubstituted nucleotides are potent antagonists selective for P2X1, $\mathrm{P} 2 \mathrm{X} 3$, and heteromeric $\mathrm{P} 2 \mathrm{X} 2 / 3$ receptors. Molecular Pharmacology. 1998;53:969-973

[59] Taruno A. ATP release channels. International Journal of Molecular Sciences. 2018;19:808 
[60] Melani A, Corti F, Stephan H, Müller CE, Donati C, Bruni P, et al. Ecto-ATPase inhibition: ATP and adenosine release under physiological and ischemic in vivo conditions in the rat striatum. Experimental Neurology. 2012;233:193-204

[61] Kitagawa H, Mori A, Shimada J, Mitsumoto Y, Kikuchi T. Intracerebral adenosine infusion improves neurological outcome after transient focal ischemia in rats. Neurological Research. 2002;24:317-323

[62] Ådén U, Halldner L, Lagercrantz H, Dalmau I, Ledent C, Fredholm BB. Aggravated brain damage after hypoxic ischemia in immature adenosine A2A knockout mice. Stroke. 2003;34:739-744

[63] Domercq M, Perez-Samartin A, Aparicio D, Alberdi E, Pampliega O, Matute C. P2X7 receptors mediate ischemic damage to oligodendrocytes. Glia. 2010;58:730-740

[64] Barnes PJ. Theophylline. American Journal of Respiratory and Critical Care Medicine. 2013;188:901-906

[65] Sattin A, Rall TW, Zanella J. Regulation of cyclic adenosine 3' $5^{\prime}$-monophosphate levels in guinea-pig cerebral cortex by interaction of alpha adrenergic and adenosine receptor activity. The Journal of Pharmacology and Experimental Therapeutics.

1975;192:22-32

[66] Weisman GA, Camden JM, Peterson TS, Ajit D, Woods LT, Erb L. P2 receptors for extracellular nucleotides in the central nervous system: role of $\mathrm{P} 2 \mathrm{X} 7$ and $\mathrm{P} 2 \mathrm{Y}_{2}$ receptor interactions in neuroinflammation. Molecular Neurobiology. 2012;46:96-113

[67] Wang L-Y, Cai W-Q, Chen P-H, Deng Q-Y, Zhao C-M. Downregulation of $\mathrm{P} 2 \mathrm{X} 7$ receptor expression in rat oligodendrocyte precursor cells after hypoxia ischemia. Glia. 2009;57:307-319
[68] Rodriguez-Alvarez N, JimenezMateos EM, Engel T, Quinlan S, Reschke CR, Conroy RM, et al. Effects of $\mathrm{P} 2 \mathrm{X} 7$ receptor antagonists on hypoxia-induced neonatal seizures in mice. Neuropharmacology. 2017;116:351-363. Available from: http://www.sciencedirect.com/science/ article/pii/S0028390817300059

[69] Wixey JA, Reinebrant HE, Carty ML, Buller KM. Delayed P2X4R expression after hypoxia-ischemia is associated with microglia in the immature rat brain. Journal of Neuroimmunology. 2009;212:35-43

[70] Cavaliere F, Dinkel K, Reymann K. Microglia response and P2 receptor participation in oxygen/glucose deprivation-induced cortical damage. 2005;136:615-623. Available from: http://www.sciencedirect.com/science/ article/pii/S0306452205004549

[71] Kaczmarek-Hajek K, Zhang J, Kopp R, Grosche A, Rissiek B, Saul A, et al. Re-evaluation of neuronal P2X7 expression using novel mouse models and a P2X7-specific nanobody. Elife. 2018;7:e36217. Available from: https:// doi.org/10.7554/eLife.36217

[72] Dbouk HA, Mroue RM, El-Sabban ME, Talhouk RS. Connexins: A myriad of functions extending beyond assembly of gap junction channels. Cell Communication and Signaling: CCS. 2009;7:4. Available from: https://www.ncbi.nlm.nih.gov/ pubmed/19284610

[73] Donahue HJ, Qu RW, Genetos DC. Joint diseases: From connexins to gap junctions. Nature Reviews Rheumatology. 2017;14:42. DOI: 10.1038/nrrheum.2017.204

[74] Lapato AS, Tiwari-Woodruff SK. Connexins and pannexins: At the junction of neuro-glial homeostasis $\&$ disease. Journal of Neuroscience Research. 2018;96:31-44. Available 
The Role of Purinergic Signaling in the Pathophysiology of Perinatal Hypoxic-Ischemic... DOI: http://dx.doi.org/10.5772/intechopen.86425

from: https://www.ncbi.nlm.nih.gov/ pubmed/28580666

[75] Söhl G, Willecke K. Gap junctions and the connexin protein family. Cardiovascular Research. 2004;62:228-232. DOI: 10.1016/j. cardiores.2003.11.013

[76] Aasen T, Johnstone S, Vidal-Brime L, Lynn KS, Koval M. Connexins: Synthesis, post-translational modifications, and trafficking in health and disease. International Journal of Molecular Sciences. 2018;19:1296. Available from: https://www.ncbi.nlm. nih.gov/pubmed/29701678

[77] Solan JL, Lampe PD. Connexin43 phosphorylation: Structural changes and biological effects. The Biochemical Journal. 2009;419:261-272. Available from: https://www.ncbi.nlm.nih.gov/ pubmed/19309313

[78] Grosely R, Sorgen PL. A history of gap junction structure: Hexagonal arrays to atomic resolution. Cell Communication \& Adhesion. 2013;20:11-20. Available from: https://www.ncbi.nlm.nih.gov/ pubmed/23469928

[79] Sinyuk M, Mulkearns-Hubert EE, Reizes O, Lathia J. Cancer connectors: Connexins, gap junctions, and communication. Frontiers in Oncology. 2018;8:646. Available from: https://www.ncbi.nlm.nih.gov/ pubmed/30622930

[80] Xing L, Yang T, Cui S, Chen G. Connexin hemichannels in astrocytes: Role in CNS disorders. Frontiers in Molecular Neuroscience. 2019;12:23. Available from: https:// www.ncbi.nlm.nih.gov/pmc/articles/ PMC6372977/

[81] Kim Y, Davidson JO, Green CR, Nicholson LFB, O'Carroll SJ, Zhang J. Connexins and pannexins in cerebral ischemia. Biochimica et Biophysica
Acta-Biomembranes. 2018;1860: 224-236. Available from: http://www. sciencedirect.com/science/article/pii/ S0005273617301001

[82] Zhao Y, Xin Y, He Z, Hu W. Function of connexins in the interaction between glial and vascular cells in the central nervous system and related neurological diseases. Neural Plasticity. 2018;2018:6323901. Available from: https://www.ncbi.nlm.nih.gov/ pubmed/29983707

[83] Galinsky R, Davidson JO, Dean JM, Green CR, Bennet L, Gunn AJ. Glia and hemichannels: Key mediators of perinatal encephalopathy. Neural Regeneration Research. 2018;13:181-189. Available from: https://www.ncbi.nlm. nih.gov/pubmed/29557357

[84] Davidson JO, Green CR, Bennet L, Gunn AJ. Battle of the hemichannelsConnexins and pannexins in ischemic brain injury. International Journal of Developmental Neuroscience. 2015;45:66-74. DOI: 10.1016/j. ijdevneu.2014.12.007

[85] Davidson JO, Green CR, Bennet L, Nicholson LF, Danesh-Meyer H, O'Carroll SJ, et al. A key role for connexin hemichannels in spreading ischemic brain injury. Current Drug Targets. 2013;14:36-46. Available from: http://www.eurekaselect.com/ node/105915/article

[86] Mallard C, Davidson JO, Tan S, Green CR, Bennet L, Robertson NJ, et al. Astrocytes and microglia in acute cerebral injury underlying cerebral palsy associated with preterm birth. Pediatric Research. 2013;75:234. DOI: 10.1038/pr.2013.188

[87] Decrock E, De Vuyst E, Vinken M, Van Moorhem M, Vranckx K, Wang N, et al. Connexin 43 hemichannels contribute to the propagation of apoptotic cell death in a rat $\mathrm{C} 6$ glioma cell model. Cell Death and 
Differentiation. 2008;16:151. DOI: $10.1038 /$ cdd. 2008.138

[88] Spray DC, Ye Z-C, Ransom BR. Functional connexin "hemichannels": A critical appraisal. Glia. 2006;54: 758-773. Available from: https:// onlinelibrary.wiley.com/doi/ abs/10.1002/glia.20429

[89] Le Feuvre RA, Brough D, Touzani O, Rothwell NJ. Role of P2X7 receptors in ischemic and excitotoxic brain injury in vivo. Journal of Cerebral Blood Flow and Metabolism. 2003;23:381-384. DOI: 10.1097/01. WCB.0000048519.34839.97

[90] Dosch M, Gerber J, Jebbawi F, Beldi G. Mechanisms of ATP release by inflammatory cells. International Journal of Molecular Sciences. 2018;19:1222. Available from: https://www.ncbi.nlm.nih.gov/ pubmed/29669994

[91] O’Carroll SJ, Alkadhi M, Nicholson LFB, Green CR. Connexin 43 mimetic peptides reduce swelling, astrogliosis, and neuronal cell death after spinal cord injury. Cell Communication \& Adhesion. 2008;15:27-42. DOI: $10.1080 / 15419060802014164$

[92] Danesh-Meyer HV, Huang R, Nicholson LFB, Green CR. Connexin 43 antisense oligodeoxynucleotide treatment down-regulates the inflammatory response in an in vitro interphase organotypic culture model of optic nerve ischaemia. Journal of Clinical Neuroscience. 2008;15:1253-1263. DOI: 10.1016/j.jocn.2008.08.002

[93] Nakase T, Fushiki S, Naus CCG. Astrocytic gap junctions composed of connexin 43 reduce apoptotic neuronal damage in cerebral ischemia. Stroke. 2003;34:1987-1993

[94] Naus CCG, Nakase T, Fushiki S. Astrocytic gap junctions composed of connexin 43 reduce apoptotic neuronal damage in cerebral ischemia. Stroke. 2003;34:413-417. Available from: http://www.ncbi.nlm.nih.gov/ pubmed/12843358

[95] Sosinsky GE, Boassa D, Dermietzel R, Duffy HS, Laird DW, MacVicar B, et al. Pannexin channels are not gap junction hemichannels. Channels. 2011;5:193-197. DOI: 10.4161/ chan.5.3.15765

[96] Penuela S, Bhalla R, Gong X-Q, Cowan KN, Celetti SJ, Cowan BJ, et al. Pannexin 1 and pannexin 3 are glycoproteins that exhibit many distinct characteristics from the connexin family of gap junction proteins. Journal of Cell Science. 2007;120:3772-3783. Available from: http://jcs.biologists.org/ content/120/21/3772.abstract

[97] Penuela S, Gehi R, Laird DW. The biochemistry and function of pannexin channels. Biochimica et Biophysica Acta-Biomembranes. 2013;1828: 15-22. Available from: http://www. sciencedirect.com/science/article/pii/ S0005273612000211

[98] Boassa D, Ambrosi C, Qiu F, Dahl G, Gaietta G, Sosinsky G. Pannexin1 channels contain a glycosylation site that targets the hexamer to the plasma membrane. The Journal of Biological Chemistry. 2007;282:31733-31743. Available from: http://www.jbc.org/ content/282/43/31733.abstract

[99] Whyte-Fagundes P, Zoidl G. Mechanisms of pannexin 1 channel gating and regulation. Biochimica et Biophysica Acta-Biomembranes. 2018;1860:65-71. Available from: http:// www.sciencedirect.com/science/article/ pii/S0005273617302341

[100] MacVicar BA, Thompson RJ. Nonjunction functions of pannexin-1 channels. Trends in Neurosciences. 2010;33:93-102. DOI: 10.1016/j. tins.2009.11.007 
The Role of Purinergic Signaling in the Pathophysiology of Perinatal Hypoxic-Ischemic... DOI: http://dx.doi.org/10.5772/intechopen.86425

[101] Pelegrin P, Surprenant A.

Pannexin-1 mediates large pore formation and interleukin $-1 \beta$ release by the ATP-gated $\mathrm{P} 2 \mathrm{X} 7$ receptor. The EMBO Journal. 2006;25:5071-5082.

Available from: http://emboj.embopress. org/content/25/21/5071.abstract

[102] Kovalzon VM, Moiseenko LS, Ambaryan AV, Kurtenbach S, Shestopalov VI, Panchin YV. Sleepwakefulness cycle and behavior in pannexin1 knockout mice. Behavioural Brain Research. 2017;318:24-27. Available from: http://www.sciencedirect.com/ science/article/pii/S016643281630794X

[103] Shestopalov VI. Pannexins are potential new players in the regulation of cerebral homeostasis during sleepwake cycle. Frontiers in Cellular Neuroscience. 2017;11:210. DOI: 10.3389/fncel.2017.00210

[104] Scemes E, Iglesias R, Alberto AP, Roque A, Dahl G, Spray DC, et al. $\mathrm{P} 2 \mathrm{X} 7$ receptor-pannexin 1 complex: Pharmacology and signaling. American journal of physiology. Cell physiology. 2008;295:C752-C760

[105] Yanguas SC, Willebrords J, Johnstone SR, Maes M, Decrock E, de BM, et al. Pannexin1 as mediator of inflammation and cell death. Biochimica et Biophysica ActaMolecular Cell Research. 2017;1864:5161. Available from: http://www. sciencedirect.com/science/article/pii/ S0167488916302609

[106] Gowers WR. Clinical lectures on the borderland of epilepsy. III.migraine. British Medical Journal. 1906;2:1617-1622

[107] Leao AAP. Spreading depression of activity in the cerebral cortex. Journal of Neurophysiology. 1944;7:359-390. DOI: 10.1152/jn.1944.7.6.359

[108] Charles a, Brennan KC. Cortical spreading depression-New insights and persistent questions. Cephalalgia. 2009;29:1115-1124

[109] Lauritzen M, Dreier JP, Fabricius M, Hartings JA, Graf R, Strong AJ. Clinical relevance of cortical spreading depression in neurological disorders: Migraine, malignant stroke, subarachnoid and intracranial hemorrhage, and traumatic brain injury. Journal of Cerebral Blood Flow and Metabolism. 2011;31:17-35

[110] Gorji A, Zahn PK, Pogatzki EM, Speckmann E-J. Spinal and cortical spreading depression enhance spinal cord activity. Neurobiology of Disease. 2004;15:70-79

[111] Streit DS, Ferreira Filho CR, Martins-Ferreira H. Spreading depression in isolated spinal cord. Journal of Neurophysiology. 1995;74:888-890

[112] Van Harreveld A, Khattab FI. Changes in cortical extracellular space during spreading depression investigated with the electron microscope. Journal of Neurophysiology. 1967;30:911-929

[113] Martins-Ferreira H, De Oliveira Castro G, Struchiner CJ, Rodrigues PS. Circling spreading depression in isolated chick retina. Journal of Neurophysiology. 1974;37:773-784. DOI: 10.1152/jn.1974.37.4.773

[114] Pietrobon D, Moskowitz MA. Chaos and commotion in the wake of cortical spreading depression and spreading depolarizations. Nature Reviews. Neuroscience. 2014;15:379. DOI: $10.1038 / \mathrm{nrn} 3770$

[115] Nedergaard M, AJL C, Goldman SA. Gap junctions are required for the propagation of spreading depression. Journal of Neurobiology. 1995;28:

433-444. DOI: $10.1002 /$

neu. 480280404 
[116] Choudhuri R, Cui MDL, Yong C, Bowyer S, Klein RM, Welch MD KMA, et al. Cortical spreading depression and gene regulation: Relevance to migraine. Annals of Neurology. 2002;51:499-506. DOI: 10.1002/ ana.10158

[117] Heinemann U, Dieter Lux H. Ceiling of stimulus induced rises in extracellular potassium concentration in the cerebral cortex of cat. Brain Research. 1977;120:231-249

[118] Enger R, Nagelhus EA, Vindedal GF, Jensen V, Tang W, Johannes Helm P, et al. Dynamics of ionic shifts in cortical spreading depression. Cerebral Cortex. 2015;25:4469-4476. DOI: 10.1093/ cercor/bhv054

[119] Basarsky TA, Duffy SN, Andrew $\mathrm{RD}$, MacVicar BA. Imaging spreading depression and associated intracellular calcium waves in brain slices. The Journal of Neuroscience. 1998;18:7189-7199. Available from: http://www.jneurosci. org/content/18/18/7189.abstract

[120] Shroff RC, Shanahan CM. The vascular biology of calcification. Seminars in Dialysis. 2007;20:103-109

[121] Torrente D, Mendes-da-Silva RF, Lopes AAC, González J, Barreto GE, Guedes RCA. Increased calcium influx triggers and accelerates cortical spreading depression in vivo in male adult rats. Neuroscience Letters.

2014;558:87-90. Available from: http:// www.sciencedirect.com/science/article/ pii/S0304394013009956

[122] Murphy TH, Li P, Betts K, Liu R. Two-photon imaging of stroke onset in vivo reveals that NMDA-receptor independent ischemic depolarization is the major cause of rapid reversible damage to dendrites and spines. The Journal of Neuroscience. 2008;28:1756-1772

[123] Dietz RM, Weiss JH, Shuttleworth CW. $\mathrm{Zn}^{2+}$ influx is critical for some forms of spreading depression in brain slices. The Journal of Neuroscience. 2008;28:8014-8024

[124] Chuquet J, Hollender L, Nimchinsky EA. High-resolution in vivo imaging of the neurovascular unit during spreading depression. The Journal of Neuroscience. 2007;27:4036-4044

[125] Cotrina ML, Lin JHC, AlvesRodrigues A, Liu S, Li J, Azmi-Ghadimi $\mathrm{H}$, et al. Connexins regulate calcium signaling by controlling ATP release. Proceedings of the National Academy of Sciences of the United States of America. 1998;95:15735-15740

[126] Osipchuk Y, Cahalan M. Cell-tocell spread of calcium signals mediated by ATP receptors in mast cells. Nature. 1992;359:241-244. Available from: https://doi.org/10.1038/359241a0. 1992:241-244

[127] Palmer RK, Yule DI, Shewach DS, Williams JA, Fisher SK. Paracrine mediation of calcium signaling in human SK-N-MCIXC neuroepithelioma cells. The American journal of physiology. 1996;271:C43-C53. DOI: 10.1152/ajpcell.1996.271.1.C43

[128] Schlosser SF, Burgstahler AD, Nathanson $\mathrm{MH}$. Isolated rat hepatocytes can signal to other hepatocytes and bile duct cells by release of nucleotides. Proceedings of the National Academy of Sciences. 1996;93:9948-9953. Available from: http://www.pnas.org/ content/93/18/9948.abstract

[129] Steffensen AB, Sword J, Croom D, Kirov SA, MacAulay N. Chloride cotransporters as a molecular mechanism underlying spreading depolarization-induced dendritic beading. The Journal of Neuroscience. 2015;35:12172-12187

[130] Greenwood SM, Mizielinska SM, Frenguelli BG, Harvey J, Connolly 
The Role of Purinergic Signaling in the Pathophysiology of Perinatal Hypoxic-Ischemic... DOI: http://dx.doi.org/10.5772/intechopen.86425

CN. Mitochondrial dysfunction and dendritic beading during neuronal toxicity. The Journal of Biological Chemistry. 2007;282:26235-26244

[131] Jarvis CR. Anoxic depolarization mediates acute damage independent of glutamate in neocortical brain slices. Cerebral Cortex. 2002;11:249-259

[132] Obeidat AS, Jarvis CR, Andrew RD. Glutamate does not mediate acute neuronal damage after spreading depression induced by $\mathrm{O}_{2}$ /glucose deprivation in the hippocampal slice. Journal of Cerebral Blood Flow \& Metabolism. 2000;20:412-422. Available from: https://doi. org/10.1097/00004647-20000200000024

[133] Hinzman JM, DiNapoli VA, Mahoney EJ, Gerhardt GA, Hartings JA. Spreading depolarizations mediate excitotoxicity in the development of acute cortical lesions. Experimental Neurology. 2015;267:243-253

[134] Melani A, Turchi D, Vannucchi MG, Cipriani S, Gianfriddo M, Pedata F. ATP extracellular concentrations are increased in the rat striatum during in vivo ischemia. Neurochemistry International. 2005;47:442-448

[135] Bargiotas P, Muhammad S, Rahman M, Jakob N, Trabold R, Fuchs E, et al. Connexin 36 promotes cortical spreading depolarization and ischemic brain damage. Brain Research. 2012;1479:80-85

[136] Dahl G, Qiu F, Wang J. The bizarre pharmacology of the ATP release channel pannexin1. Neuropharmacology. 2013;75:583-593

[137] Pfanner N, Warscheid B, Wiedemann N. Mitochondrial proteins: From biogenesis to functional networks. Nature Reviews Molecular Cell Biology. 2019;20:267-284.

Available from: https://doi.org/10.1038/ s41580-018-0092-0
[138] Ly JD, Grubb DR, Lawen A. The mitochondrial membrane potential $(\Delta \psi \mathrm{m})$ in apoptosis: An update. Apoptosis. 2003;8:115-128

[139] Friedman JR, Nunnari J. Mitochondrial form and function.

Nature. 2014;505:335

[140] Solaini G, Baracca A, Lenaz G, Sgarbi G. Hypoxia and mitochondrial oxidative metabolism. Biochimica et Biophysica Acta-Bioenergetics. 2010;1797:1171-1177

[141] Oliver CN, Starke-Reed PE, Stadtman ER, Liu GJ, Carney JM, Floyd RA. Oxidative damage to brain proteins, loss of glutamine synthetase activity, and production of free radicals during ischemia/reperfusion-induced injury to gerbil brain. Proceedings of the National Academy of Sciences. 1990;87:5144-5147

[142] Lu Y, Tucker D, Dong Y, Zhao N, Zhuo X, Zhang Q. Role of mitochondria in neonatal hypoxic-ischemic brain injury. Journal of neuroscience and rehabilitation. 2015;2:1-14

[143] Kristián T. Metabolic stages, mitochondria and calcium in hypoxic/ ischemic brain damage. Cell Calcium. 2004;36:221-233

[144] Scemes E, Spray DC. Extracellular $\mathrm{K}^{+}$and astrocyte signaling via connexin and pannexin channels. Neurochemical Research. 2012;37:2310-2316

[145] Farahani R, Pina-Benabou MH, Kyrozis A, Siddiq A, Barradas PC, Chiu $\mathrm{FC}$, et al. Alterations in metabolism and gap junction expression may determine the role of astrocytes as "good Samaritans" or executioners. Glia. 2005;50:351-361

[146] Herreras O, Largo C, Ibarz JM, Somjen GG, Martin del Rio R. Role of neuronal synchronizing mechanisms in the propagation of spreading depression 
in the in vivo hippocampus. The Journal of Neuroscience. 1994;14:7087-7098

[147] Wu Q, Chen W, Sinha B, Tu Y, Manning S, Thomas N, et al.

Neuroprotective agents for neonatal hypoxic-ischemic brain injury. Drug Discovery Today. 2015;20:1372-1381. Available from: http://europepmc.org/ abstract/MED/26360053

[148] Liu F, Mccullough LD. Inflammatory responses in hypoxic ischemic encephalopathy. Acta Pharmacologica Sinica. 2013;34:1121-1130. DOI: 10.1038/ aps.2013.89

[149] Ziemka-Nalecz M, Jaworska J, Zalewska T. Insights into the neuroinflammatory responses after neonatal hypoxia-ischemia. Journal of Neuropathology \& Experimental Neurology. 2017;76:644-654. Available from: https://doi.org/10.1093/jnen/ nlx046

[150] Sinha B et al. Protection of melatonin in experimental models of newborn hypoxic-ischemic brain injury through MT1 receptor. Journal of Pineal Research. 2018;64:e12443. DOI: 10.1111/jpi.12443

[151] Shigemoto-Mogami Y, Koizumi S, Tsuda M, Ohsawa K, Kohsaka $\mathrm{S}$, et al. Mechanisms underlying extracellular ATP-evoked interleukin-6 release in mouse microglial cell line, MG-5. Journal of Neurochemistry. 2001;78:1339-1349. Available from: https://onlinelibrary.wiley.com/doi/ abs/10.1046/j.1471-4159.2001.00514.x

[152] Inoue K. Microglial activation by purines and pyrimidines. Glia. 2001;78:1339-1349. Available from: https://onlinelibrary.wiley.com/doi/ abs/10.1002/glia.10150

[153] Li F, Wang L, Li J-W, Gong M, He L, Feng R, et al. Hypoxia induced amoeboid microglial cell activation in postnatal rat brain is mediated by ATP receptor P2X4. BMC Neuroscience.
2011;12:111. Available from: https://doi. org/10.1186/1471-2202-12-111

[154] Aly H, Khashaba MT, El-Ayouty M, El-Sayed O, Hasanein BM. IL-1 $\beta$, IL- 6 and TNF- $\alpha$ and outcomes of neonatal hypoxic ischemic encephalopathy. Brain \& development. 2006;28:178-182. Available from: http:// www.sciencedirect.com/science/article/ pii/S0387760405001233

[155] Chiesa C, Pellegrini G, Panero A, De Luca T, Assumma M, Signore F, et al. Umbilical cord interleukin-6 levels are elevated in term neonates with perinatal asphyxia. European Journal of Clinical Investigation. 2003;33:352-358. DOI: 10.1046/j.1365-2362.2003.01136.x

[156] Sävman K, Blennow M, Gustafson K, Tarkowski E, Hagberg $\mathrm{H}$. Cytokine response in cerebrospinal fluid after birth asphyxia. Pediatric Research. 1998;43:746. DOI: 10.1203/00006450-199806000-00006

[157] Jenkins DD, Rollins LG, Perkel JK, Wagner CL, Katikaneni LP, Bass WT, et al. Serum cytokines in a clinical trial of hypothermia for neonatal hypoxicischemic encephalopathy. Journal of Cerebral Blood Flow and Metabolism. 2012;32:1888-1896. Available from: https://www.ncbi.nlm.nih.gov/ pubmed/22805873

[158] Wang X, Figueroa BE, Stavrovskaya IG, Zhang Y, Sirianni AC, Zhu S, et al. Methazolamide and melatonin inhibit mitochondrial cytochrome $\mathrm{C}$ release and are neuroprotective in experimental models of ischemic injury. Stroke. 2009;40:1877-1885. Available from: https://www.ncbi.nlm.nih.gov/ pubmed/19299628

[159] Chalak LF, Sánchez PJ, AdamsHuet B, Laptook AR, Heyne RJ, Rosenfeld CR. Biomarkers for severity of neonatal hypoxic-ischemic encephalopathy and outcomes in 
The Role of Purinergic Signaling in the Pathophysiology of Perinatal Hypoxic-Ischemic...

newborns receiving hypothermia therapy. The Journal of Pediatrics. 2014;164:468-474.e1. Available from: https://www.ncbi.nlm.nih.gov/ pubmed/24332821

[160] Moon CJ, Youn YA, Yum SK, Sung IK. Cytokine changes in newborns with therapeutic hypothermia after hypoxic ischemic encephalopathy. Journal of Perinatology. 2016;36:1092. DOI: 10.1038/jp.2016.132

[161] Leão AAP. Further observations on the spreading depression of activity in the cerebral cortex. Journal of Neurophysiology. 1947;10:409-414. DOI: 10.1152/jn.1947.10.6.409

[162] Peters A. Golgi, Cajal, and the fine structure of the nervous system. Brain Research Reviews. 2007;55:256-263. Available from: https://www.ncbi.nlm. nih.gov/pubmed/17270274

[163] Melani A, Amadio S, Gianfriddo M, Vannucchi MG, Volonte C, Bernardi $\mathrm{G}$, et al. P2X7 receptor modulation on microglial cells and reduction of brain infarct caused by middle cerebral artery occlusion in rat. Journal of Cerebral Blood Flow and Metabolism. 2006;26:974-982

[164] Chu K, Yin B, Wang J, Peng G, Liang $\mathrm{H}, \mathrm{Xu} \mathrm{Z}$, et al. Inhibition of P2X7 receptor ameliorates transient global cerebral ischemia/reperfusion injury via modulating inflammatory responses in the rat hippocampus. Journal of Neuroinflammation. 2012;9:69

[165] Yu Q, Guo Z, Liu X, Ouyang Q, He C, Burnstock G, et al. Block of P2X7 receptors could partly reverse the delayed neuronal death in area CA1 of the hippocampus after transient global cerebral ischemia. Purinergic Signal. 2013;9:663-675

[166] Bindra CS, Jaggi AS, Singh N. Role of $\mathrm{P} 2 \mathrm{X} 7$ purinoceptors in neuroprotective mechanism of ischemic postconditioning in mice. Molecular and Cellular Biochemistry. 2014;390: 161-173

[167] Schock SC, Munyao N, Yakubchyk Y, et al. Cortical spreading depression releases ATP into the extracellular space and purinergic receptor activation contributes to the induction of ischemic tolerance. Brain Research. 2007;1168:129-138

[168] Iwabuchi S, Kawahara K. Possible Involvement of Extracellular ATP-P2Y Purinoceptor Signaling in Ischemiainduced Tolerance of Astrocytes in Culture. Neurochemical Research. 2009;34:1542-1554. Available from: https://doi.org/10.1007/ s11064-009-9942-7

[169] de Pina-Benabou MH, Szostak V, Kyrozis A, Rempe D, Uziel D, Urban-Maldonado M, et al. Blockade of gap junctions in vivo provides neuroprotection after perinatal global ischemia. Stroke. 2005;36:2232-2237

[170] Davidson JO, Green CR, Nicholson LFB, O'Carroll SJ, Fraser M, Bennet L, et al. Connexin hemichannel blockade improves outcomes in a model of fetal ischemia. Annals of Neurology. 2012;71:121-132

[171] Li X, Zhao H, Tan X, Kostrzewa RM, Du G, Chen Y, et al. Inhibition of connexin43 improves functional recovery after ischemic brain injury in neonatal rats. Glia. 2015;63:1553-1567

[172] Wei R, Wang J, Xu Y, Yin B, He F, $\mathrm{Du} \mathrm{Y}$, et al. Probenecid protects against cerebral ischemia/reperfusion injury by inhibiting lysosomal and inflammatory damage in rats. Neuroscience.

2015;301:168-177

[173] Xiong X-X, Gu L-J, Shen J, Kang X-H, Zheng Y-Y, Yue S-B, et al. Probenecid protects against transient focal cerebral ischemic injury by inhibiting HMGB1 release 
and attenuating AQP4 expression in mice. Neurochemical Research. 2014;39:216-224

[174] Dunwiddie TV, Diao L, Proctor WR. Adenine nucleotides undergo rapid, quantitative conversion to adenosine in the extracellular space in rat hippocampus. The Journal of Neuroscience. 1997;17:7673-7682

[175] Zou R, Xiong T, Zhang L, Li S, Zhao F, Tong Y, et al. Proton magnetic resonance spectroscopy biomarkers in neonates with hypoxic-ischemic encephalopathy: A systematic review and meta-analysis. Frontiers in Neurology. 2018;9:732. Available from: https://www.frontiersin.org/ article/10.3389/fneur.2018.00732

[176] Cheong JLY, Cady EB, Penrice J, Wyatt JS, Cox IJ, Robertson NJ. Proton MR spectroscopy in neonates with perinatal cerebral hypoxic-ischemic injury: Metabolite peak-area ratios, relaxation times, and absolute concentrations. American Journal of Neuroradiology. 2006;27:1546-1554

[177] Thayyil S, Chandrasekaran M, Taylor A, Bainbridge A, Cady EB, Chong WKK, et al. Cerebral magnetic resonance biomarkers in neonatal encephalopathy: A meta-analysis. Pediatrics. 2010;125:e382-e395

[178] Kondratskyi A, Kondratska K, Skryma R, Prevarskaya N. Ion channels in the regulation of apoptosis. Biochimica et Biophysica ActaBiomembranes. 2015;1848:2532-2546. Available from: http://www. sciencedirect.com/science/article/pii/ S0005273614003654

[179] McGeough MD, Pena CA, Mueller JL, Pociask DA, Broderick L, Hoffman HM, et al. Cutting Edge: IL-6 is a marker of inflammation with no direct role in inflammasome-medaited mouse models. Journal of Immunology. 2012;189:2707-2711. Available from: http://www.jimmunol.org/ content $/ 189 / 6 / 2707$

[180] Burm SM, Zuiderwijk-Sick EA, Weert PM, Bajramovic JJ. ATP-induced IL-1 $\beta$ secretion is selectively impaired in microglia as compared to hematopoietic macrophages. Glia. 2016;64:2231-2246. DOI: 10.1002/glia.23059 
Section 3

\section{Structure and New Prototypes}





\title{
A Brief View of Molecular Modeling Approaches to P2 Receptors
}

\author{
Anael V.P. Alberto, Lucianna H.S. Santos, Rafael Ferreira, \\ Dinarte N.M. Ferreira and Luiz A. Alves
}

\begin{abstract}
Purinergic receptors are a class of receptors distributed into two groups, P1 and P2. P1 receptors are activated by nucleosides, like adenosine, while nucleotides active $\mathrm{P} 2$ receptors. In turn, $\mathrm{P} 2$ receptors comprise two families, metabotropic P2Y and ionotropic P2X. P2Y receptors consist in eight members, namely, P2Y1, P2Y2, P2Y4, P2Y6, P2Y11, P2Y12, P2Y13, and P2Y14, described in mammals, while P2X includes seven members, numbered $\mathrm{P} 2 \mathrm{X} 1$ to $\mathrm{P} 2 \mathrm{X} 7$. These receptors have been described as expressed in practically all cells studied to date. In this context, P2 receptors are suggested as participating in certain diseases. The general approach applied in the discovery of new drugs is expensive and lengthy. Alternatively, in the last 20 years, molecular modeling has emerged as an exciting tool for the design of new drugs, in less time and at low costs. These tools allow for in silico testing of thousands of molecules against a target protein, as well as toxicity, absorption, distribution, metabolism, and constant affinity predictions of a given interaction. Thus, molecular modeling algorithms emerge as an increasingly important tool for the design of drugs targeting purinergic receptors as therapeutic targets of many diseases, including cancer, pain, inflammation, cardiovascular, and endocrine conditions.
\end{abstract}

Keywords: molecular modeling, molecular dynamics, virtual screening, homology modeling, drug discovery, $\mathrm{P} 2 \mathrm{X}$ receptors, $\mathrm{P} 2 \mathrm{Y}$ receptors

\section{Introduction}

Purinergic receptors are a class of transmembrane proteins activated by extracellular nucleotides and nucleosides. They consist in the P1 receptor (mainly activated by adenosine) and $\mathrm{P} 2$ receptors distributed into two families, P2Y (G protein-coupled receptors) and $\mathrm{P} 2 \mathrm{X}$ (ionotropic receptor).

$\mathrm{P} 2 \mathrm{Y}$ receptors comprise eight members in mammals (P2Y1, P2Y2, P2Y4, P2Y6, P2Y11, P2Y12, P2Y13, P2Y14) and are activated mainly by adenosine diphosphate and uracil nucleotides, such as UTP and UDP. Regarding distribution, P2Y receptors are widely distributed throughout the organism. The structure of P2Y receptors comprises seven transmembrane segments with an extracellular amino terminal, an intracellular carboxyl-terminal, and three segments connecting the transmembrane 
domains, and two subtypes have been resolved by X-ray crystallography, P2Y1 and P2Y12 [1-3].

The first resolved P2Y structure was P2Y12 in 2014, in two papers published by Zhao group describing the crystal structure (Figure 1) of the receptor bound to an antithrombotic drug and two agonists (2MeSADP and 2MeSATP) [1, 3]. As this receptor is related to thrombosis, with at least three drugs available in the market, this finding was relevant to address the development of new antithrombotic drugs. Surprisingly, the authors also reported a different behavior of the receptor linked to nucleotide and non-nucleotide ligands, presenting different binding pockets that share only a small portion of the site.

Another subtype that has been resolved by X-ray crystallography is P2Y1 that plays a similar role in thrombosis, facilitating platelet aggregation, and that could be a new candidate for the discovery of antithrombotic treatments. In this case, the resolution was even higher, at $2.2 \AA$, than P2Y12. The authors described two distinct binding pockets, one allosteric and another orthosteric. The allosteric site is located close to the lipid bilayer, while the orthosteric site is formed by an extracellular loop-2, VI and VII helices, and a portion of the amino-termini domain. It is important to note that the binding modes are entirely different from that reported for P2Y12.

Regarding P2X receptors, these are nonselective cation channels gated by extracellular ATP, also expressed in various systems throughout the organism [4-6]. To date, seven different P2X subtypes (P2X1-P2X7) have been found, assembled as homo- or heterotrimers with two transmembrane segments, an extracellular ligand binding loop and both intracellular amino and carboxy termini that modulate channel gating $[7,8]$. In general, the $\mathrm{P} 2 \mathrm{X}$ receptors when activated open a channel permeating mono and divalent cations except for the P2X5 that permeates anions as. Another receptor that has a different behavior is the P2X7 that opens a channel activated by low concentrations of ATP, but under high concentration stimulation
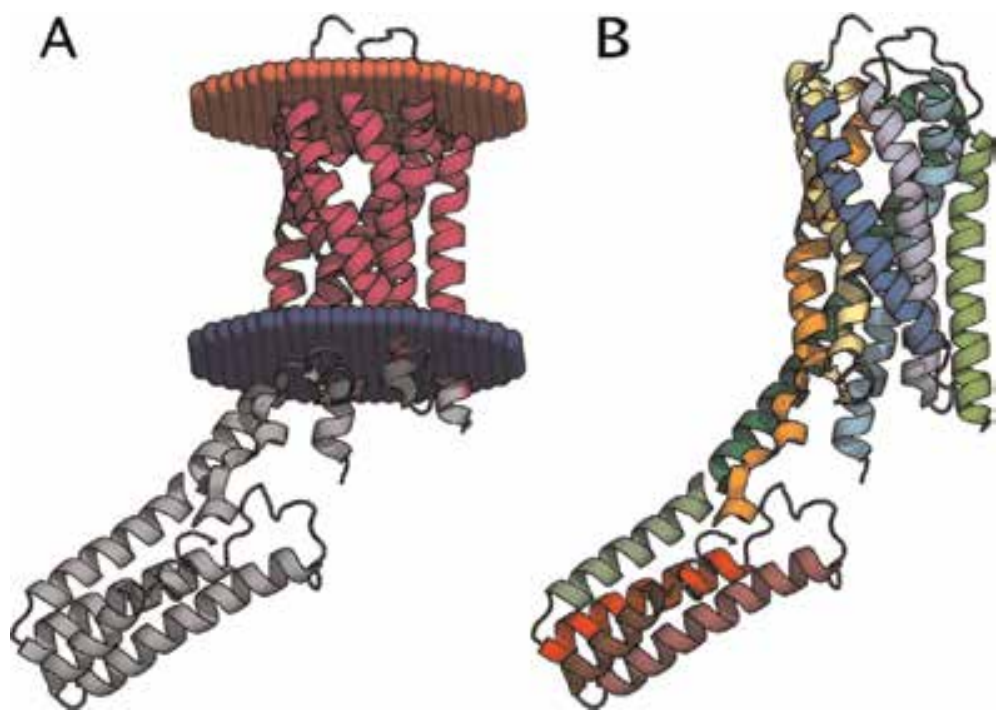

Figure 1.

Three-dimensional structure of $P_{2} Y_{12}$ bound to $2 M e S A D P$. (A) Crystal structure of $P_{2} Y_{12}$ (PDB code 4 PXZ) with the transmembrane regions depicted in pink. The receptor structure is represented as a cartoon comprising different colors (gray, light blue, and green). $2 M e S A D P$ molecules are shown as a stick representation.

(B) $P_{2} Y_{12}$ crystal structure without any ligand (PDB code $\left.4 P X Z\right)$. In (B), each helix is shown as a different color. 
( $>100 \mu \mathrm{M}$ ), it opens a pore, allowing the passage of molecules up to $900 \mathrm{Da}$, including fluorescent molecules [9-11]. With the recent crystal structure determination of some P2X receptors, some of the questions and hypothesis gathered in previous studies were confirmed, and it was also possible to postulate a reasonable mechanism for channel activation [8]. However, the molecular machinery involved in the high-conductance pore formation remains uncertain and under discussion.

A significant advance in the understanding of $\mathrm{P} 2 \mathrm{X}$ receptors was the determination of the crystal structures of zebrafish P2X4 (zfP2X4) in both the apo- (closedchannel state) and ATP-bound (open-channel state) forms (Figure 2) [12]. Before this, assumptions concerning the receptor structures were carried out through bioinformatics and molecular and biochemical studies, since overexpression, reconstitution, and the overall structure determination of membrane proteins are challenging [13]. In addition, no sequence homology exists between P2X and other ion channels [14]. Therefore, the crystallographic structures of zfP2X4 demonstrated the particular three-dimensional organization of the P2X family and the folding of each subunit, marking a new era for P2X studies.

The architecture of P2X receptors is compared to a dolphin [8] (Figure 1), where the highly conserved residues, found in a rigid $\beta$-sheet structure, form a sizeable glycosylated ectodomain denoted as the dolphin body. Four other flexible domains make up the head, dorsal fin, and left and right flippers. The TM1 and TM2
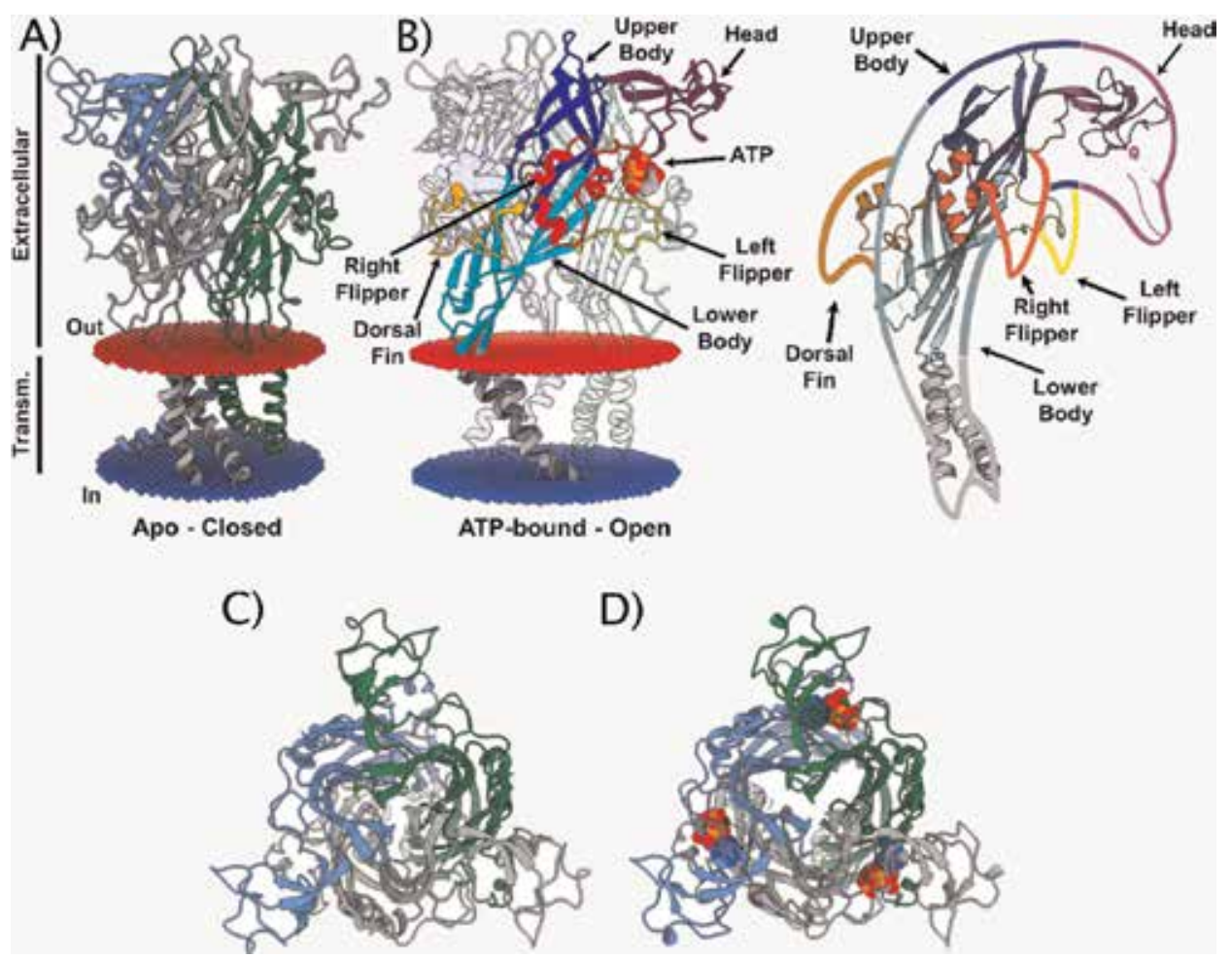

Figure 2.

Three-dimensional structures of the closed and open (ATP-bound) $\mathrm{P}_{2} \mathrm{X}_{4}$ states. (A) Crystal structure of the ${ }_{2} \mathrm{P}_{2} \mathrm{X}_{4}$ in a closed state ( $P D B$ code ${ }_{4} D W 0$ ) with the transmembrane regions depicted in blue and red. The three subunits are represented as a cartoon and in different colors (gray, light blue, and green). (B) Crystal structure of the $\mathrm{ZfP}_{2} \mathrm{X}_{4}$ bound to $A T P\left(P D B\right.$ code $\left.4 D W_{1}\right)$. ATP molecules are displayed as a van der Waals $(v d w)$ representation. One of the subunits is colored according to the dolphin-like model. $(C)$ The same structure as in (A), viewed from the top along the axis of the central channel. (D) The same structure as in (B), seen from the top along the axis of the central channel. 
transmembrane domains (dolphin tail) are organized into alpha helices, and the ion-conducting channel is formed by the association of three of the TM2 alpha helices. It was also possible through the $\mathrm{zfP} 2 \mathrm{X} 4$ crystal structures to confirm the ATP-binding site region [12]. The residues are located within a cavity surrounded by the head, left flipper, and dorsal fin [8]. Besides, two possible ion pathways were recognized. Ions theoretically either pass through the channel vertically, through three related vestibules positioned along the central axis of the receptors, or laterally through three fenestrations positioned above the gate region, located approximately halfway down the length of the TM2 helix [8].

Over the years, crystal structure determination and in silico modeling allowed for inferences regarding gating action. Gating may begin with ATP binding that incites conformation changes all around the receptor and the contraction of regions surrounding the ATP-binding site. Subunits bend outside and rotate, flexing the lower regions of the receptor and the extension of the lateral fenestrations. Since the lower areas of the receptor are connected to the transmembrane domain, their movement displaces the outer ends of the TM helices, followed by pore opening [15].

Recently, other P2X crystal structures have been determined, such as the Gulf Coast tick P2X (gcP2X) receptor [7], the human P2X3 (hP2X3) receptor [16, 17], the panda P2X7 (pdP2X7) receptor [18], and the chicken P2X7 (ckP2X7) receptor [7]. Surprisingly, it has been demonstrated that some antagonists thought to be competitive antagonists were, in fact, allosteric antagonists. These structures led to an understanding concerning channel activation, desensitization, and the recognition of P2X family agonists and antagonists. On the one hand, the elucidation of the various P2X structures opens the possibility of structural comparisons between subtypes. For instance, the ckP2X7 conformation was noted as presenting an extended, incompletely activated conformation of the channel and a different ATP recognition mechanism compared to other P2X crystal structures [7]. On the other hand, the availability of crystal structures in both open- and closed-channel states also increases the use of computational methods to predict P2X receptor structures from sequences and aid in drug design studies targeting the P2X family.

\section{In silico approaches applied to drug discovery}

The classical pharmacology approach to study protein and ligand interactions searching for new drugs based on high-throughput screening with thousands of molecules takes up significant amounts of time and financial resources. The computational approach, on the other hand, allows for substantial overall cost reductions.

In silico methods comprising pharmacophore modeling, homology models, quantitative structure-activity relationships, molecular docking, or databases are mostly used alongside other experimental techniques, such as in vitro methodologies, creating models to test, discover, and optimize molecules to attribute a pharmacological target. The in silico approaches to drug discovery or computational pharmacology and therapeutics comprise biomedical data for simulations and predictions, suggesting hypotheses and aiding in creating shortcuts between the idea and the designed drug, whereas all new drug design process takes about 15 years [19].

In silico approaches alter the way the pharmacology industry discovers and optimizes drugs, using human genome information. The genomic sequence emerges with confidence in biological and chemical sciences [20, 21]. The various genesequenced species to date, including humans, have contributed to increasing all 
databases and databanks worldwide. Besides, the new biochemistry challenge is to apply this information to solve the 3D structure of macromolecules, mainly proteins (i.e., enzymes, receptors). As these structures order the major functionality of the human body, reading, solving, and interpreting this structural information may be the future of medicine. Elucidating protein structures opens up possibilities for drug research using the solved 3D structures as molecular targets [22]. However, although available gene and protein information exist, a knowledge gap is also observed [23]. In this context, structure-based methods are frequently used to predict or optimize new drugs, enabling both improvements and predictions concerning pharmacodynamic (bioactivity and toxicity) and pharmacokinetic (absorption, distribution, metabolism, and excretion) properties [24].

However, each approach was developed for a specific proposal, and none was capable of solving all issues. In this sense, over time many researchers have noted that mixed strategies can be used as complementary, filling the gaps present in each method. This point of view emerges to aid in the study of human P2 receptors, as no experimental 3D structure is available. In this sense, comparative modeling based on homologous template proteins associated with molecular docking and a virtual screening (VS) approach is a standard protocol for computer-aided drug design. The following section details some procedures applied to computational structureactivity relationship studies.

\subsection{Comparative modeling}

The experimental determination of a protein structure is frequently delayed by difficulties in the cloning, expression, and purification of the target protein. Additionally, technical and methodological problems concerning crystallization can also occur, which may nullify the effort to obtain a crystal structure. Therefore, methods that deal with structure prediction are highly sought out. One of these methods is termed comparative modeling, also known as homology modeling. This method is based on the concept that two proteins from the same family, which share similarities in their amino acid sequence, will display similar three-dimensional structures, as the degree of conservation of three-dimensional structure elements in a protein family is higher than sequence conservation.

The precision of comparative modeling relies on the sequence alignment between what is called the template (related homologous protein) and the target sequence (protein to be constructed) [25]. Usually, the sequence identity must be higher than $70 \%$ to ensure a successful prediction, as sequence identities lower than $30 \%$ may produce models presenting inaccurate structural predictions. Membrane proteins, especially transmembrane domains, can be constructed into acceptable models with sequence identities equal or higher than 30\%, although the alignments in soluble regions may be less accurate [26]. In addition to sequence identity, inherited structural deficiencies, such as crystal packing and the presence of detergents for solubilization from the template structure, may also contribute to an unreliable predicted model. Popular comparative modeling programs include MODELER, SWISS-MODEL, and ROSETTA [27-29].

Predicted receptor structures for P2X1, P2X2, P2X3, P2X4, and P2X7 have been constructed in several studies (see more details in the review by Grimes and Young) [30]. These structural studies provided evidence to the identification of the critical amino acid residues and regions of the P2X receptor function have been previously investigated only by experimental assessments. In addition, comparative modeling has led to interesting developments regarding modified P2X receptors, by point mutations in important residues. Mutations in crucial residues can introduce different mobility concerning channel opening and closing, as well as different 
interactions between the receptors and ATP [8]. For example, the substitution of glycine, located in the lower body, to alanine in the P2X4 receptor resulted in a more rigid structure, decreased ATP sensitivity, slower activation, and desensitization [31].

\subsection{Molecular docking}

One of the first steps in a computational drug discovery campaign is molecular docking. Molecular docking, or simply docking, is a computational method that predicts the favored binding mode of one molecule to another when they may form a complex. Usually, the binding molecule, known as a ligand, has its rotational or translational space probed, while the other particle, known as the receptor, remains rigid. A receptor structure can originate from modeling or experimental approaches, such as comparative modeling and crystallographic structures. Several docking programs and tools are available for both academic and commercial uses, such as AutoDock [32], DOCK [33], Glide [34], and GOLD [35]. Docking programs consist of a search algorithm and score functions that return a conformation of the ligand, known as a pose.

In the algorithm search, the ligand conformation is evaluated recursively until convergence to minimum energy is reached [31]. In docking methods, the energy is estimated by a scoring function that ranks the conformations, usually by the sum of electrostatic and van der Waals energies. A docking run does not require a lot of computational power, taking from seconds to a few minutes at most to detect a conformation [36]. Although docking approaches are fast, one of the crucial operational issues is obtaining accurate results due to flexibility and score function limitations [36]. Therefore, a docking result should not be viewed as a drug, but just as a priority candidate for optimization and experimental testing.

With the existence of known P2X receptor three-dimensional structures, searching for compounds that selectively activate or block specific P2X receptor subtypes indicates promising therapeutic targets for many diseases, such as cancer, pain, inflammation, cardiovascular, and endocrine conditions [37]. To date, numerous P2X ligands have been described, mostly derivatives from the endogenous agonist ATP developed to increase ATP stability and reduce its degradation rate by extracellular ectonucleotidases [38, 39]. Other structural compound classes, such as nucleotide derivatives, irreversible antagonists, suramin-like analogs, and pyrimidine or purine derivatives, have been reported [37]. Therefore, strategies that predict the druggability of a compound to a target and, in turn, contribute and accelerate optimization are frequently applied in drug discovery campaigns.

Recently, a study performed an effort in the field of structure-based modeling and the understanding of interactions between compounds with drug-like properties and $\mathrm{P} 2 \mathrm{X}$ receptors. Dal Ben and colleagues used comparative model structures for $\mathrm{rP} 2 \mathrm{X} 2$ and $\mathrm{hP} 2 \mathrm{X} 2$, using the $\mathrm{zP} 2 \mathrm{X} 4$ crystal structure as a template, to perform docking experiments concerning ATP and ATP analogs as P2X agonists in the ATPbinding site [37]. In addition, they also assessed nucleotide and non-nucleotide antagonists (a P2X3 antagonist, suramin derivatives, anthraquinones, azoles, and cyanoguanidine derivatives) in different binding sites. The docking results indicated agonist interactions, which may act in a comparable way to endogenous ATP [37]. It is also clear that, alongside mutagenesis analyses, comparative modeling and docking can provide key residues regarding P2X receptor agonist and antagonist potency and selectivity.

This technique was also applied to test specific ligands that already have been tested on the wet bench. Some authors demonstrated that, in a P2Y1 model based on the X-ray crystallography-resolved rhodopsin structure, some antagonist affinities were very similar to that obtained in experiments [40]. Other P2Y member models 
have been described based on other $G$ protein-coupled receptors, to discover new antagonists; see more details in Jacobson et al. [41].

\subsection{Virtual screening}

Molecular docking experiments of a compound series are important and enlightening. However, in silico screening of large chemical libraries may improve the chance of finding candidates for optimization. Therefore, virtual screening is the computational and low-cost counterpart of time-consuming high-throughput screening strategies [42]. Virtual screening can be structure-based, using molecular docking as a method, or ligand-based. Compound libraries to be screened can be formed by thousand to millions of compounds presenting similarities, or not, to known target ligands. However, only a small percentage of compounds from the top-ranking conformations can be examined for interaction patterns and prioritized to be purchased or synthesized [42].

Regarding the P2Y family, a study applying virtual screening was carried out by Costanzi et al. [43], who tested 250,000 molecules for P2Y1. At the end of the screening, they selected only 110 hits clustered in 59 groups. The substances presented antagonistic behavior in a low molar range; however, compound optimization was still required [43].

With the help of structure-based virtual screening, Caseley and co-workers were able to identify three novel $\mathrm{hP} 2 \mathrm{X} 7$ antagonists with micromolar potency (IC50 $<6 \mu \mathrm{M}$ ) from a library of over 100,000 structurally diverse ligands [44]. VS was performed in the hP2X7 ATP-binding pocket (enclosing $10 \AA$ of the site), and 42 of the highest-ranked scores were commercially available to be tested. Ligand similarity was also considered and used in inhibition tests. From functional testing, one of the three compounds showed favored inhibition of the large pore formation without consequence to ion channel function. Studies such as this suggest that P2X receptors are indeed an attractive pharmacological target and that computational finds can corroborate experiments and vice versa.

\subsection{Molecular dynamics}

In their most basic application, structure-based methods rely on a single "snapshot" of the target protein. This factor may be due to the lack of experimental or reliable modeled structures or just the reduction of docking and virtual screening computational demands [45]. However, with the recent progress in computational power, methods that account for structural flexibility can replicate in solution dynamics. One of the most applied methods to investigate protein motion, with or without a ligand, is known as classical molecular dynamics simulation. Molecular dynamics (MD) comprises simulations based on Newton's motion equation and can designate the progress of the conformational state and energy landscape as a function of time in a feasible time scale [42]. Classical MD is used because it includes temperatures and pressure effects, provides an alternative interpretation for experiments, aids in obtaining molecular level information, and is computationally cheaper than other MD approaches, such as quantum mechanics/molecular mechanics $(\mathrm{QM} / \mathrm{MM})$ or quantum chemistry (MD/QC). One of the reasons for this is that QM methods use the Schrodinger equation solution to represent the electronnuclear relation considering static nuclei, since in classical MD atom nuclei use an average field to describe the electrons [46-48].

Despite the advances in computational power, molecular dynamics simulations still present a limited time scale, ranging from hundreds of nanoseconds to hundreds of microseconds depending on the system, making its length not enough to 
sample most biological processes. In the case of transport through membranes or channels, the massive, conformational changes during gating are complicated and time-consuming, due to systems with over 200,000 atoms (receptor structure, water molecules, lipid bilayer, and neutralizing ions) accomplishing, at most, hundreds of nanoseconds [49]. However, even with limited simulation times, interesting structural information can be obtained. For instance, regarding a molecular dynamics simulation of the crystal structure of zfP2X4, it was possible to infer that ATP binding may terminate hydrophobic interactions between the left flipper and the dorsal fin, producing a downward movement of the left flipper and upward motion of the dorsal fin [50]. Moreover, molecular dynamics predicted ion passage through the lateral fenestrations, which were confirmed later in cysteine accessibility assay experiments [12, 51].

Nevertheless, molecular dynamics assessments have only been employed in a few studies. Alternatives to sidestep time scale and length shortcomings in the ion channel, such as coarse-grained simulations and enhanced sampling methods (replica-exchange molecular dynamics, metadynamics, and simulated annealing), are performed instead of classical molecular dynamics. In coarse-grained methods, a system is represented by a reduced number of degrees of freedom, thus eliminating some interactions and allocating fewer resources than all-atom representation, while enhanced sampling methods can help the system cross specific high-energy barriers that separate low-energy conformations. Recently, a coarse-grained simulation of a model structure of rP2X2 within a lipid bilayer was performed [44], and the authors observed that lipids were interposed between the transmembrane helices during the simulation, thus indicating that these molecules may be able to stabilize the open receptor state [30]. All data about the results concerning the techniques described above (comparative modeling, molecular docking, and molecular dynamics) could be seen in Table 1.

\subsection{Artificial intelligence applied to drug discovery}

Artificial intelligence (AI) is considered the hallmark of The Fourth Industrial Revolution [52]. AI comprises several definitions but can be defined briefly as a part of computer science capable of performing activities ascribed to human intelligence, such as solving problems, with similar and, in some instances, superior cognitive abilities, for instance, in some cases involving image recognition and playing games, such as Go, Chess, and Shogi [53]. It is important to point out that the game tree complexity of Go is $10^{360}$ [54]. AI is implemented through machine learning (ML) algorithms to be used in different fields.

Currently, ML tools have been used to rapidly identify biologically active molecules from libraries containing thousands of substances in a less costly manner compared to a bench approach $[55,56]$. As mentioned previously, several ML algorithms are available, such as k-nearest neighbors, Naïve Bayesian, decision trees, deep neural networks, support vector machines (SVM), and random forest, although the two most applied in this decade which aimed at drug discovery have been SVM and deep neural networks [57]. SVM was developed by Cortes and Vapnik, presenting applications in several fields [58]. Essentially, a hyperplane (in a Cartesian plane, for instance, with one variable per line) separates two samples by attempting to find the maximum distance between data points and the hyperplane. The closest points in each side are termed support vectors. An excellent review on SVM applied to drug discovery has been recently published by Maltarollo [59]. SVM can predict interactions between ligand and receptors based on physicochemical features and protein and compound descriptors, regardless of structural information. 
Artificial neural networks are a mathematical representation of neurons, based on how they work in the animal brain, containing several hidden layers, in some cases. Several subtypes have been noted, but a central character is to train the network to learn specific task patterns. In other words, the algorithm "writes" itself through modifications, applying certain variables such as weights and bias in the neural network. The work of a neural network is similar to the brain plasticity that occurs in animals in order to learn new tasks, where new synaptic contacts are formed, producing other biological networks. An interesting review of this issue has been recently published by Carpenter [57]. Several subtypes of artificial neural networks have been applied in drug discovery [57].

Nevertheless, the future is promising, since several drugs have been developed applying ML. Besides, the new Google AlphaZero program has learned to play several games by self-playing and has defeated machine learning programs such as AlphaGo and AlphaGo Zero, which had previously defeated human Go champions

\begin{tabular}{|c|c|c|c|}
\hline Receptor & Technique & Target Domain & Reference \\
\hline$h 92 \times 3$ & 2tP2X4 Homologx moder & $\begin{array}{l}\text { Mead Domsn I Orihoslebe Bnding } \\
\text { Site }\end{array}$ & {$[73$} \\
\hline$h P 2 \times 7$ & $\begin{array}{l}\text { 2PPXX4 Homology modek: } \\
\text { Docking }\end{array}$ & $\begin{array}{l}\text { Head Domain / Orthostebie Binding } \\
\text { Site }\end{array}$ & 174 \\
\hline $\mathrm{rP} 2 \times 2$ & $2 \mathrm{TP} 2 \mathrm{X} 4$ Homology mose: & $\begin{array}{c}\text { Head Domin / Orthostetie Binding } \\
\text { Site }\end{array}$ & [75] \\
\hline $\mathrm{rP} 2 \times 2$ & 252X44 Honology model & $\begin{array}{c}\text { Head Domain f Onthostetie Bindng } \\
\text { Site }\end{array}$ & [D] \\
\hline$P 2 \times 1-5, P 2 \times 7$ & $\begin{array}{l}202 \times 4 \text { Homology mosek. } \\
\text { Docking }\end{array}$ & $\begin{array}{c}\text { Head Dotnain / Ortheitetie Binding } \\
\text { Sale. }\end{array}$ & BI \\
\hline$h 92 \times 7$ & $\begin{array}{l}\text { 2fP2X4 Homology modek, } \\
\text { Docking. Molecular Dynamics }\end{array}$ & $\begin{array}{c}\text { Head Doenain / Orthostetic Bindng } \\
\text { Site }\end{array}$ & 174 \\
\hline $\operatorname{mP2XT}$ & $\begin{array}{l}\text { Homology modet: } \\
\text { Docking }\end{array}$ & $\begin{array}{c}\text { Hesa Domain / Orthostebe Binang } \\
\text { Sine }\end{array}$ & {$[\pi]$} \\
\hline$h P 2 \times 7$ & $\begin{array}{l}\text { pdP2X7 Homology modet: } \\
\text { Docking. Nolecilar Dynamies }\end{array}$ & $\begin{array}{c}\text { Hesd Doman / Orthostetie Binding } \\
\text { Site }\end{array}$ & {$[78]$} \\
\hline$h P 2 \times 1$ & IfP2X, Homology model & Body and nppors domains & {$[79]$} \\
\hline$r P 2 \times 2$ & 2fP2X44 Homology model & Body and fippers domains & 1801 \\
\hline $2 \operatorname{tp} 2 \times 4$ & 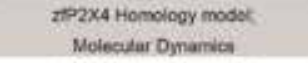 & Body and fippers domains & Foj \\
\hline $\operatorname{rp2} 24$ & $\begin{array}{l}\text { 2tp2X4 Homology modek: } \\
\text { Molecular Dynamics }\end{array}$ & Body and Appers domains & {$[01]$} \\
\hline$h P 2 \times 7$ & ztP2X, Homology model & Body and Sppers domains & [44] \\
\hline $2 f: 2 \times 4$ & Molecular Drnamies & Bedy and fippers demains & [82] \\
\hline $\operatorname{raz} \times 2$ & ztP2X4 Homology model & Ion accoss pathwity & (83) \\
\hline$h_{P 2} \times 4$ & 2tP2X4 Honology model & Ion access pattwingy & [B4] \\
\hline$n P 2 \times 3$ & Molecular Dynarica & Ion access patinay & 117 \\
\hline $2 f 92 \times 4$ & Molecular Dynamics & Transmentbrane Domains & (85) \\
\hline$h_{92 \times 7}$ & $292 \times 44$ Homology modei & Transmmmorane Domains & [BO] \\
\hline rP2X7 & ztP2X4 Homology model & Trantmembrane Domains & 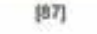 \\
\hline P2ri & Baclenorhodopen Homology model & $\begin{array}{l}\text { Ornostete } \\
\text { Einding Site }\end{array}$ & |вยI \\
\hline P2Y1 & Bactenorhedopain Homology model & $\begin{array}{l}\text { Orthostebie } \\
\text { Binding Sitn }\end{array}$ & [B:] \\
\hline P2Y1 & Bactenomocopin Hamology model & $\begin{array}{l}\text { Ormostetic } \\
\text { Binding Sile }\end{array}$ & POI \\
\hline P2Y1 & Bovins thedepsin Hemolegy model & $\begin{array}{l}\text { Orthostebe } \\
\text { Binding Site }\end{array}$ & 814 \\
\hline
\end{tabular}




\begin{tabular}{|c|c|c|c|}
\hline P2ri & $\begin{array}{l}\text { Bovine ihodossin Homology modet, } \\
\text { Moiecular dynamics, Docking }\end{array}$ & $\begin{array}{l}\text { Orthosinte } \\
\text { Binsing site }\end{array}$ & 1921 \\
\hline P2ri & $\begin{array}{l}\text { Bovine thodopsin Homology modet: } \\
\text { Moieculor oynamics; Dosking }\end{array}$ & $\begin{array}{l}\text { Orthostetic } \\
\text { Binding sile }\end{array}$ & |931 \\
\hline P2ri & $\begin{array}{l}\text { Bovine modossh Homology modet: } \\
\text { Doding }\end{array}$ & $\begin{array}{l}\text { Orthostets } \\
\text { Binang site }\end{array}$ & 194 \\
\hline P2ri & Docking & $\begin{array}{l}\text { Orthostebs } \\
\text { Binding site }\end{array}$ & 199 \\
\hline P2ri & Doding & $\begin{array}{l}\text { Orithosinte } \\
\text { Binsing Site }\end{array}$ & 196 \\
\hline P2rz & Bacteriorhodopen Hismology model & $\begin{array}{l}\text { Orthostetia } \\
\text { Binding site }\end{array}$ & $|97|$ \\
\hline Parz & $\begin{array}{l}\text { Bovine thodossin Homology modet: } \\
\text { dockine }\end{array}$ & $\begin{array}{l}\text { Orthostetse } \\
\text { Bindng Site }\end{array}$ & 198 \\
\hline P2rz & $\begin{array}{l}\text { P2r1 Homology modet: } \\
\text { Docking }\end{array}$ & $\begin{array}{l}\text { Orthostetic } \\
\text { Binding site }\end{array}$ & 199 \\
\hline P2YUP2Y12 & CaCR4 Homology mooks Dooving & $\begin{array}{l}\text { Orthostrbe } \\
\text { gunang site }\end{array}$ & nool \\
\hline P2Y4 & $\begin{array}{l}\text { Pary Hemolegy model; } \\
\text { Docking }\end{array}$ & Onding Silte & [101] \\
\hline P2Ys & 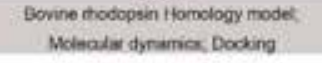 & $\begin{array}{l}\text { Orenostelic } \\
\text { Onding Ste }\end{array}$ & 1004 \\
\hline PZY' & $\begin{array}{l}\text { P2YUPZY12 Homology modec: } \\
\text { Docking }\end{array}$ & $\begin{array}{l}\text { Orthosietc } \\
\text { Binding Sint }\end{array}$ & 11009 \\
\hline P2Y11 & $\begin{array}{l}\text { Bovine thodopsin Homology modes } \\
\text { Molesiler donnamics }\end{array}$ & $\begin{array}{l}\text { Orrosteto } \\
\text { Binding Sithe }\end{array}$ & [104] \\
\hline P2Y12 & $\begin{array}{l}\text { Bovine thodopsin Homology modet: } \\
\text { Molecular synamics }\end{array}$ & $\begin{array}{l}\text { Orhostetc } \\
\text { Binding sine }\end{array}$ & 1109 \\
\hline P2Y12 & CXCRA Hemologer mosel; Docking & $\begin{array}{l}\text { Orthosteto } \\
\text { Bindina Sine: }\end{array}$ & {$[106]$} \\
\hline P2r12 & Dooking & $\begin{array}{l}\text { Orhostotic } \\
\text { Bnding Site }\end{array}$ & tion \\
\hline P2Y12 & $\begin{array}{l}\text { Homology model; Molecoular dynamics; } \\
\text { Docking }\end{array}$ & $\begin{array}{l}\text { Orthosteto } \\
\text { Binding Site: }\end{array}$ & 1109 \\
\hline P2r12 & Docking & $\begin{array}{l}\text { Orhostetio } \\
\text { Bnding sine }\end{array}$ & (100) \\
\hline P2Y12 & $\begin{array}{l}\text { Homology model; Molecilar oynamics; } \\
\text { Decing }\end{array}$ & $\begin{array}{l}\text { Orthottetio } \\
\text { Bhoing She }\end{array}$ & 11109 \\
\hline P2Y14 & P2Y12 Homology modot; Dooding & $\begin{array}{l}\text { Ortrosteto } \\
\text { Binding Sine }\end{array}$ & [111] \\
\hline P2Y14 & $\begin{array}{l}\text { P2V12 Homology modet Molecily } \\
\text { dynamies. Dooking }\end{array}$ & $\begin{array}{l}\text { Orbostute } \\
\text { Binding sile }\end{array}$ & {$[112]$} \\
\hline P2Y14 & P2Y12 Homclogy modet; Doding & $\begin{array}{l}\text { Ortrostetc } \\
\text { Binding Sine }\end{array}$ & [113] \\
\hline P2rit & $\begin{array}{l}\text { P2Vi2 } 2 \text { Homology modot Molseuly } \\
\text { drnamies Dooking }\end{array}$ & $\begin{array}{l}\text { Oresostute } \\
\text { Benging sne: }\end{array}$ & [114] \\
\hline
\end{tabular}

Table 1.

$P_{2}$ receptors and In Silico approaches widely applied to elucidate tridimensional strutuctures, interactions, and binding mechanisms between $P_{2}$ receptors and their suitable ligands.

$[53,55,60,61]$. To date, no medicine has been produced with the aid of machine learning algorithms, and no studies on $\mathrm{P} 2$ receptors are available.

\section{The in silico approach: putative applications and disadvantages}

Bioinformatics is a multidisciplinary field that comprises knowledge on chemistry, biology, and physics. This type of approach has emerged as a prevalent tool in some areas of research, mainly those engaged in the discovery of new compounds. The computational method user includes pharmaceutical industries that rather than spending money and time on the selection and optimization of synthetic molecules would be able to test several parameters of thousands of substances, at low costs [62-64]. The development of a new compound takes from 10 to 16 years comprising the initial steps of preclinical studies (also using a lot of test in animals) and, 
later, clinical trials, which cost about 1.2 billion, with the added factor that the molecule can still fail during any phase of the trial. Thus, computational approaches can be a low-cost option to test, at atomic resolution level, hypothesis that might require costly lab experiments.

Computational approaches also have their disadvantages. In general, in silico methodologies work with the concept of models. Models are an approximation of reality; thus, they give only partial information of the whole biological system. For example, structure-based methods, such as comparative modeling, molecular docking, molecular dynamics, and other mentioned methods, often rely on threedimensional models from previously experimentally determined structures. However, experimentally determined structures also carries out uncertainties introduced during the transformation from observed electron density data to an atomic level structure. The position of protein atoms, ligands, water molecules, and other cofactors might be affected by crystallization conditions, and the difficulties in using a physiologically relevant environment might lead to ambiguous conclusions in the structure determination. Therefore, the accuracy of structure-based methods might be questionable due to these unreliable models.

Approximation of reality is also present in software's algorithms. Molecular docking, for instance, often disregards protein flexibility to speed the process, and their ability of predicting binding affinities is limited by their small derivation/ training set used by the scoring function. Also, molecular dynamics have limited time scale and sampling, and the physical models (force fields) used are not intended for all types of biologically appropriate molecules failing in reproducing properties under different temperature, pressure, $\mathrm{pH}$, ion concentration, and solvent types. Some approximations can be overcome by increasing computational power and using of graphical units; however, this might go against the cost efficiency promoted by means of in silico approaches, since it might be expensive to build and maintain a cluster of computers or supercomputers.

Nevertheless, computational resources can be applied to other areas of knowledge, such as in forensic analyses [65], pharmacokinetics parameter predictions (absorption, distribution, metabolism, excretion, and toxicity) [66], binding kinetics predictions $\left(\mathrm{k}_{\mathrm{on}}\right.$ and $\left.\mathrm{K}_{\mathrm{off}}\right)$ [67], understanding the role of water molecules [68], binding site predictions (orthosteric, allosteric, and hotspots) [69], compound optimization [70], and the creation of new synthetic pathways [71].

In relation to the $\mathrm{P} 2$ receptors, a lot of data has been generated by computational approaches (or molecular modeling), even describing some features not detailed by common molecular and structural techniques as the passage of the ions through the lateral fenestration and more recently the docking of some molecules inside the pore of the P2X7 suggesting an allosteric pocket of binding molecules [72]. Although there is no compound approved by FDA targeting P2 receptors derived from molecular modeling, various compounds are under investigation in the preclinical phase.

So, synthetic engineering is only in the beginning and will, in a very close future, aid in facilitating an enormous number of processes in biology and other areas.

\section{Conclusions}

Bioinformatics is a growing subject of study that was incorporated in various fields of knowledge as engineering, physics, chemistry, and biology. This growth was strengthened by hardware and software improvements, mainly in the opensource software. In biology/chemistry, the most used is the molecular modeling, a field of science that encompasses all approaches, mimicking and modeling the 
behavior of molecules. The pharmaceutical industry has added routinely the in silico experiments to select hits and subsequently new drugs. And in the future, it seems that these techniques will be routinely applied in other fields, facilitating results and saving time and cost. Moreover, the artificial intelligence development could be directed to retouch weak point in molecular modeling approaches.

Notwithstanding, the new age began in which every process will be facilitated by machine learning algorithms.

\section{Author details}

Anael V.P. Alberto ${ }^{1}$, Lucianna H.S. Santos ${ }^{2}$, Rafael Ferreira ${ }^{3}$, Dinarte N.M. Ferreira ${ }^{1}$ and Luiz A. Alves ${ }^{1 *}$

1 Laboratório de Comunicação Celular, Instituto Oswaldo Cruz, Fundação Oswaldo Cruz, Rio de Janeiro, Brazil

2 Laboratório de Modelagem Molecular e Planejamento de Fármacos, Departamento de Bioquímica e Imunologia, Instituto de Ciências Biológicas, Universidade Federal de Minas Gerais, Belo Horizonte, Minas Gerais, Brazil

3 Grupo de Biofísica Computacional e Modelagem Molecular, Programa de Computação Científica, Fundação Oswaldo Cruz, Rio de Janeiro, Brazil

*Address all correspondence to: alveslaa@gmail.com

\section{IntechOpen}

(C) 2019 The Author(s). Licensee IntechOpen. This chapter is distributed under the terms of the Creative Commons Attribution License (http://creativecommons.org/licenses/ by/3.0), which permits unrestricted use, distribution, and reproduction in any medium, provided the original work is properly cited. (cc) BY 


\section{References}

[1] Zhang D et al. Two disparate ligandbinding sites in the human P2Y1 receptor. Nature. 2015;520(7547): 317-321

[2] Zhang K et al. Structure of the human P2Y12 receptor in complex with an antithrombotic drug. Nature. 2014; 509(7498):115-118

[3] Zhang J et al. Agonist-bound structure of the human $\mathrm{P} 2 \mathrm{Y} 12$ receptor. Nature. 2014;509(7498):119-122

[4] Chen CC et al. A P2X purinoceptor expressed by a subset of sensory neurons. Nature. 1995;377(6548): 428-431

[5] Valera S et al. A new class of ligandgated ion channel defined by $\mathrm{P} 2 \mathrm{x}$ receptor for extracellular ATP. Nature. 1994;371(6497):516-519

[6] Brake AJ, Wagenbach MJ, Julius D. New structural motif for ligand-gated ion channels defined by an ionotropic ATP receptor. Nature. 1994;371(6497): 519-523

[7] Kasuya G et al. Structural insights into the competitive inhibition of the ATP-gated P2X receptor channel.

Nature Communications. 2017;8(1):876

[8] Habermacher C et al. Molecular structure and function of $\mathrm{P} 2 \mathrm{X}$ receptors. Neuropharmacology. 2016; 104:18-30

[9] Iglesias $\mathrm{R}$ et al. P2X7 receptorpannexin1 complex: Pharmacology and signaling. American Journal of Physiology. Cell Physiology. 2008; 295(3):C752-C760

[10] Alberto AV et al. Is pannexin the pore associated with the $\mathrm{P} 2 \mathrm{X} 7$ receptor? Naunyn-Schmiedeberg's Archives of Pharmacology. 2013;386(9):775-787
[11] Coutinho-Silva R, Persechini PM. P2Z purinoceptor-associated pores induced by extracellular ATP in macrophages and J774 cells. The American Journal of Physiology. 1997; 273(6 Pt 1):C1793-C1800

[12] Hattori M, Gouaux E. Molecular mechanism of ATP binding and ion channel activation in $\mathrm{P} 2 \mathrm{X}$ receptors. Nature. 2012;485(7397):207-212

[13] Koehler Leman J, Ulmschneider MB, Gray JJ. Computational modeling of membrane proteins. Proteins. 2015; 83(1):1-24

[14] Evans RJ. Structural interpretation of P2X receptor mutagenesis studies on drug action. British Journal of Pharmacology. 2010;161(5):961-971

[15] Browne LE, Jiang LH, North RA. New structure enlivens interest in P2X receptors. Trends in Pharmacological Sciences. 2010;31(5):229-237

[16] Wang J et al. Druggable negative allosteric site of $\mathrm{P} 2 \mathrm{X} 3$ receptors.

Proceedings of the National Academy of Sciences of the United States of America. 2018;115(19):4939-4944

[17] Mansoor SE et al. X-ray structures define human $\mathrm{P} 2 \mathrm{X}$ (3) receptor gating cycle and antagonist action. Nature. 2016;538(7623):66-71

[18] Karasawa A, Kawate T. Structural basis for subtype-specific inhibition of the P2X7 receptor. eLife. 2016;5:pii: e22153

[19] Swaan PW, Ekins S. Reengineering the pharmaceutical industry by crashtesting molecules. Drug Discovery Today. 2005;10(17):1191-1200

[20] Morris GM, Lim-Wilby M. Molecular docking. Methods in Molecular Biology. 2008;443:365-382 
[21] Biggin PC, Bond PJ. Molecular dynamics simulations of membrane proteins. Methods in Molecular Biology. 2008;443:147-160

[22] Ekins S, Mestres J, Testa B. In silico pharmacology for drug discovery: Methods for virtual ligand screening and profiling. British Journal of Pharmacology. 2007;152(1):9-20

[23] Whittaker PA. What is the relevance of bioinformatics to pharmacology? Trends in Pharmacological Sciences. 2003;24(8): 434-439

[24] Testa B, Kramer SD. The biochemistry of drug metabolism-an introduction: Part 5. Metabolism and bioactivity. Chemistry \& Biodiversity. 2009;6(5):591-684

[25] Mosimann S, Meleshko R, James MN. A critical assessment of comparative molecular modeling of tertiary structures of proteins. Proteins. 1995;23(3):301-317

[26] Forrest LR, Tang CL, Honig B. On the accuracy of homology modeling and sequence alignment methods applied to membrane proteins. Biophysical Journal. 2006;91(2):508-517

[27] Webb B, Sali A. Comparative protein structure modeling using modeller. Current Protocols in Bioinformatics. 2016;54:5-6.1-5-6.37

[28] Waterhouse A et al. Swiss-model: Homology modelling of protein structures and complexes. Nucleic Acids Research. 2018;46(W1):W296-W303

[29] Simons KT et al. Ab initio protein structure prediction of CASP III targets using ROSETTA. Proteins. 1999;3 (Suppl):171-176

[30] Grimes L, Young MT. Purinergic P2X receptors: Structural and functional features depicted by X-ray and molecular modelling studies. Current Medicinal Chemistry. 2015;22(7): 783-798

[31] Yan Z et al. Participation of the Lys313-Ile333 sequence of the purinergic $\mathrm{P} 2 \mathrm{X} 4$ receptor in agonist binding and transduction of signals to the channel gate. The Journal of Biological Chemistry. 2006;281(43): 32649-32659

[32] Morris GM et al. AutoDock4 and AutoDockTools4: Automated docking with selective receptor flexibility. Journal of Computational Chemistry. 2009;30(16):2785-2791

[33] Allen WJ et al. DOCK 6: Impact of new features and current docking performance. Journal of Computational Chemistry. 2015;36(15):1132-1156

[34] Friesner RA et al. Glide: A new approach for rapid, accurate docking and scoring. 1. Method and assessment of docking accuracy. Journal of Medicinal Chemistry. 2004;47(7): 1739-1749

[35] Jones G et al. Development and validation of a genetic algorithm for flexible docking. Journal of Molecular Biology. 1997;267(3):727-748

[36] Chen YC. Beware of docking! Trends in Pharmacological Sciences. 2015;36(2):78-95

[37] Dal Ben D et al. Purinergic P2X receptors: Structural models and analysis of ligand-target interaction. European Journal of Medicinal Chemistry. 2015;89:561-580

[38] Adelman SA. Quantum generalized Langevin equation approach to gas/solid collisions. Chemical Physics Letters. 1976;40(4):495-499

[39] Evans RJ et al. Pharmacological characterization of heterologously expressed ATP-gated cation channels 
(P2x purinoceptors). Molecular

Pharmacology. 1995;48(2):178-183

[40] Costanzi S et al. P2Y1 antagonists: Combining receptor-based modeling and QSAR for a quantitative prediction of the biological activity based on consensus scoring. Journal of Medicinal Chemistry. 2007;50(14):3229-3241

[41] Jacobson KA, Jayasekara MP, Costanzi S. Molecular structure of P2Y receptors: Mutagenesis, modeling, and chemical probes. Wiley Interdisciplinary Reviews: Membrane Transport and Signaling. 2012;1(6):1-19

[42] Spyrakis F, Cavasotto CN. Open challenges in structure-based virtual screening: Receptor modeling, target flexibility consideration and active site water molecules description. Archives of Biochemistry and Biophysics. 2015; 583:105-119

[43] Costanzi S et al. Virtual screening leads to the discovery of novel nonnucleotide P2Y(1) receptor antagonists. Bioorganic \& Medicinal Chemistry. 2012;20(17):5254-5261

[44] Caseley EA et al. Structure-based identification and characterisation of structurally novel human $\mathrm{P} 2 \mathrm{X} 7$ receptor antagonists. Biochemical Pharmacology. 2016;116:130-139

[45] Ivetac A, McCammon JA. Molecular recognition in the case of flexible targets. Current Pharmaceutical Design. 2011;17(17):1663-1671

[46] Walker RC, Crowley MF, Case DA. The implementation of a fast and accurate QM/MM potential method in Amber. Journal of Computational Chemistry. 2008;29(7):1019-1031

[47] Brunk E, Rothlisberger U. Mixed quantum mechanical/molecular mechanical molecular dynamics simulations of biological systems in ground and electronically excited states.
Chemical Reviews. 2015;115(12): 6217-6263

[48] Armunanto R, Schwenk CF, Setiaji AHB, Rode BM. Classical and QM/MM molecular dynamics simulations of $\mathrm{Co}_{2}$ in water. Chemical Physics. 2003;295: 63-70

[49] Bernardi RC, Melo MCR, Schulten $\mathrm{K}$. Enhanced sampling techniques in molecular dynamics simulations of biological systems. Biochimica et Biophysica Acta. 2015;1850(5):872-877

[50] Zhao WS et al. Relative motions between left flipper and dorsal fin domains favour P2X4 receptor activation. Nature Communications. 2014;5:4189

[51] Kawate T et al. Crystal structure of the ATP-gated P2X(4) ion channel in the closed state. Nature. 2009;

460(7255):592-598

[52] Min Xu JMD, Kim SH. The fourth industrial revolution: Opportunities and challenges. International Journal of Financial Research. 2018;9(2):1

[53] Silver D et al. A general reinforcement learning algorithm that masters chess, shogi, and go through self-play. Science. 2018;362(6419): 1140-1144

[54] van den Herik HJ, Uiterwijk JWHM, van Rijswijck J. Games solved: Now and in the future. Artificial Intelligence. 2002;134(1):277-311

[55] Rifaioglu AS, Atas H, Martin MJ, Cetin-Atalay R, Atalay V, Doğan T. Recent applications of deep learning and machine intelligence on in silico drug discovery: Methods, tools and databases. Briefings in Bioinformatics. 2018. Available from: https://doi.org/10.1093/ bib/bby061

[56] Lavecchia A. Machine-learning approaches in drug discovery: Methods 
and applications. Drug Discovery Today. 2015;20(3):318-331

[57] Carpenter KA, Cohen DS, Jarrell JT, Huang X. Deep learning and virtual drug screening. Future Medicinal Chemistry. 2018;10(21):2557-2568

[58] Cortes C, Vapnik V. Support-vector networks. Machine Learning. 1995;

20(3):273-297

[59] Maltarollo VG et al. Advances with support vector machines for novel drug discovery. Expert Opinion on Drug Discovery. 2019;14(1):23-33

[60] Ratni $\mathrm{H}$ et al. Specific correction of alternative survival motor neuron 2 splicing by small molecules: Discovery of a potential novel medicine to treat spinal muscular atrophy. Journal of Medicinal Chemistry. 2016;59(13):6086-6100

[61] Walton MI et al. CCT244747 is a novel potent and selective CHK1 inhibitor with oral efficacy alone and in combination with genotoxic anticancer drugs. Clinical Cancer Research. 2012; 18(20):5650-5661

[62] Tang Y et al. New technologies in computer-aided drug design: Toward target identification and new chemical entity discovery. Drug Discovery Today: Technologies. 2006;3(3):307-313

[63] Kore PP, Mutha MM, Antre RV, Oswal RJ, Kshirsagar SS. Computeraided drug design: An innovative tool for modeling. Open Journal of Medicinal Chemistry. 2012;2(4):139-148

[64] Hillisch A, Heinrich N, Wild H. Computational chemistry in the pharmaceutical industry: From childhood to adolescence. ChemMedChem. 2015;10(12):1958-1962

[65] Liu YY, Harbison S. A review of bioinformatic methods for forensic DNA analyses. Forensic Science International. Genetics. 2018;33:117-128
[66] Zheng M, Zhao J, Cui C, Fu Z, Li X, Liu X, et al. Computational chemical biology and drug design: Facilitating protein structure, function, and modulation studies. Medical Research Reviews. 2018;38:914-950

[67] Copeland RA, Pompliano DL, Meek TD. Drug-target residence time and its implications for lead optimization. Nature Reviews Drug Discovery. 2006; 5(9):730-739

[68] Spyrakis F et al. The roles of water in the protein matrix: A largely untapped resource for drug discovery. Journal of Medicinal Chemistry. 2017; 60(16):6781-6827

[69] Roche DB, Brackenridge DA, McGuffin LJ. Proteins and their interacting partners: An introduction to protein-ligand binding site prediction methods. International Journal of Molecular Sciences. 2015;16(12): 29829-29842

[70] Xu Z et al. Utilization of halogen bond in lead optimization: A case study of rational design of potent phosphodiesterase type 5 (PDE5) inhibitors. Journal of Medicinal Chemistry. 2011;54(15):5607-5611

[71] Smanski MJ et al. Synthetic biology to access and expand nature's chemical diversity. Nature Reviews Microbiology. 2016;14(3):135-149

[72] Bidula SM et al. Mapping a novel positive allosteric modulator binding site in the central vestibule region of human P2X7. Scientific Reports. 2019; 9(1):3231

[73] Bodnar M et al. Amino acid residues constituting the agonist binding site of the human P2X3 receptor. The Journal of Biological Chemistry. 2011;286(4): 2739-2749

[74] Allsopp RC et al. Unique residues in the ATP gated human P2X7 receptor 
define a novel allosteric binding pocket for the selective antagonist AZ10606120. Scientific Reports. 2017;7(1):725

[75] Jiang R et al. Tightening of the ATPbinding sites induces the opening of $\mathrm{P} 2 \mathrm{X}$ receptor channels. The EMBO Journal. 2012;31(9):2134-2143

[76] Hausmann R et al. Salt bridge switching from Arg290/Glu167 to Arg290/ATP promotes the closed-toopen transition of the $\mathrm{P} 2 \mathrm{X} 2$ receptor. Molecular Pharmacology. 2013;83(1): 73-84

[77] Pasqualetto G, Brancale A, Young MT. The molecular determinants of small-molecule ligand binding at P2X receptors. Frontiers in Pharmacology. 2018;9:58

[78] Allsopp RC et al. Mapping the allosteric action of antagonists A740003 and A438079 reveals a role for the left flipper in ligand sensitivity at P2X7 receptors. Molecular Pharmacology. 2018;93(5):553-562

[79] Roberts JA et al. Agonist binding evokes extensive conformational changes in the extracellular domain of the ATP-gated human $\mathrm{P} 2 \mathrm{X} 1$ receptor ion channel. Proceedings of the National Academy of Sciences of the United States of America. 2012;109(12): 4663-4667

[80] Stelmashenko O et al. Ectodomain movements of an ATP-gated ion channel (P2X2 receptor) probed by disulfide locking. The Journal of Biological Chemistry. 2014;289(14): 9909-9917

[81] Wang J et al. Intersubunit physical couplings fostered by the left flipper domain facilitate channel opening of P2X4 receptors. The Journal of Biological Chemistry. 2017;292(18):7619-7635

[82] Du J, Dong H, Zhou HX. Gating mechanism of a $\mathrm{P} 2 \mathrm{X} 4$ receptor developed from normal mode analysis and molecular dynamics simulations. Proceedings of the National Academy of Sciences of the United States of America. 2012;109(11):4140-4145

[83] Kawate $\mathrm{T}$ et al. Ion access pathway to the transmembrane pore in $\mathrm{P} 2 \mathrm{X}$ receptor channels. The Journal of General Physiology. 2011;137(6): 579-590

[84] Samways DS et al. Preferential use of unobstructed lateral portals as the access route to the pore of human ATP-gated ion channels (P2X receptors). Proceedings of the National Academy of Sciences of the United States of America. 2011;108(33): 13800-13805

[85] Heymann G et al. Inter- and intrasubunit interactions between transmembrane helices in the open state of P2X receptor channels. Proceedings of the National Academy of Sciences of the United States of America. 2013; 110(42):E4045-E4054

[86] Pippel A et al. Localization of the gate and selectivity filter of the fulllength P2X7 receptor. Proceedings of the National Academy of Sciences of the United States of America. 2017;114(11): E2156-E2165

[87] Browne LE et al. P2X7 receptor channels allow direct permeation of nanometer-sized dyes. The Journal of Neuroscience. 2013;33(8): 3557-3566

[88] Van Rhee AM et al. Modelling the $\mathrm{P} 2 \mathrm{Y}$ purinoceptor using rhodopsin as template. Drug Design and Discovery. 1995;13(2):133-154

[89] Moro S et al. Human P2Y1 receptor: Molecular modeling and site-directed mutagenesis as tools to identify agonist and antagonist recognition sites. Journal of Medicinal Chemistry. 1998;41(9): 1456-1466 
[90] Nandanan E et al. Synthesis, biological activity, and molecular modeling of ribose-modified deoxyadenosine bisphosphate analogues as P2Y(1) receptor ligands. Journal of Medicinal Chemistry. 2000;43(5): 829-842

[91] Kim HS et al. Acyclic and cyclopropyl analogues of adenosine bisphosphate antagonists of the P2Y1 receptor: Structure-activity relationships and receptor docking. Journal of Medicinal Chemistry. 2001; 44(19):3092-3108

[92] Major DT, Fischer B. Molecular recognition in purinergic receptors. 1. A comprehensive computational study of the h-P2Y1-receptor. Journal of Medicinal Chemistry. 2004;47(18): 4391-4404

[93] Major DT et al. Molecular recognition in purinergic receptors. 2 . Diastereoselectivity of the h-P2Y1receptor. Journal of Medicinal Chemistry. 2004;47(18):4405-4416

[94] Costanzi S et al. Architecture of P2Y nucleotide receptors: Structural comparison based on sequence analysis, mutagenesis, and homology modeling. Journal of Medicinal Chemistry. 2004; 47(22):5393-5404

[95] Yi F et al. In silico approach for antithrombosis drug discovery: P2Y1R structure-based TCMs screening. Frontiers in Pharmacology. 2016;7:531

[96] Peng J et al. Design, synthesis, and biological evaluation of 2(phenoxyaryl)-3-urea derivatives as novel P2Y1 receptor antagonists. European Journal of Medicinal Chemistry. 2018;158:302-310

[97] Erb L et al. Site-directed mutagenesis of P2U purinoceptors. Positively charged amino acids in transmembrane helices 6 and 7 affect agonist potency and specificity. The
Journal of Biological Chemistry. 1995; 270(9):4185-4188

[98] Hillmann P et al. Key determinants of nucleotide-activated $\mathrm{G}$ proteincoupled P2Y(2) receptor function revealed by chemical and pharmacological experiments, mutagenesis and homology modeling. Journal of Medicinal Chemistry. 2009; 52(9):2762-2775

[99] Rafehi M et al. Molecular recognition of agonists and antagonists by the nucleotide-activated $G$ proteincoupled P2Y2 receptor. Journal of Medicinal Chemistry. 2017;60(20): 8425-8440

[100] Maruoka H et al. Pyrimidine nucleotides with 4-alkyloxyimino and terminal tetraphosphate delta-ester modifications as selective agonists of the P2Y(4) receptor. Journal of Medicinal Chemistry. 2011;54(12): 4018-4033

[101] Rafehi M et al. Development of potent and selective antagonists for the UTP-activated P2Y4 receptor. Journal of Medicinal Chemistry. 2017;60(7): 3020-3038

[102] Costanzi S et al. Human P2Y(6) receptor: Molecular modeling leads to the rational design of a novel agonist based on a unique conformational preference. Journal of Medicinal Chemistry. 2005;48(26):8108-8111

[103] Jacob TF et al. A promising drug candidate for the treatment of glaucoma based on a P2Y6-receptor agonist. Purinergic Signal. 2018;14(3): 271-284

[104] Zylberg J et al. Structure and ligand-binding site characteristics of the human P2Y11 nucleotide receptor deduced from computational modelling and mutational analysis. The Biochemical Journal. 2007;405(2): 277-286 
[105] Jacobson KA et al. Structure activity and molecular modeling analyses of ribose- and base-modified uridine $5^{\prime}$-triphosphate analogues at the human $\mathrm{P} 2 \mathrm{Y} 2$ and $\mathrm{P} 2 \mathrm{Y} 4$ receptors.

Biochemical Pharmacology. 2006;71(4): 540-549

[106] Deflorian F, Jacobson KA. Comparison of three GPCR structural templates for modeling of the P2Y12 nucleotide receptor. Journal of Computer-Aided Molecular Design. 2011;25(4):329-338

[107] Vistoli G et al. Naturally occurring $\mathrm{N}(6)$-substituted adenosines (cytokinin ribosides) are in vitro inhibitors of platelet aggregation: An in silico evaluation of their interaction with the P2Y(12) receptor. Bioorganic \& Medicinal Chemistry Letters. 2014; 24(24):5652-5655

[108] Paoletta S et al. Modeling ligand recognition at the $\mathrm{P} 2 \mathrm{Y} 12$ receptor in light of X-ray structural information. Journal of Computer-Aided Molecular Design. 2015;29(8):737-756

[109] Maione F et al. Molecular mechanism of tanshinone IIA and cryptotanshinone in platelet antiaggregating effects: An integrated study of pharmacology and computational analysis. Fitoterapia. 2015;100:174-178

[110] Zhou S et al. Investigating the binding mechanism of novel 6-aminonicotinate-based antagonists with P2Y12 by 3D-QSAR, docking and molecular dynamics simulations. Journal of Biomolecular Structure \& Dynamics. 2017;35(13):2938-2965

[111] Kiselev E et al. Exploring a 2-naphthoic acid template for the structure-based design of P2Y14 receptor antagonist molecular probes. ACS Chemical Biology. 2014;9(12): 2833-2842
[112] Trujillo K et al. Molecular modeling of the human P2Y14 receptor: A template for structure-based design of selective agonist ligands. Bioorganic \& Medicinal Chemistry. 2015;23(14): 4056-4064

[113] Kiselev E et al. Design, synthesis, pharmacological characterization of a fluorescent agonist of the P2Y(1)(4) receptor. Bioorganic \& Medicinal Chemistry Letters. 2015;25(21): 4733-4739

[114] Junker A et al. Structure-based design of 3-(4-aryl-1H-1,2,3-triazol-1-yl)biphenyl derivatives as P2Y14 receptor antagonists. Journal of Medicinal Chemistry. 2016;59(13):6149-6168 


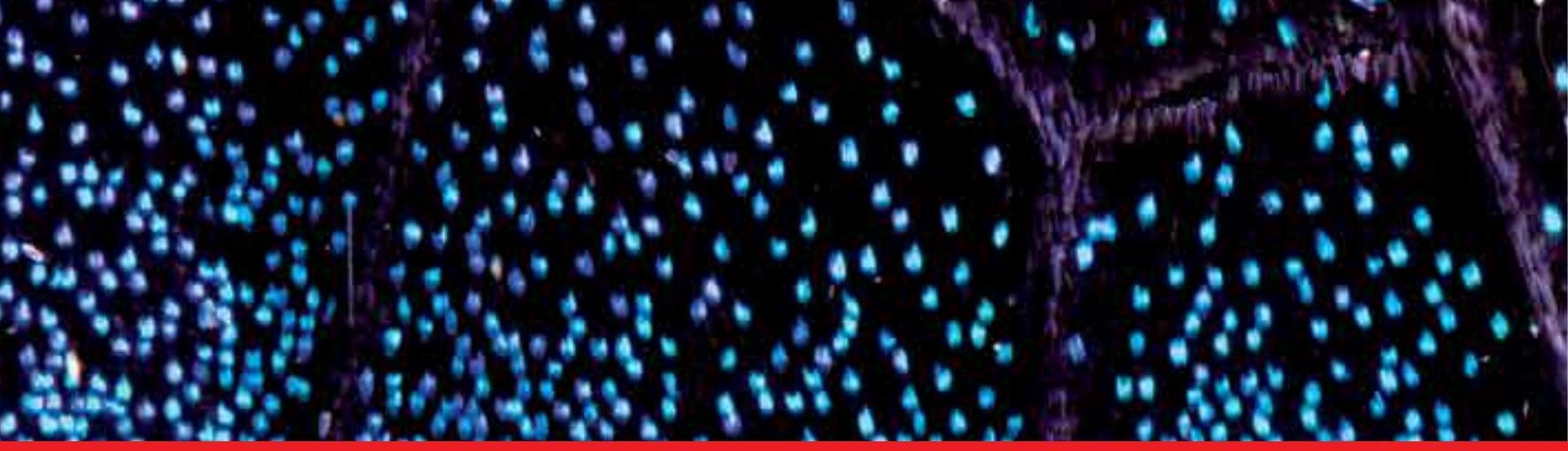

\section{Edited by Robson Faria}

This book aims to provide a brief update on the functions of purinergic receptors in various systems, in addition to the signaling pathway activated to mediate these functions. We address the influence of hypoxia by modulating the activity of these receptors under physiological and pathophysiological conditions. Additionally, we describe the mechanisms of induction of pain and inflammation in different systems. Finally, the book discusses some of the main bioinformatics tools currently used to improve or discover new prototypes capable of selectively acting on these receptors with estimated parameters of satisfactory solubility and toxicity for possible commercial implementation.

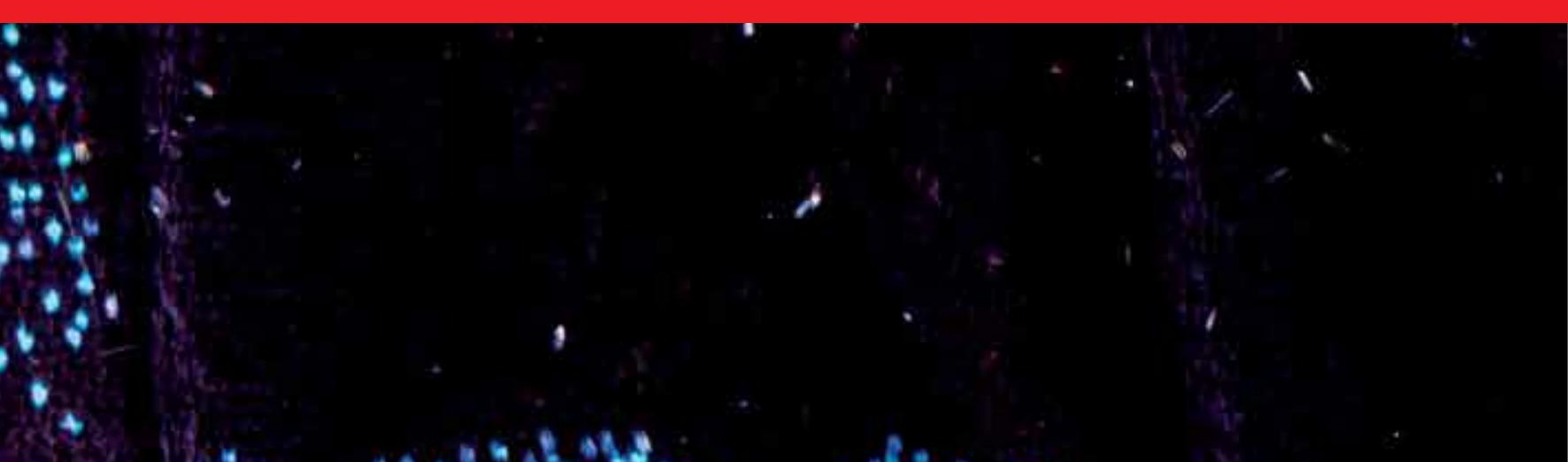

